Old Dominion University

ODU Digital Commons

Mechanical \& Aerospace Engineering Theses \&

Dissertations

Mechanical \& Aerospace Engineering

Spring 2017

\title{
An Investigation into the Potential Benefits of Distributed Electric Propulsion on Small UAVS at Low Reynolds Numbers
}

\author{
Engin Baris \\ Old Dominion University, ebari001@odu.edu
}

Follow this and additional works at: https://digitalcommons.odu.edu/mae_etds

Part of the Propulsion and Power Commons

\section{Recommended Citation}

Baris, Engin. "An Investigation into the Potential Benefits of Distributed Electric Propulsion on Small UAVS at Low Reynolds Numbers" (2017). Master of Science (MS), Thesis, Mechanical \& Aerospace Engineering, Old Dominion University, DOI: 10.25777/t6qk-cr93

https://digitalcommons.odu.edu/mae_etds/24

This Thesis is brought to you for free and open access by the Mechanical \& Aerospace Engineering at ODU Digital Commons. It has been accepted for inclusion in Mechanical \& Aerospace Engineering Theses \& Dissertations by an authorized administrator of ODU Digital Commons. For more information, please contact digitalcommons@odu.edu. 
AN INVESTIGATION INTO THE POTENTIAL BENEFITS OF DISTRIBUTED

ELECTRIC PROPULSION ON SMALL UAVS AT LOW REYNOLDS NUMBERS

by

Engin Baris

B.S. June 2012, Sakarya University

A Thesis Submitted to the Faculty of

Old Dominion University in Partial Fulfillment of the

Requirements for the Degree of

MASTER OF SCIENCE

MECHANICAL AND AEROSPACE ENGINEERING

OLD DOMINION UNIVERSITY

May 2017

Approved by:

Drew Landman (Director)

Colin P. Britcher (Member)

Thomas A. Alberts (Member) 


\begin{abstract}
AN INVESTIGATION INTO THE POTENTIAL BENEFITS OF DISTRIBUTED ELECTRIC PROPULSION ON SMALL UAVS AT LOW REYNOLDS NUMBERS

Engin Baris

Old Dominion University, 2017

Director: Dr. Drew Landman
\end{abstract}

Distributed electric propulsion systems benefit from the inherent scale independence of electric propulsion. This property allows the designer to place multiple small electric motors along the wing of an aircraft instead of using a single or several internal combustion motors with gear boxes or other power train components. Aircraft operating at low Reynolds numbers are ideal candidates for benefiting from increased local flow velocities as provided by distributed propulsion systems.

In this study, a distributed electric propulsion system made up of eight motor/propellers was integrated into the leading edge of a small fixed wing-body model to investigate the expected improvements on the aerodynamics available to small UAVs operating at low Reynolds numbers. Wind tunnel tests featuring a Design of Experiments (DOE) methodology were used for aerodynamic characterization. Experiments were performed in four modes: all-propellers-on, wing-tip-propellers-alone-on, wing-alone mode, and two-inboard-propellers-on-alone mode. In addition, the all-propeller-on, wing-alone, and a single-tractor configuration were analyzed using VSPAERO, a vortex lattice code, to make comparisons between these different configurations. Results show that the distributed propulsion system has higher normal force, endurance, and range features, despite a potential weight penalty. 
Copyright, 2017, by Engin Baris, All Rights Reserved. 
This thesis is dedicated to my wife, who has always supported me. 


\section{ACKNOWLEDGEMENTS}

There are many people who have contributed to the successful completion of this thesis. I would like to extend my gratitude to my advisor, Dr. Drew Landman, for providing invaluable guidance and endless support during the research. I also extend many thanks to my committee members, Dr. Colin Britcher and Dr. Thomas Alberts. I would also like to thank Brian Duvall and Omer Faruk Keskin. Finally, I am very thankful to the Turkish Military Academy for granting me this opportunity. 


\section{NOMENCLATURE}
A
Axial Force
A-o-A Angle of Attack
$\alpha_{c} \quad$ Corrected Angle of Attack
ANOVA Analysis of Variance
$\beta \quad$ Regression Coefficient
b Regression Coefficient Vector
$b_{\mathrm{r}} \quad$ Systematic Standard Uncertanity
c Wing Chord Length
C Wind Tunnel Cross Sectional Area
$\mathrm{C}_{\mathrm{A}} \quad$ Axial Force Coefficient
$\mathrm{C}_{\mathrm{D}} \quad$ Drag Coefficient
$\mathrm{C}_{\mathrm{Du}} \quad$ Uncorrected Drag Coefficient
$\mathrm{C}_{\mathrm{jj}} \quad$ Diagonal Elements of Hat Matrix
$\mathrm{C}_{\mathrm{L}} \quad$ Lift Coefficient
$\mathrm{C}_{\mathrm{Lw}} \quad$ Wing Lift Coefficient
$\mathrm{C}_{\mathrm{N}} \quad$ Normal Force Coefficient
$\mathrm{C}_{\mathrm{T}} \quad$ Thrust Coefficient
CAD Computer Aided Design
CCD Central Composite Design
D Drag Force
$\mathrm{D}_{\text {prop }} \quad$ Propeller Diameter
DOE Design-of-Experiments 


\begin{tabular}{|c|c|}
\hline$\delta$ & Boundary Correction Factor \\
\hline e & Residual \\
\hline ESC & Electronic Speed Controller \\
\hline$\varepsilon_{\mathrm{sb}, \mathrm{w}}$ & Wing Solid Blockage Correction Factor \\
\hline$\varepsilon_{\mathrm{sb}, \mathrm{b}}$ & Body Solid Blockage Correction Factor \\
\hline$\varepsilon_{\mathrm{wb}}$ & Wake Blockage Correction Factor \\
\hline$\varepsilon_{\mathrm{T}}$ & Total Blockage Correction Factor \\
\hline $\mathrm{F}_{0}$ & F-Test Statistic \\
\hline FCD & Face-Centered Design \\
\hline $\mathrm{g}$ & Acceleration due to Gravity $\left(\mathrm{m} / \mathrm{s}^{2}\right)$ \\
\hline $\mathrm{H}$ & Hat Matrix \\
\hline $\mathrm{H}_{0}$ & Null Hypothesis \\
\hline $\mathrm{H}_{1}$ & Alternate Hypothesis \\
\hline$\eta$ & Efficiency \\
\hline $\mathrm{J}$ & Advance Ratio \\
\hline $\mathrm{k}$ & Percent Charge of Batteries \\
\hline $\mathrm{K}_{1}$ & Wing Shape Factor \\
\hline $\mathrm{K}_{3}$ & Body shape Factor \\
\hline $\mathrm{L}$ & Lift Force \\
\hline $\mathrm{L} / \mathrm{D}$ & Lift to Drag Ratio \\
\hline L1 & Left Motor 1 \\
\hline $\mathrm{L} 2$ & Left Motor 2 \\
\hline L3 & Left Motor 3 \\
\hline
\end{tabular}




\begin{tabular}{|c|c|}
\hline L4 & Left Motor 4 \\
\hline $\mathrm{m}$ & Number of Factor Levels \\
\hline MS & Mean Square \\
\hline $\mathrm{n}$ & Sample Size \\
\hline $\mathrm{n}_{\text {prop }}$ & Propeller revolution per second value \\
\hline $\mathrm{N}$ & Normal Force \\
\hline OFAT & One Factor at A Time \\
\hline $\mathrm{p}$ & Number of Model Parameters \\
\hline$\Delta \mathrm{P}$ & Pressure Difference \\
\hline $\mathrm{P}_{\mathrm{atm}}$ & Atmospheric Pressure \\
\hline PRESS & Prediction Error of Sum of Squares \\
\hline q & Dynamic Pressure \\
\hline $\mathrm{q}_{\mathrm{A}}$ & Uncorrected Dynamic Pressure \\
\hline $\mathrm{q}_{\mathrm{c}}$ & Corrected Dynamic Pressure \\
\hline $\mathrm{R}$ & Gas Constant of Air $(\mathrm{J} / \mathrm{kgK})$ \\
\hline $\mathrm{R}^{2}$ & Coefficient of Determination \\
\hline $\mathrm{R}_{\text {adj }}^{2}$ & Adjusted Coefficient of Determination \\
\hline $\mathrm{R}_{\text {pred }}^{2}$ & Predicted Coefficient of Determination \\
\hline $\operatorname{Re}$ & Reynolds Number \\
\hline RPM & Revolutions Per Minute \\
\hline RPS & Revolutions Per Second \\
\hline RSM & Response Surface Methodology \\
\hline $\mathrm{R} 1$ & Right Motor 1 \\
\hline
\end{tabular}




\begin{tabular}{|c|c|}
\hline R2 & Right Motor 2 \\
\hline R3 & Right Motor 2 \\
\hline $\mathrm{R} 4$ & Right Motor 4 \\
\hline$\rho$ & Density $\left(\mathrm{kg} / \mathrm{m}^{3}\right)$ \\
\hline $\mathrm{S}_{\mathrm{ref}}$ & Reference Wing Area \\
\hline SS & Sum of Squares \\
\hline $\mathrm{S}_{\mathrm{r}}$ & Random Standard Uncertainty \\
\hline$\sigma^{2}$ & Error Variance \\
\hline $\mathrm{t}$ & T-statistic \\
\hline $\mathrm{T}$ & Temperature $(\mathrm{K})$ \\
\hline$\tau_{1}$ & Wind Tunnel Test Section Shape Factor \\
\hline$\tau_{3}$ & Boundary Induced Up-wash Correction Factor \\
\hline $\mathrm{u}$ & Battery Energy Density $\left(\mathrm{J} / \mathrm{m}^{3}\right)$ \\
\hline$U_{\mathrm{r}}$ & Overall Uncertainty \\
\hline UAV & Unmanned Air Vehicle \\
\hline $\mathrm{V}$ & Free Stream Velocity \\
\hline $\mathrm{V}_{\mathrm{A}}$ & Uncorrected Free Stream Velocity \\
\hline $\mathrm{V}_{\mathrm{c}}$ & Corrected Free Stream Velocity \\
\hline VTOL & Vertical Take-Off or Landing \\
\hline $\mathrm{W}$ & Total Model Weight \\
\hline $\mathrm{W}_{\text {bat }}$ & Battery Weight \\
\hline $\mathrm{X}$ & Model Matrix \\
\hline $\mathrm{x}_{0}$ & Design Point \\
\hline
\end{tabular}


Response Matrix

$\mu$

Dynamic Viscosity ( $\mathrm{kg} / \mathrm{ms})$ 


\section{TABLE OF CONTENTS}

Chapter

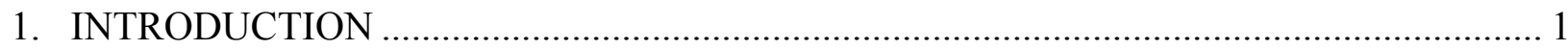

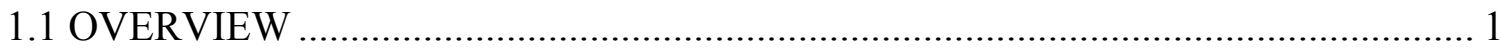

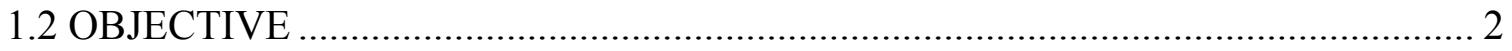

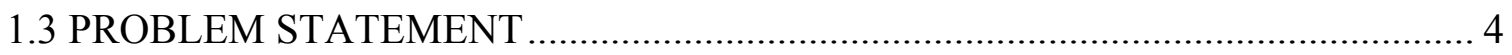

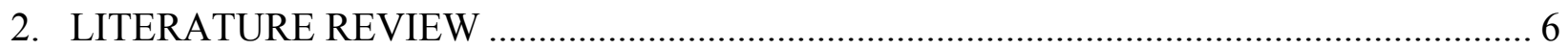

2.1 DISTRIBUTED PROPULSION DEFINITIONS AND CONCEPTS.......................... 6

2.2 EXPERIMENTAL STUDIES ......................................................................... 14

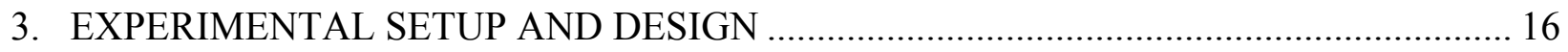

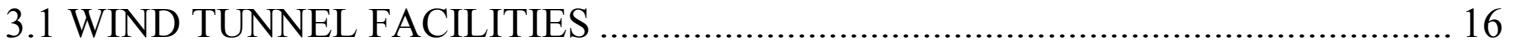

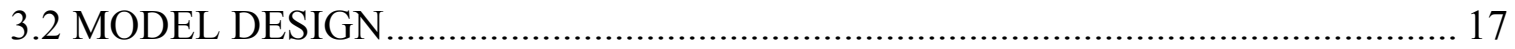

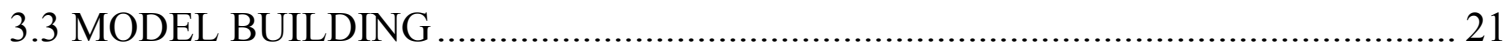

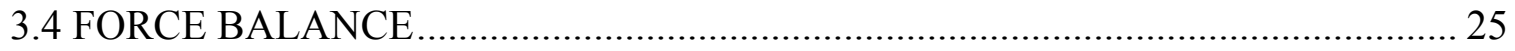

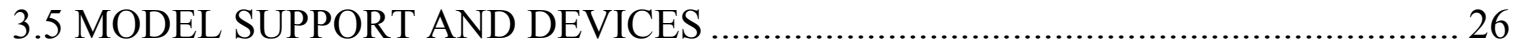

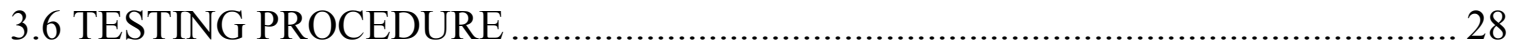

3.7 MEASUREMENT UNCERTAINTIES.............................................................. 30

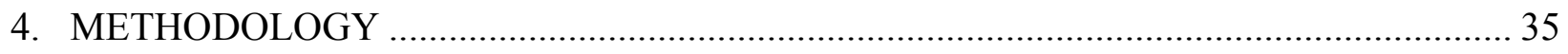

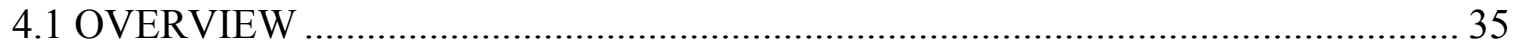

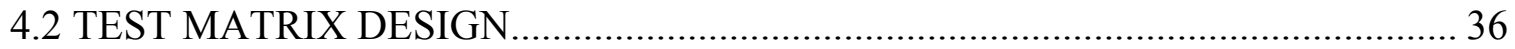

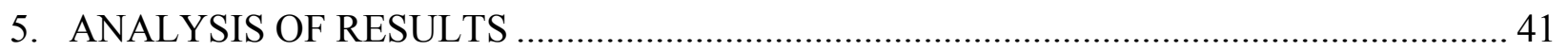

5.1 ANALYSIS OF VARIANCE (ANOVA) …………............................................ 41

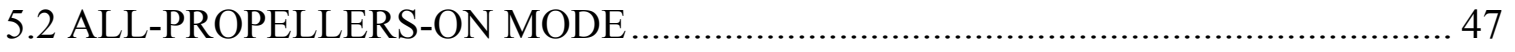

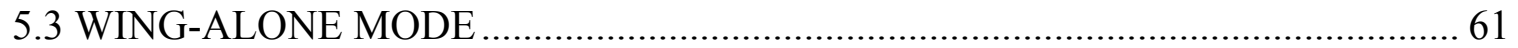

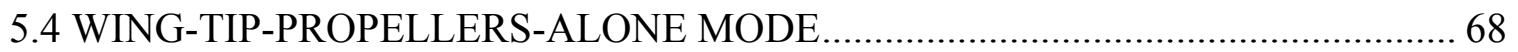

5.5 WING-TIP-PROPELLERS-ALONE AND TWO-INBOARD-PROPELLERS-

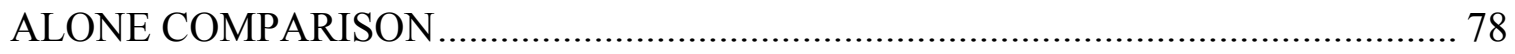

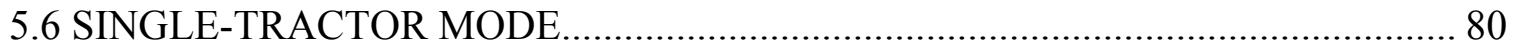




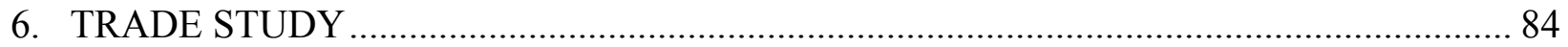

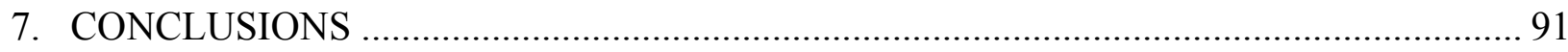

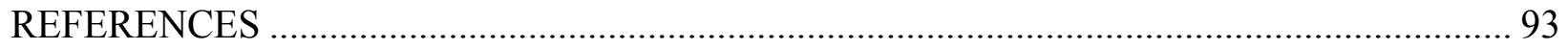

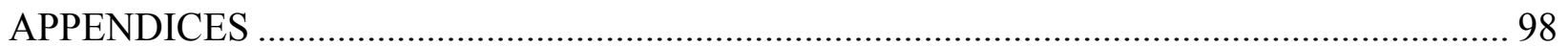

A. MODEL ASSEMBLY TECHNICAL DRAWING .............................................. 98

B. 2044A FORCE BALANCE SPECIFICATIONS ..................................................... 99

C. ALL-PROPELLERS-ON MODE ACTUAL TEXT MATRIX ................................ 100

D. WING-ALONE MODE ACTUAL TEXT MATRIX .............................................. 103

E. WING-TIP-PROPELLERS-ALONE MODE ACTUAL TEXT MATRIX ............... 104

F. WING-TIP-PROPELLERS-ALONE AND TWO-INBOARD-PROPELLERSALONE MODE ACTUAL TEXT MATRIX …....................................................... 106

G. WIND TUNNEL DATA BOUNDARY CORRECTIONS ................................... 107

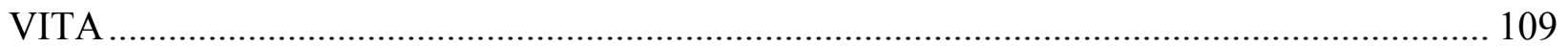




\section{LIST OF TABLES}

Table

Page

1. Systematic uncertainties of velocity measurement components................................ 31

2. Overall uncertainty of wind tunnel speed ........................................................ 32

3. Systematic uncertainties of balance measurement components .................................. 33

4. Overall uncertainty of force coefficients .......................................................... 34

5. Factors and factor limits for all-propellers-on mode ......................................... 47

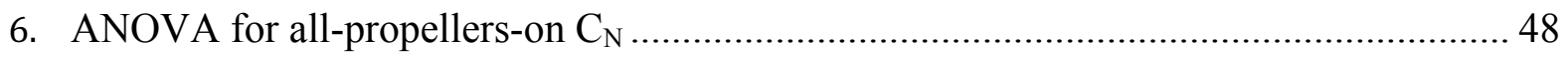

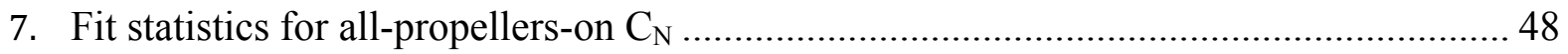

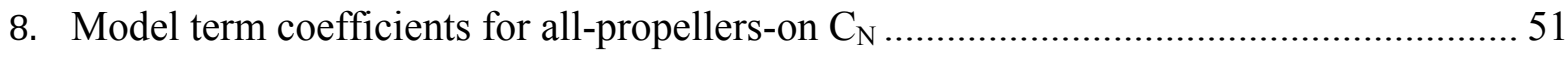

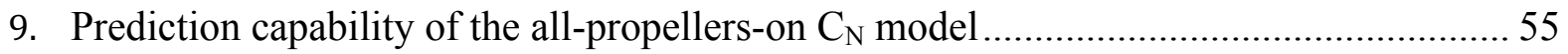

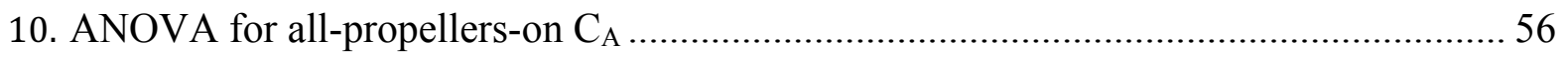

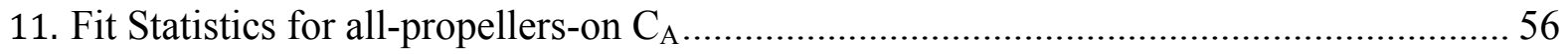

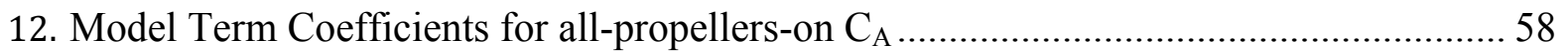

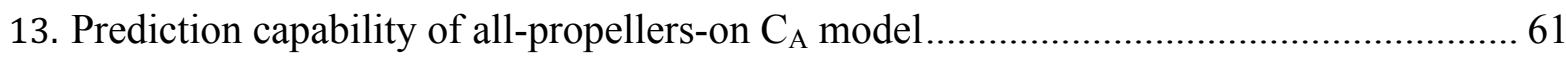

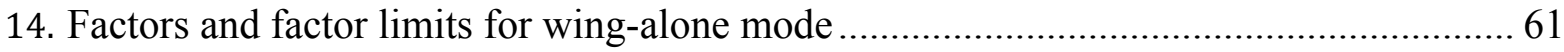

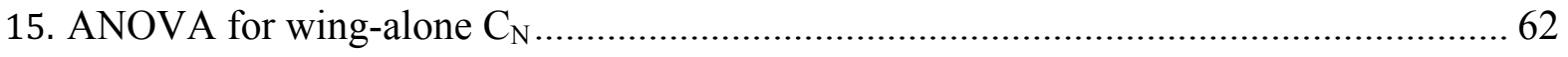

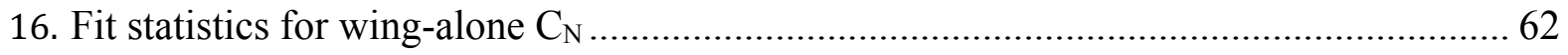

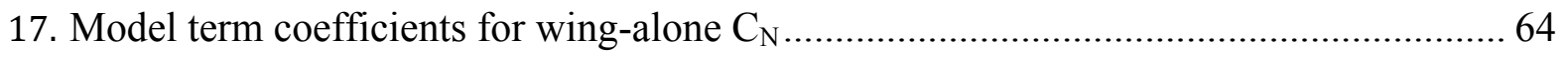

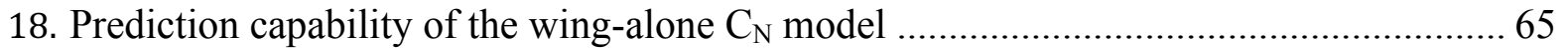

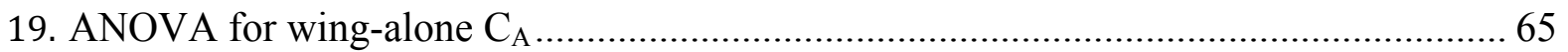

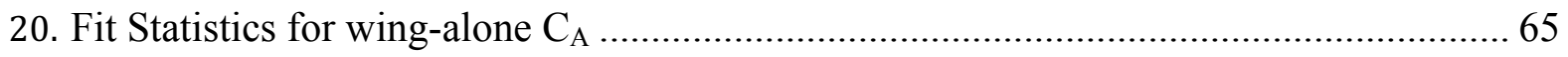

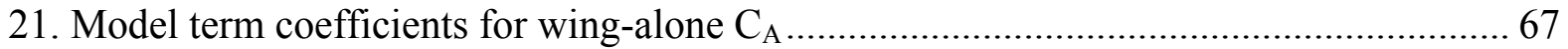




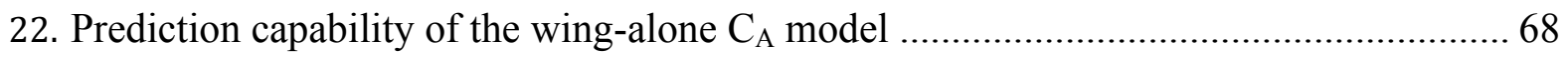

23. Factors and factor limits for wingtip-alone mode.............................................. 68

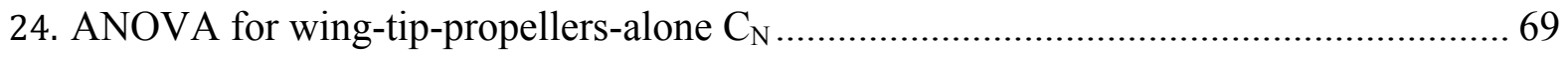

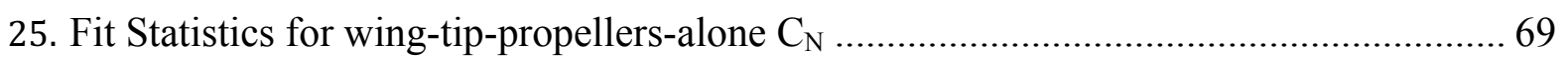

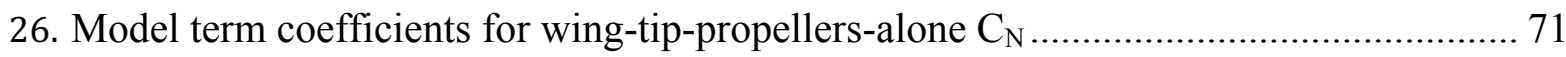

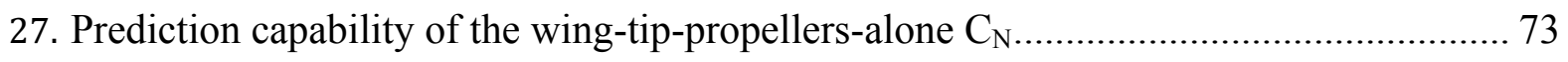

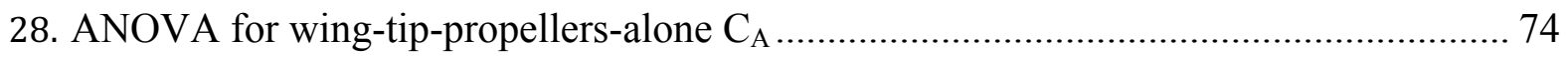

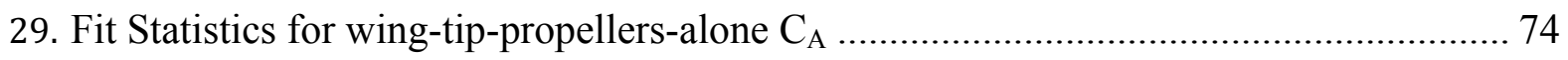

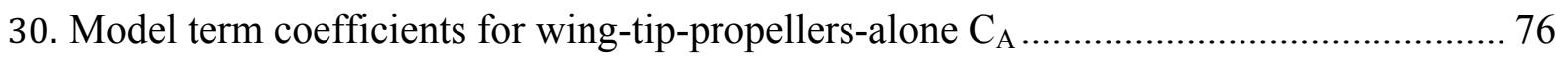

31. Prediction capability of the wing-tip-propellers-alone $\mathrm{C}_{\mathrm{A}}$ model............................. 78

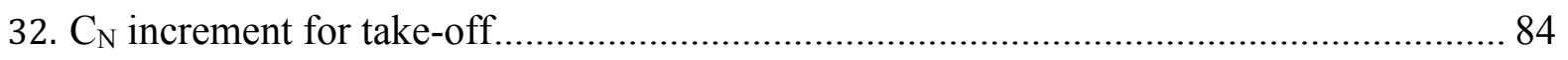

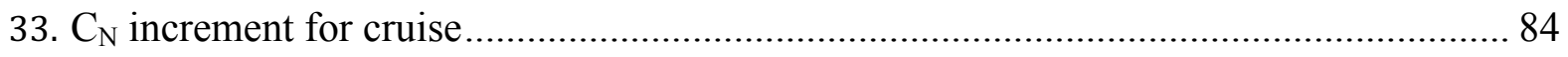

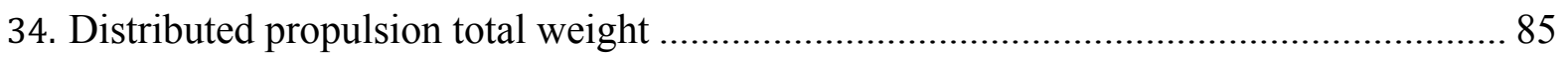

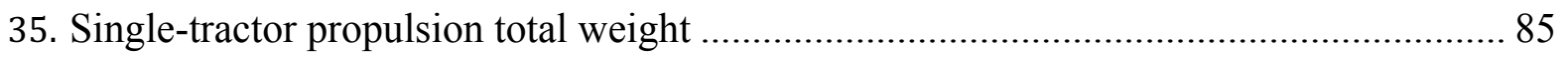

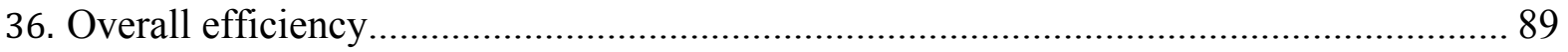




\section{LIST OF FIGURES}

Figure

1. Electric propulsion from a marketing perspective ................................................... 3

2. Cirrus SR22 and LEAPTech aircraft comparison................................................ 8

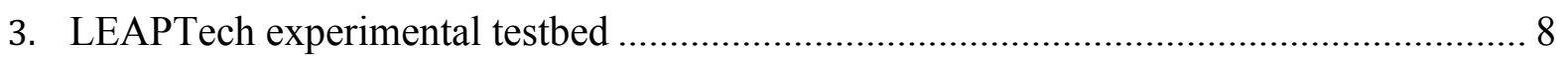

4. Tecnam P2006T aircraft and SCEPTOR design.................................................. 9

5. Existing aircraft and new design concepts...................................................... 10

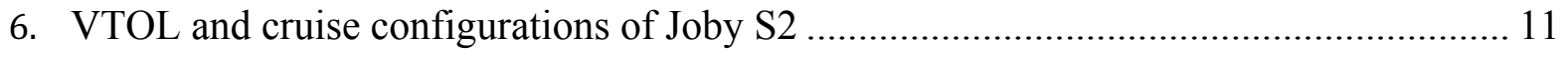

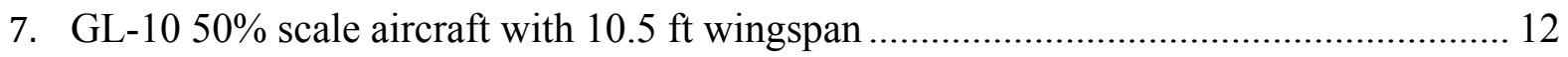

8. $20 \%$ subscale and full scale of LightningStrike................................................... 13

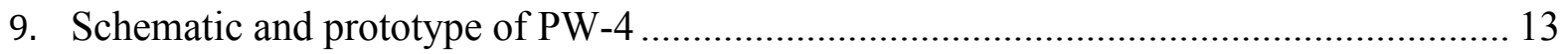

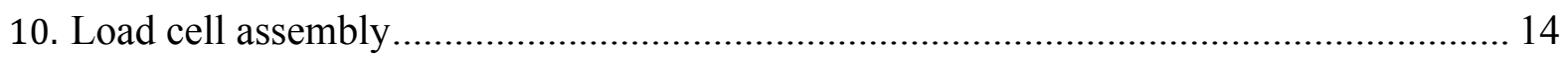

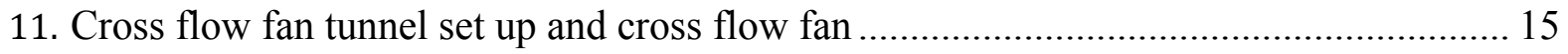

12. Old Dominion University Low Speed Wind Tunnel .............................................. 16

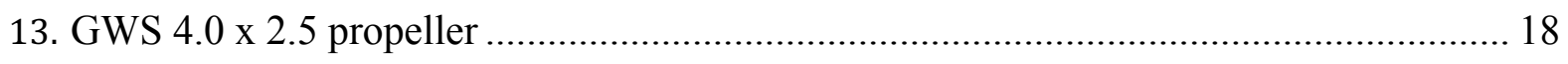

14. GWS 4.0 x 2.5 propeller thrust coefficient data .................................................. 19

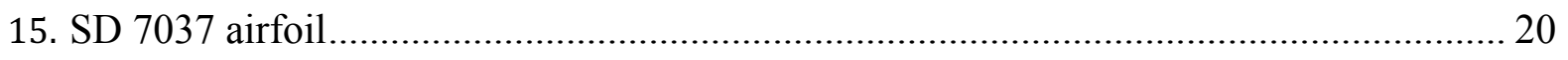

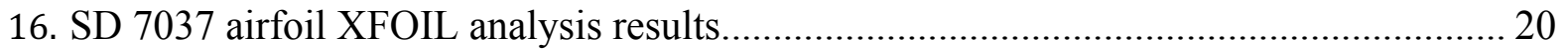

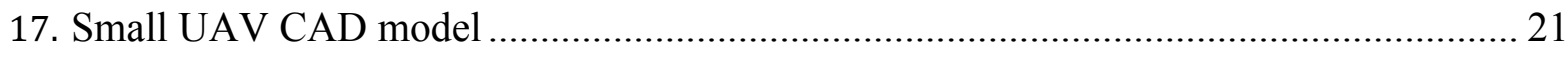

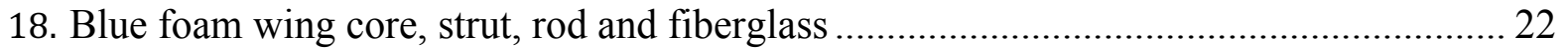

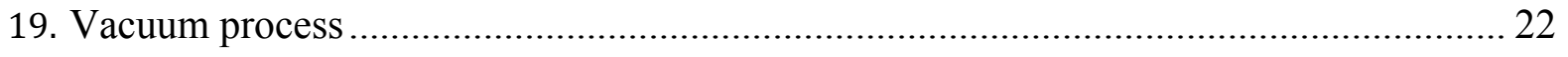

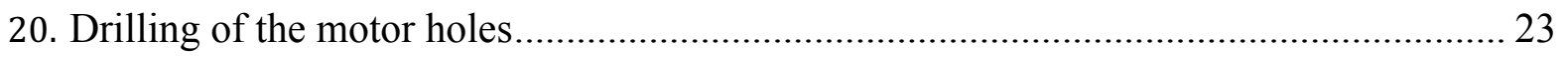

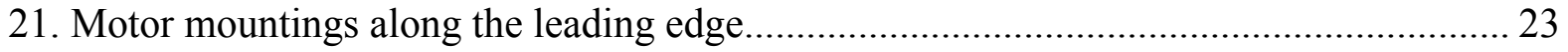


22. Bottom side of the wing (a) without motor mounting (b) with motor mounting............. 24

23. Fuselage and aluminum bulkhead before nose covering and sanding process ............... 25

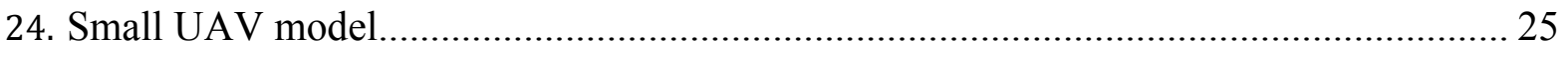

25. Balance block diagram (Philips, 2016) .................................................................. 26

26. Model and support system in test section ........................................................ 27

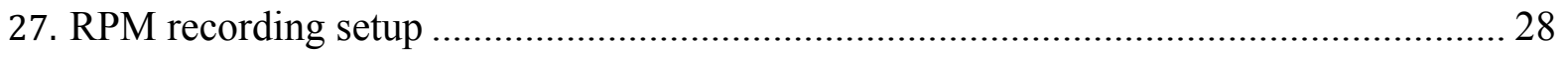

28. Reference angle (a) angle of attack (b) roll angle .................................................. 29

29. A full factorial design for two factors ................................................................ 37

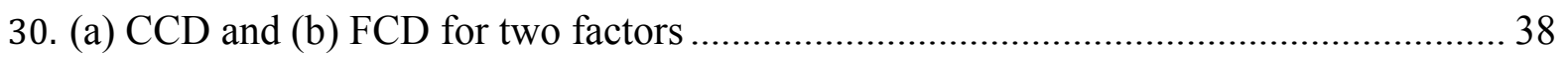

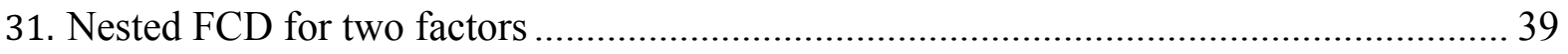

32. One-half fraction of three factors (a) principle (b) alternate fraction ........................... 40

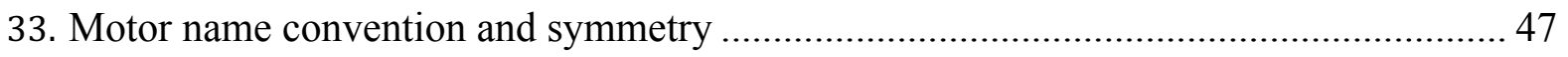

34. (a) Normality (b) Independence (c) Constant variance for all-propellers-on $\mathrm{C}_{\mathrm{N}} \ldots \ldots \ldots \ldots . . .50$

35. Response surface for all-propellers-on $\mathrm{C}_{\mathrm{N}}$ at minimum RPM level ........................... 52

36. Response surface all-propellers-on $\mathrm{C}_{\mathrm{N}}$ at maximum RPM level ............................... 52

37. $\mathrm{C}_{\mathrm{N}}$ as a function of angle of attack and velocity for all-propellers-on mode................. 53

38. $\mathrm{C}_{\mathrm{N}}$ as a function of angle of attack and L3 for all-propellers-on mode ...................... 54

39. $\mathrm{C}_{\mathrm{N}}$ as a function of angle of attack and L4 for all-propellers-on mode ........................ 54

40. (a) Normality (b) Independence (c) Constant variance for all-propellers-on $\mathrm{C}_{\mathrm{A}} \ldots \ldots \ldots \ldots . . .57$

41. Response surface for all-propellers-on $\mathrm{C}_{\mathrm{A}}$ at minimum RPM................................ 59

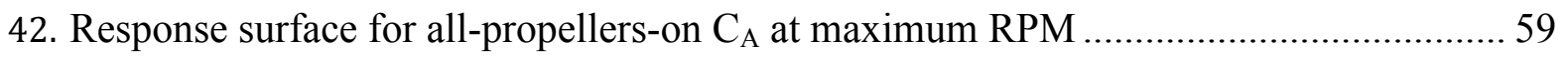

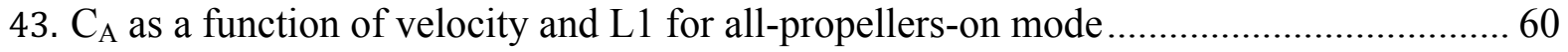


44. (a) Normality (b) Independence (c) Constant variance for wing-alone $C_{N} \ldots \ldots \ldots \ldots \ldots \ldots . . . . . .63$

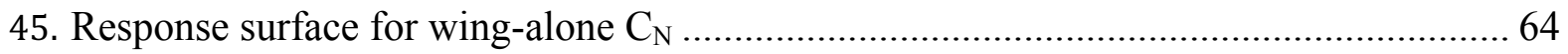

46. (a) Normality (b) Independence (c) constant variance for wing-alone $C_{A} \ldots \ldots \ldots \ldots \ldots \ldots . . . . . . .66$

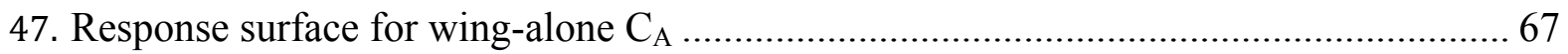

48. (a) Normality (b) Independence (c) Constant variance for wing-tip-propellers $C_{N} \ldots \ldots \ldots .70$

49. Response surface for wing-tip-propellers-alone $C_{N}$ at minimum $R P M \ldots \ldots \ldots \ldots \ldots \ldots \ldots . . . . . . . . . . .11$

50. Response surface for wing-tip-propellers-alone $C_{N}$ at maximum RPM ...................... 72

51. $\mathrm{C}_{\mathrm{N}}$ as a function of velocity and angle of attack for wingtip-propellers-alone mode ...... 73

52. (a) Normality (b) Independence (c) Constant variance for wing-tip-propellers $C_{A} \ldots \ldots . .75$

53. Response surface for wing-tip-propellers-alone $C_{A}$ at zero angle of attack ................. 76

54. Response surface for wing-tip-propellers-alone $\mathrm{C}_{\mathrm{A}}$ at eight angle of attack' ................. 77

55. $\mathrm{C}_{\mathrm{A}}$ as a function of velocity and $\mathrm{L} 1$ and $\mathrm{R} 1$ for wing-tip-propellers-alone mode ........... 78

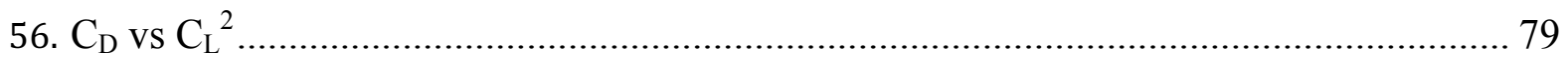

57. Induced drag difference between two-inboard and wingtip propellers mode................. 80

58. VSPAERO models (a) distributed propulsion (b) wing-alone .................................. 81

59. Distributed propulsion VSPAERO and experimental results ................................... 81

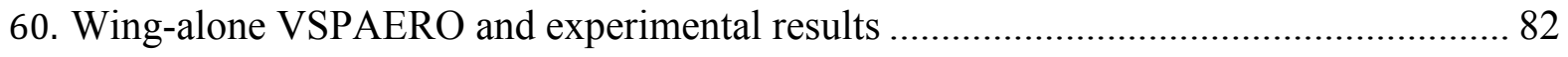

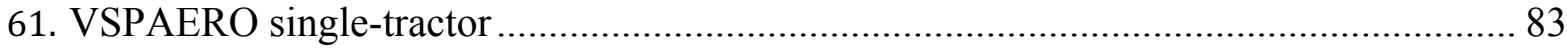

62. Experimental and VSPAERO results for wing-alone and single-tractor ...................... 83

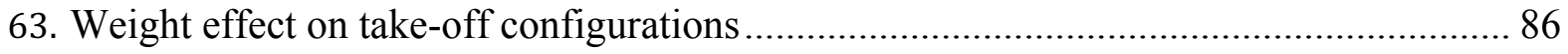

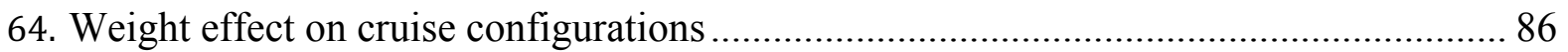

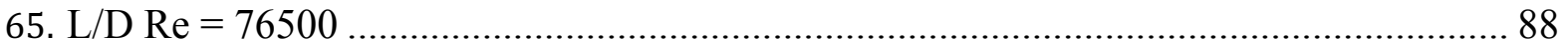

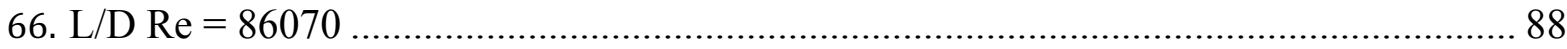

xvii 


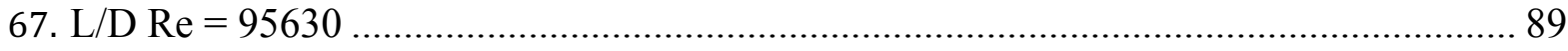

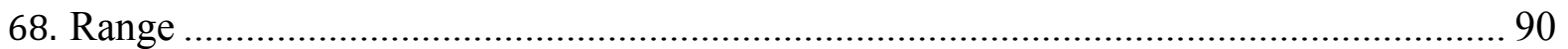

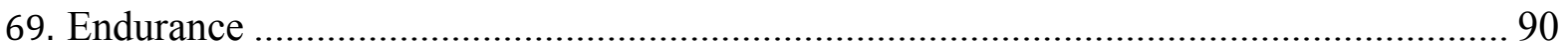




\section{CHAPTER 1}

\section{INTRODUCTION}

\subsection{Overview}

Recently, new aircraft propulsion concepts have been introduced in an effort to increase efficiency. General aviation, commercial aviation, and Unmanned Air Vehicles (UAV) may all benefit from these new technological developments. The primary aim of future aircraft designs is meeting environmental goals within desired flight conditions. Therefore, air transportation research mainly focuses on: new generation multidisciplinary propulsion technologies, noise reduction, reduced fuel consumption, safety and reliability, and optimized aircraft design. Distributed propulsion is one current trend in aviation that embodies the future focus.

The main idea behind distributed propulsion is dividing up thrust to multiple propulsive components for short take-off and landing, noise reduction, and reducing the energy consumption to increase flight range (Gohardani, Doulgeris, \& Singh, 2011). Although this system has a historical background, it has not been preferred by designers until recent years because reciprocating or turbine engines were used for initial distributed propulsion system applications. These combustion-based engines were not practical, due to several disadvantages.

Scale dependency is the biggest disadvantage and arises from the complexity of structures such as gear boxes and other power train components. Additionally, when scaled to small sizes under certain conditions, power to weight ratio, efficiency, and reliability were reduced significantly (Moore \& Fredericks, 2014). Noise pollution, high emission values, high maintenance costs, and power reduction at high altitudes are other problems to tackle for reciprocating and turbine engines. All of these disadvantages, plus recent advances in brushless 
electric motor and battery design, have driven researchers to focus on distributed electric propulsion systems.

The marriage of distributed propulsion with electric propulsion opens a new era for aircraft design concepts. Electric motor structure scales without a significant loss of efficiency. Consequently, many small size electric motors can easily be put in required places on aircraft (Moore \& Fredericks, 2014; Stoll, Bevirt, Moore, Fredericks, \& Borer, 2014). Another significant advantage is the short response time to control commands which has an important contribution to safety and reliability. Additionally, decreased energy usage, noise reduction, ride quality, reduced operation costs, resulting reduced wing area, zero emissions, and high efficiency while changing altitudes and temperatures are all potential gains of distributed electric propulsion.

\subsection{Objective}

Despite the advantages of distributed electric propulsion, current battery technology restricts the application area of this system. Therefore, initial design implementations of electric propulsion technology will likely only be for general aviation aircraft and for unmanned air vehicles in the near future. Figure 1 shows the way ahead for electric propulsion, from a marketing perspective. 


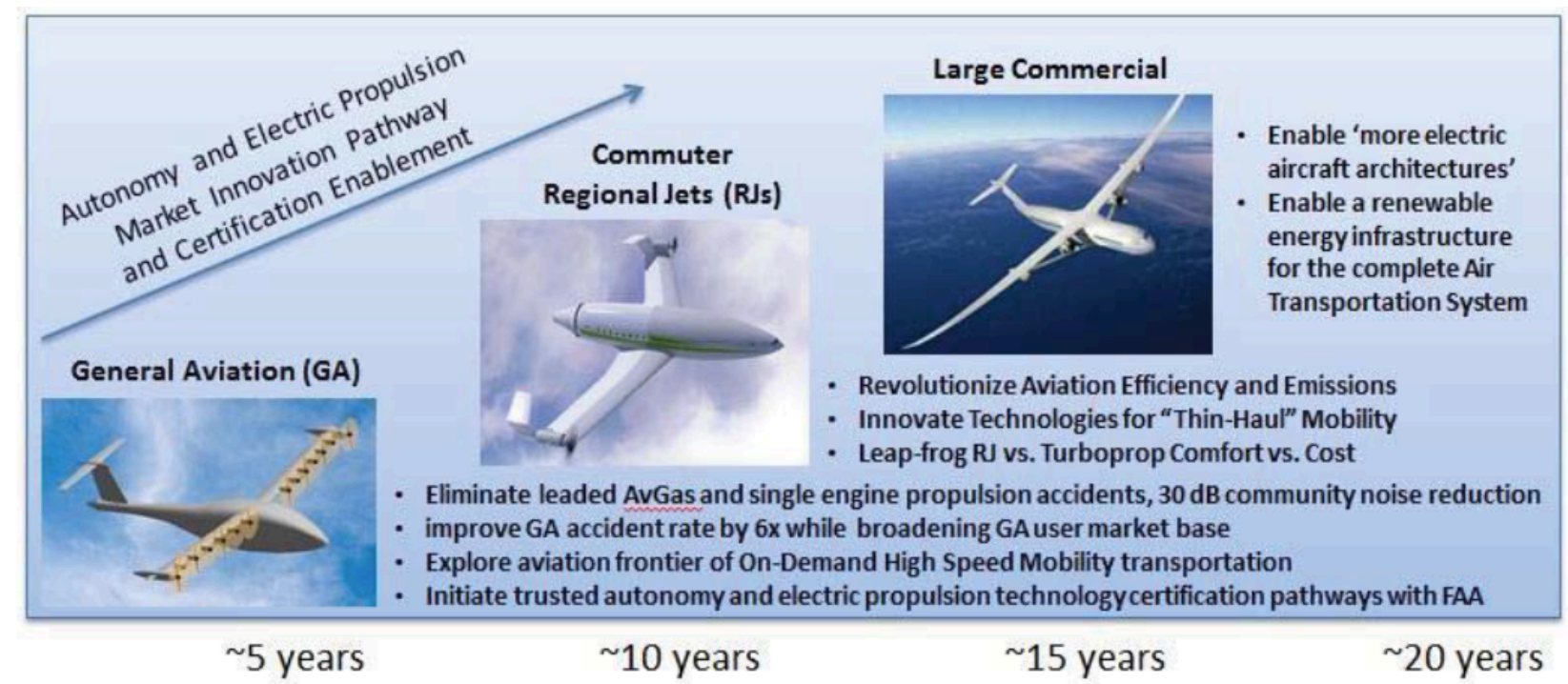

Figure 1. Electric propulsion from a marketing perspective (Moore et al., 2013)

Due to the short history of distributed electric propulsion systems, there are many facets left to investigate its benefits and effects on aviation. NASA Leading Edge Asynchronous Propellers Technology (LEAPTech) (Stoll, 2015), Joby S2 (Stoll, Bevirt, Pei, \& Stilson, 2014), and NASA Greased Lightning - 10 (GL-10) (Rothhaar et al., 2014) aircraft are recent conceptual distributed electric propulsion aircraft flying prototypes for general aviation and unmanned air vehicle systems. However, they are still in the development phase.

Based on the progress provided above, the objective of this study is to explore the potential benefits of distributed propulsion on the aerodynamics of small unmanned air vehicles at low Reynolds numbers through wind tunnel tests using the Design of Experiments for aerodynamic characterization. In addition, comparison through analytical calculations and vortex lattice methods are performed. 


\subsection{Problem Statement}

A fixed wing UAV wing-body model was considered for this study. A survey of existing UAVs and the constraints of available wind tunnel facilities drove the design and size of the model. Under these considerations, a wing was built with a 34-inch span and 5.5-inch chord length. This wing size and the availability of a 50 amp DC power supply drove the distributed propulsion concept to use eight motors and 4-inch diameter propellers along the leading edge of the wing. RPM values were chosen between 10000 and 13000 to avoid the windmill condition at free-stream velocities of $8-10 \mathrm{~m} / \mathrm{s}$. Additionally, a simple fuselage was built to provide a connection between the wing and force balance. The free-stream velocities give a chord-based Reynolds number range of 76500 to 95650 , representative of small UAV operations.

Several configurations were chosen to investigate the effects on the measured normal force coefficient $\left(\mathrm{C}_{\mathrm{N}}\right)$ and axial force coefficient $\left(\mathrm{C}_{\mathrm{A}}\right)$ :

- Powering all motors simultaneously, called all-propellers-on, was used to observe increased L/D due to reduction in tip vortices and increased momentum in the boundary layer

- The wing alone with no propulsion and props removed, called wing-alone mode, was used for baseline comparisons

- Wing tip props powered only, called wingtip-propellers-alone-on, for looking at the potential induced drag reduction while powering the UAV in cruise

- Two inboard props powered only, called two-inboard-propellers-alone-on, used for comparison to the wingtip only case.

Lastly, all-propeller-on, wing-alone, and an additional single-tractor configuration were analyzed using VSPAERO, a vortex lattice code, to make comparisons between these different 
configurations. Thrust coefficient $\left(\mathrm{C}_{\mathrm{T}}\right)$ equality was assumed for this comparison between a single tractor propeller and the distributed propulsion. 


\section{CHAPTER 2}

\section{LITERATURE REVIEW}

\subsection{Distributed Propulsion Definitions and Concepts}

Making a specific definition of distributed propulsion systems with existing descriptions cannot be sufficient to cover all applications of this system, due to its wide range of configurations. However, some classification can be performed for general identification. Sehra and Whitlow (2004) tried to classify the distributed propulsion applications into three main categories: distributed engines, common core multi-fans, and distributed exhaust. Nevertheless, this definition does not include the required number of propulsion units to describe propulsion systems as a distributed propulsion system (Gohardani, 2013).

Another definition was published by the National Research Council (2006). This definition is based on simply using many distributed small electric thrusters, propulsors, or mini gas turbine engines, instead of large engines.

Ko's (2003) doctoral dissertation drew attention to NASA's distinction between the distributed propulsion and the distributed exhaust concepts. Replacing large engines with smaller engines implies distributed propulsion, and distributing the exhaust across a large area implies distributed exhaust applications. Therefore, four, six and eight engine design configurations were used in Ko's (2003) study to understand the benefits of distributed propulsion concepts. Gohardani (2013) also mentioned the perception between distributed propulsion and the number of smaller engines. Still, there is a lack of consensus in the literature to explain distributed propulsion with an exact number of small propulsive units. 
Distributed propulsion definition of Schetz, Hosder, Dippold, and Walker (2010) emphasized the distributed exhaust concept instead of mentioning a specific number of small engines. Schetz's research model redistributed the thrust along the thick trailing edges of the wing.

In light of these selected definitions, a propulsion concept can be divided into two main streams: a small number of larger engines replaced with a large number of smaller engines, and thrust redistribution across an area or space (Gohardani, 2013).

\subsubsection{General Aviation Configurations}

Although battery energy density is a barrier for fully electric aircraft, synergistic evaluation of total efficiency for aircraft and propulsion system coupling decreases the level of this disadvantage (Moore \& Fredericks, 2014). A synergistic approach covers all system factor comparisons with each other, instead of considering a one-factor comparison between two concepts. For instance, noise reduction, low energy costs, zero emissions, high reliability and safety, high engine efficiency, and scale-free and improved aerodynamic efficiency characteristics are many advantages, despite the battery constraint. Current progress in battery technology illustrates that sufficient energy density may be available within five years for feasible general aircraft configurations, when based on historical battery progress (Moore \& Fredericks, 2014). Therefore, recent research has started to focus on designing new electrical aircraft concepts to maximize aerodynamic and environmental benefits. Distributed electric propulsion designs will be considered within this context.

LEAPTech is a pioneer configuration for a distributed electric propulsion systems. It has eighteen small propellers placed along the span. These propellers increase the local dynamic 
pressure over the wing during take-off and landing. This enables the aircraft to lower its stall speeds and use reduced wing area without the need for multi-element high-lift systems. Reduced wing area provides cruise drag reduction and improves ride quality. Additionally, the low tip speeds of the propellers reduce noise (Stoll, 2015). Figure 2 illustrates computer-based solid models of the LEAPTech configuration and Cirrus SR22, a current general aviation production aircraft. The experimental setup used to evaluate the LEAPTech concept is shown in Figure 3.
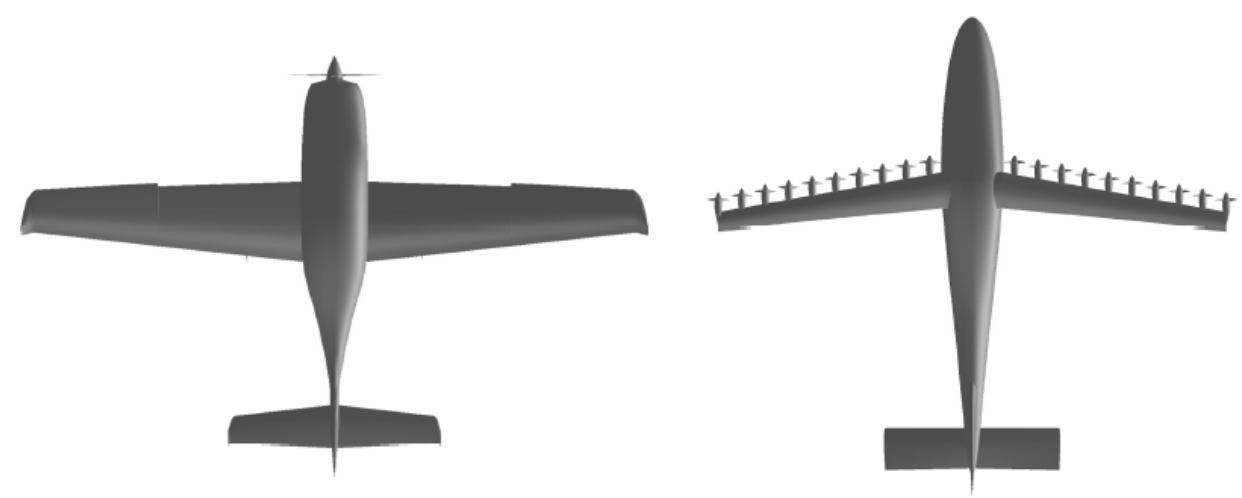

Figure 2. Cirrus SR22 and LEAPTech aircraft comparison (Stoll, 2015)

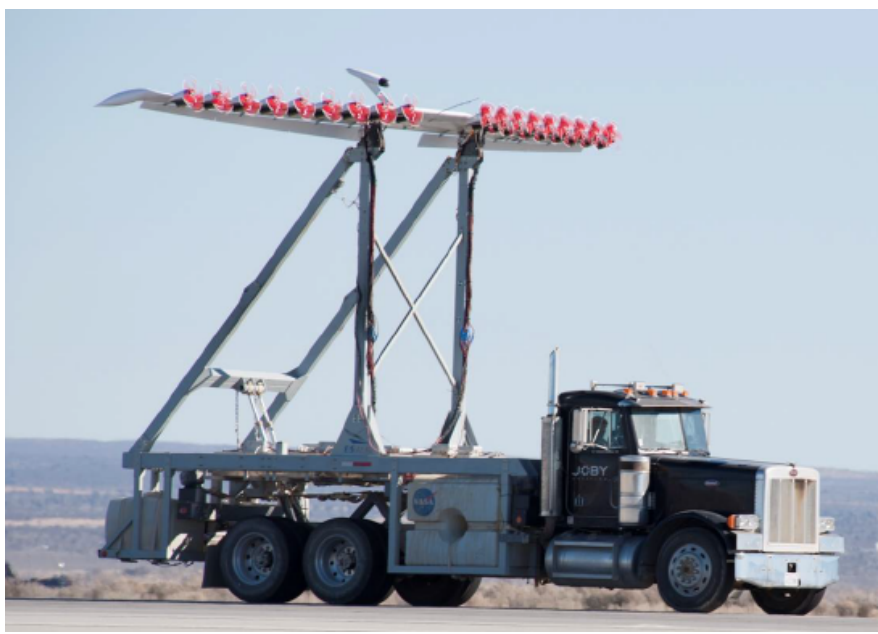

Figure 3. LEAPTech experimental testbed (Stoll, 2015)

The LEAPTech project created a foundation for NASA's Scalable Convergent Electric Propulsion Technology Operations Research (SCEPTOR) program (Borer et al., 2016). The goal 
of the program is to design a fully electric distributed propulsion general aviation aircraft which shows up to fivefold predicted efficiency improvement in the cruise mode (Borer et al., 2016; Dubois et al., 2016). After evaluation of baseline airframe selection factors (e.g. useful load, installed power, effect of stock engines, wing, and fixtures removal on location of center of gravity etc.), the Tecnam P2006T model was selected to apply a distributed electric propulsion system to demonstrate purely the gains of this propulsion system approach (Borer et al., 2016). Tecnam P2006T aircraft and SCEPTOR Design are illustrated in Figure 4.
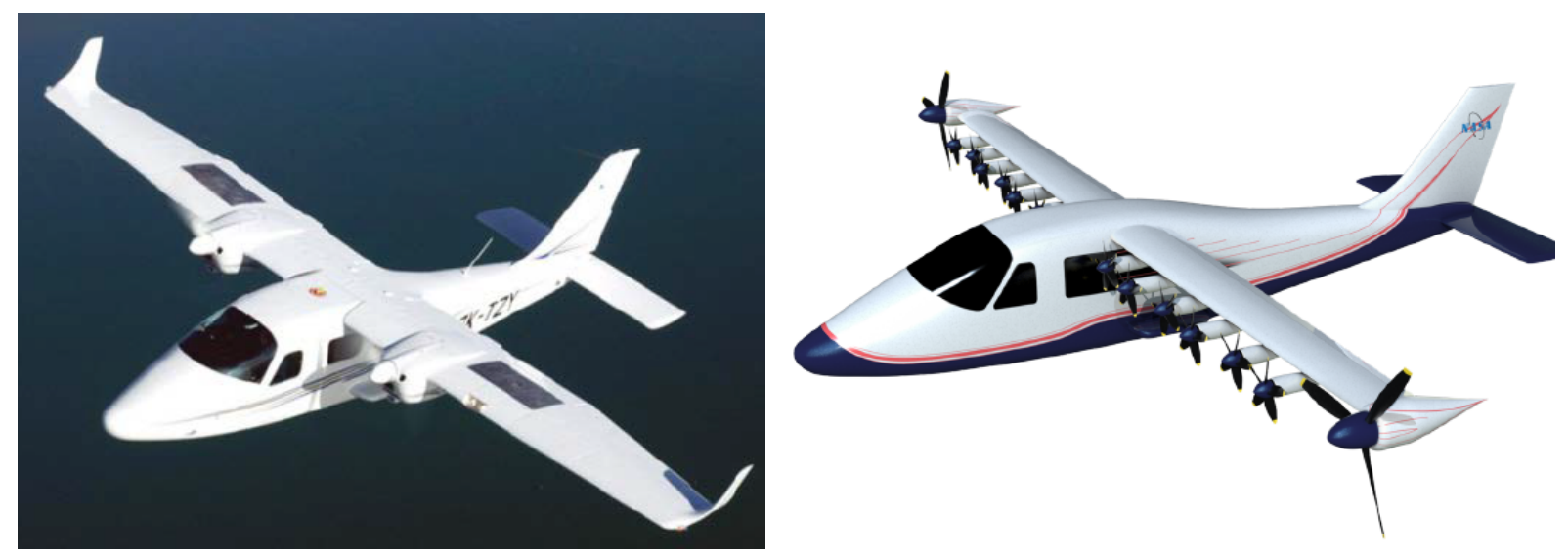

Figure 4. Tecnam P2006T aircraft and SCEPTOR design (Dubois et al., 2016; Moore et al., 2014)

SCEPTOR includes twelve small high-lift propellers and two larger wingtip propellers. The small high-lift propellers are used for flow acceleration over the wing (increased dynamic pressure) at take-off and landing. Wingtip propellers are the primary propulsors for the cruise mode. They benefit from the wingtip vortex and increase cruise efficiency. which means that less propulsive power is required for a given flight velocity (Borer et al., 2016).

Another distributed electric propulsion aircraft concept design study was conducted for the thin haul commercial aviation market (Stoll \& Mikic, 2016). This class of aircraft has short route missions with around ten passengers (e.g. Cessna 402C, Tecnam P2012). Three different 
configurations, including conventional, 3-motor and high-lift props, were considered to be optimized and then were compared with existing aircraft, as shown in Figure 5. In the designs, a battery was considered for short missions and range extenders for long missions. Computational results illustrated significant energy cost reduction again for distributed electric propulsion. However, the battery power to weight ratio still needed to be improved (Stoll \& Mikic, 2016).

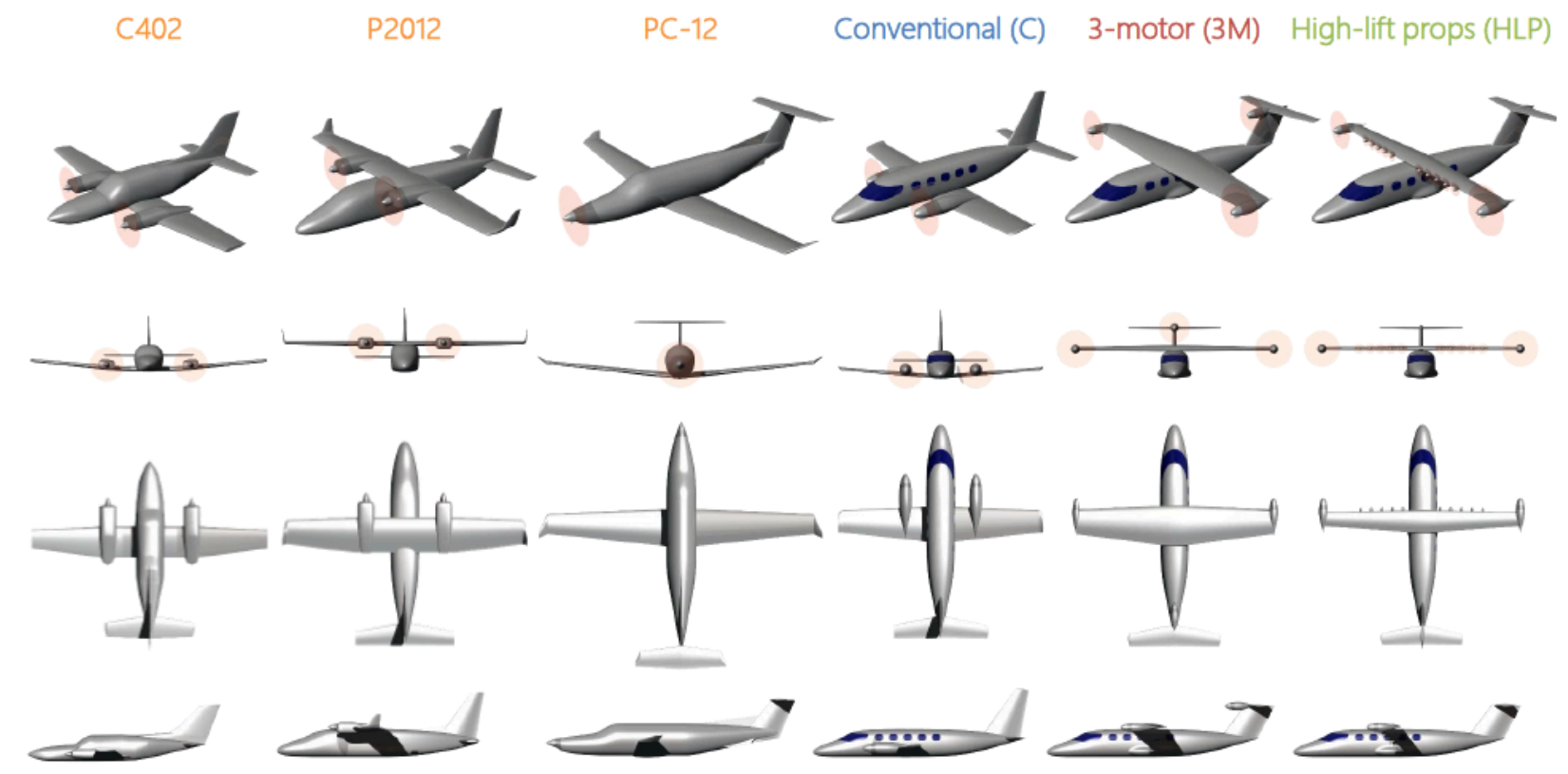

Figure 5. Existing aircraft and new design concepts (Stoll \& Mikic, 2016)

The Joby S2 is a two-seat vertical take-off and landing application of distributed electric propulsion for personal air vehicles. This concept was designed for short to medium distances where speed, noise, efficiency, and safety are of concern. It has eight tilting motors along the wing and four tilting motors at the V-tail. These propellers are used during take-off and landing. A pair of the wingtip propellers are used for cruise mode. Other propellers are folded for drag reduction in cruise mode (Stoll et al., 2014). Figure 6 shows take-off, landing, and cruise mode configurations of the Joby S2 aircraft. 

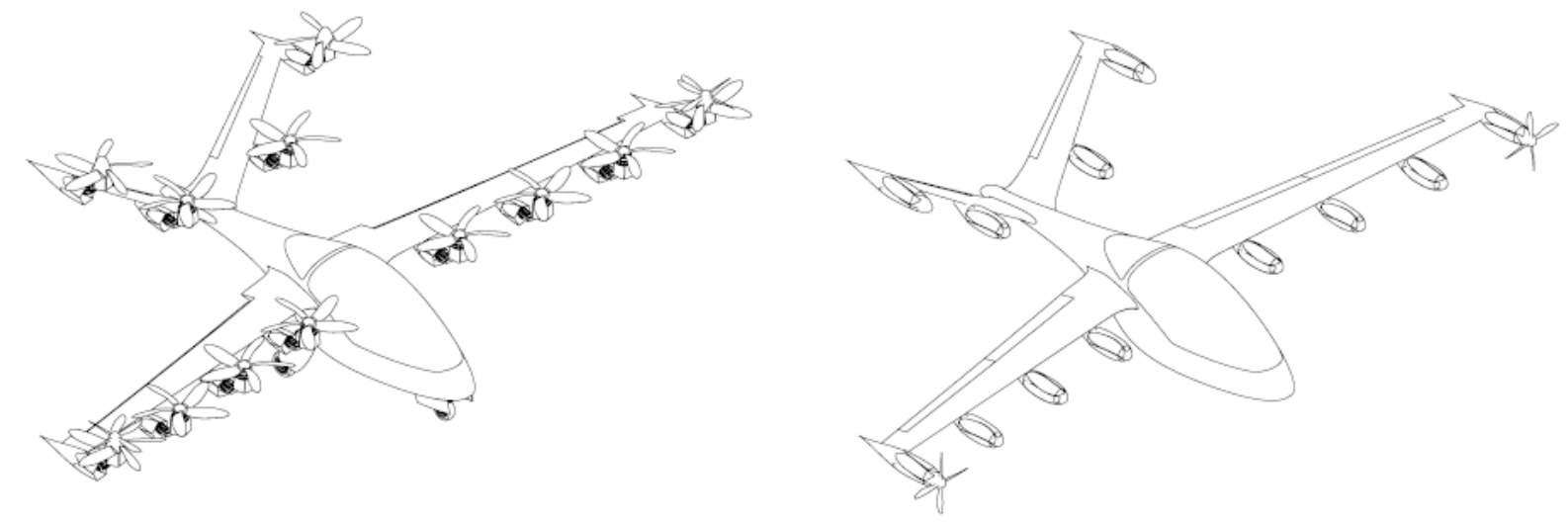

Figure 6. VTOL and cruise configurations of Joby S2 (Stoll et al., 2014)

\subsubsection{Unmanned Air Vehicle Configurations}

UAVs have become an indispensable necessity for aviation in recent years. They undertake important missions, such as search and rescue, fire control, reconnaissance, combat, aerial photography, and mapping. However, distributed electric propulsion technology has no widespread use in UAV applications at present. Gohardani (2013) demonstrated this conclusion with searching 624 UAVs in Jane's Unmanned Aerial Vehicle database ("Jane's All The World's Aircraft Homepage," 2016). Only 2.6\% of the UAVs used distributed propulsion technology. Therefore, there is a large area of study to explore the effects of distributed propulsion systems on UAVs.

The UAV concept of distributed electric propulsion technology can be clearly seen on the GL-10 Greased Lightning long endurance VTOL aircraft. Foldable propellers were distributed throughout the wingspan. Tilt wing and tilt horizontal stabilizer were used, instead of the tilt motor employed on the Joby S2 aircraft. The concept is a combination of tilt wing aircraft and distributed electric propulsion. Therefore, flight control and flight test feasibility are the primary challenges, rather than the design of the aircraft configuration (Rothhaar et al., 2014). Nevertheless, the flight control challenge was successfully completed in flight tests, which 
showed transition from hover to wing-borne flight, and then back to hover again. After this success, research has been focused on a demonstration of the aerodynamic efficiency of this concept, which is four times more efficient in cruise than a helicopter (Barnstorff, 2015). New airframe design freedom was provided again by the scale-free advantage of electric motors.

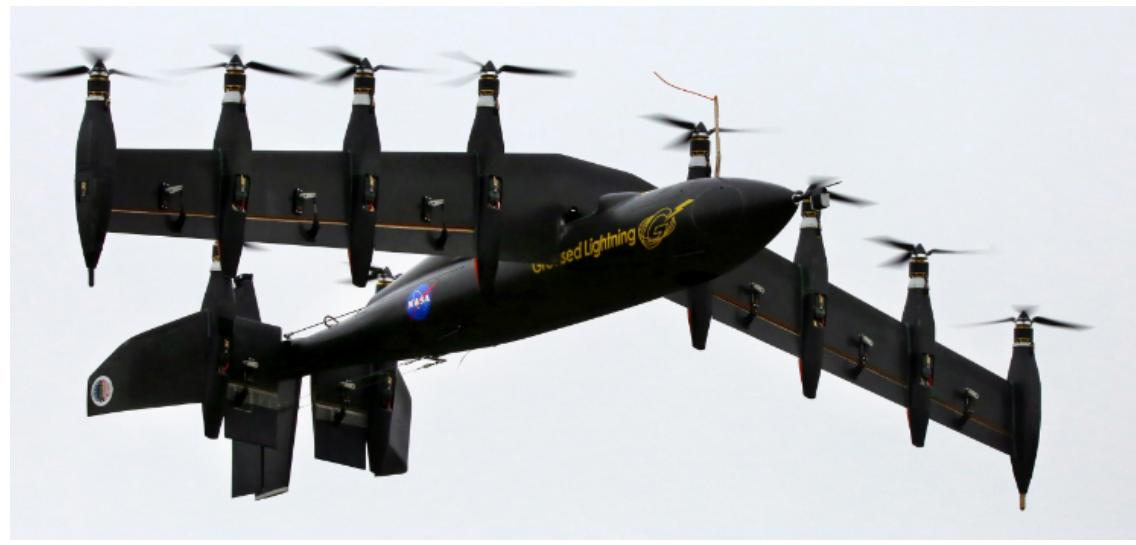

Figure 7. GL-10 50\% scale aircraft with $10.5 \mathrm{ft}$ wingspan (Rothhaar et al., 2014)

Although VTOL aircraft have improved maneuverability, the speed of VTOL UAVs needs to improve, in order to become competitive with fixed wing configurations and because long mission times increase the vulnerability to enemy attack during military operations (Bagai, 2016). For this reason, the Defense Advanced Research Projects Agency (DARPA) signed a contract with Aurora Flight Sciences to enhance the top speed of VTOL UAV aircraft to 300kt 400kt without increasing design complexity and reducing aerodynamic efficiency. In order to meet the requirements and to overcome the issues at hand, a distributed hybrid-electric propulsion system was selected by Aurora Flight Sciences. For the first phase of the project, they developed a 20\% subscale vehicle model of the LightningStrike VTOL X-Plane. The model has distributed ducted fans along the tilt wing and canard (Sheller, 2016a). Flight tests were completed successfully with a subscale model. Therefore, the second phase of the project has 
been started by the Aurora team to design a full scale unmanned LightningStrike. Figure 8 illustrates the subscale and the full scale design of LightningStrike.

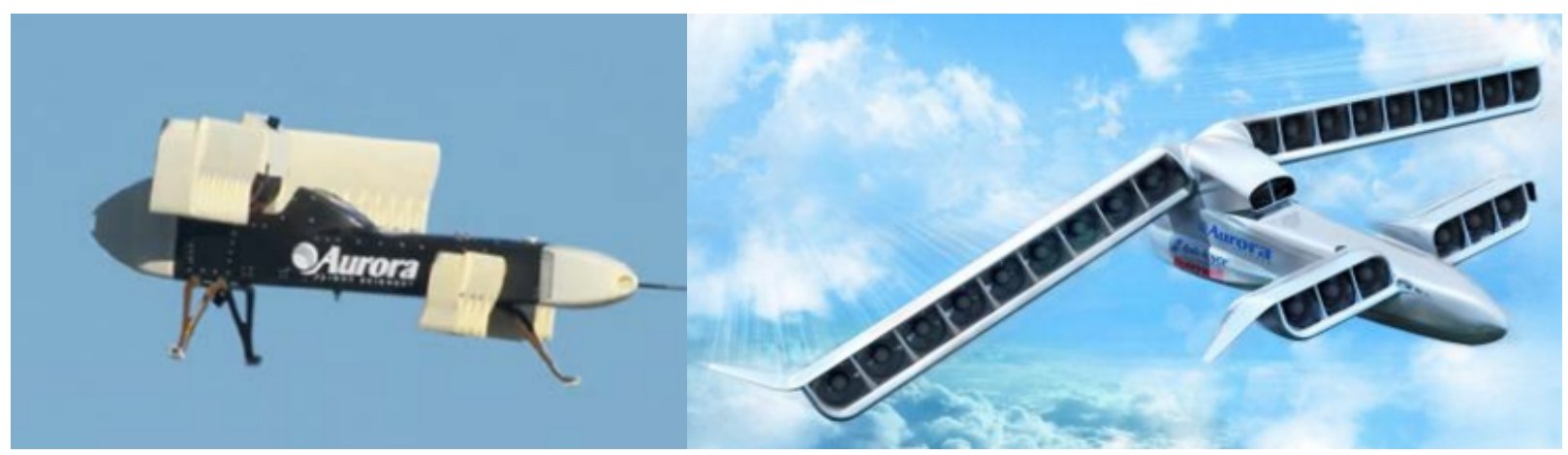

Figure 8. 20\% subscale and full scale of LightningStrike (Sheller, 2016a, 2016b)

The Propulsive Wing is an example of a distributed exhaust application of distributed propulsion systems (Kummer, 2010). A cross-flow fan was integrated along the trailing edge of a wing. This concept claims to improve the payload capacity three times, and the internal payload volume ten times, over the conventional systems for a given span. Additionally, propulsive wing aerial vehicles have shorter distances for take-off and landing (extreme high lift capability), low noise, and a high level of safety of user, due to the elimination of external rotational parts. The PW-4 unmanned prototype, which uses a distributed exhaust concept, is completed and the model is still in a flight test program at the time of this writing. Similarly, the cross-flow fan integration studies can be seen for commercial aircraft (Perry, Ansell, Kerho, Ananda, \& D’Urso, 2016). A schematic of a propulsive wing and PW-4 prototype is shown in Figure 9.

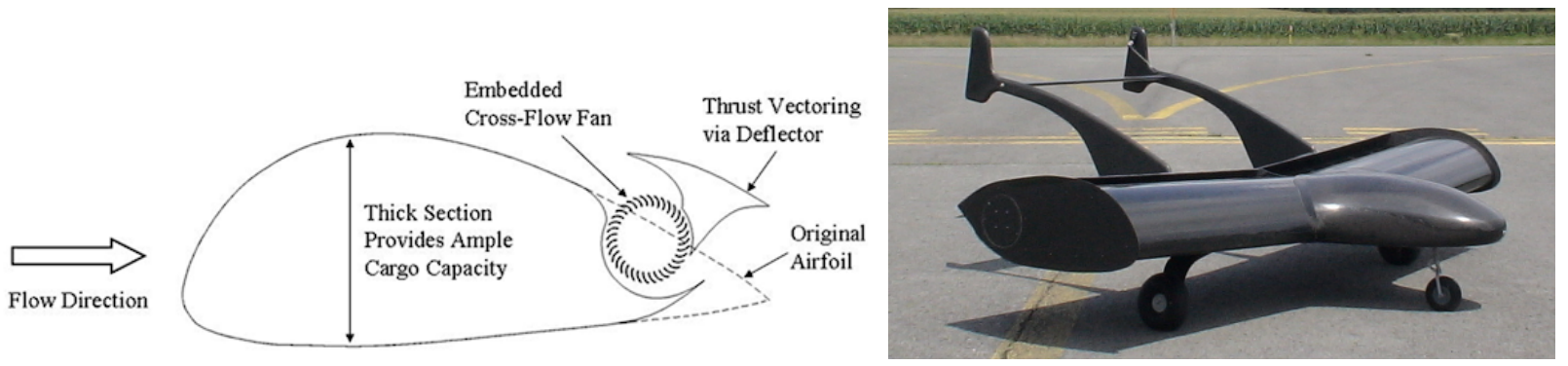

Figure 9. Schematic and prototype of PW-4 (Kummer, 2010) 


\subsection{Experimental Studies}

Full scale LEAPTech experimental studies were performed on a specially modified truck testbed, as shown in Figure 3 (Stoll, 2015). Vertical force, axial force, side force, and pitching moment were measured by a custom force balance with seven load cells as depicted in Figure 10. The experimental data was compared to STAR-CCM+, FUND3D RUNS, and VSPAREO code solutions. Although distributed propulsion systems are a complex problem for computational studies, the computational aerodynamic performance results differed from experimental results by only approximately $10 \%$. Also, the results and analytical predictions showed that the desired design $C_{\text {Lmax }}$ value of 4.3 would be exceeded. This provides lower cruise drag and improved ride quality.

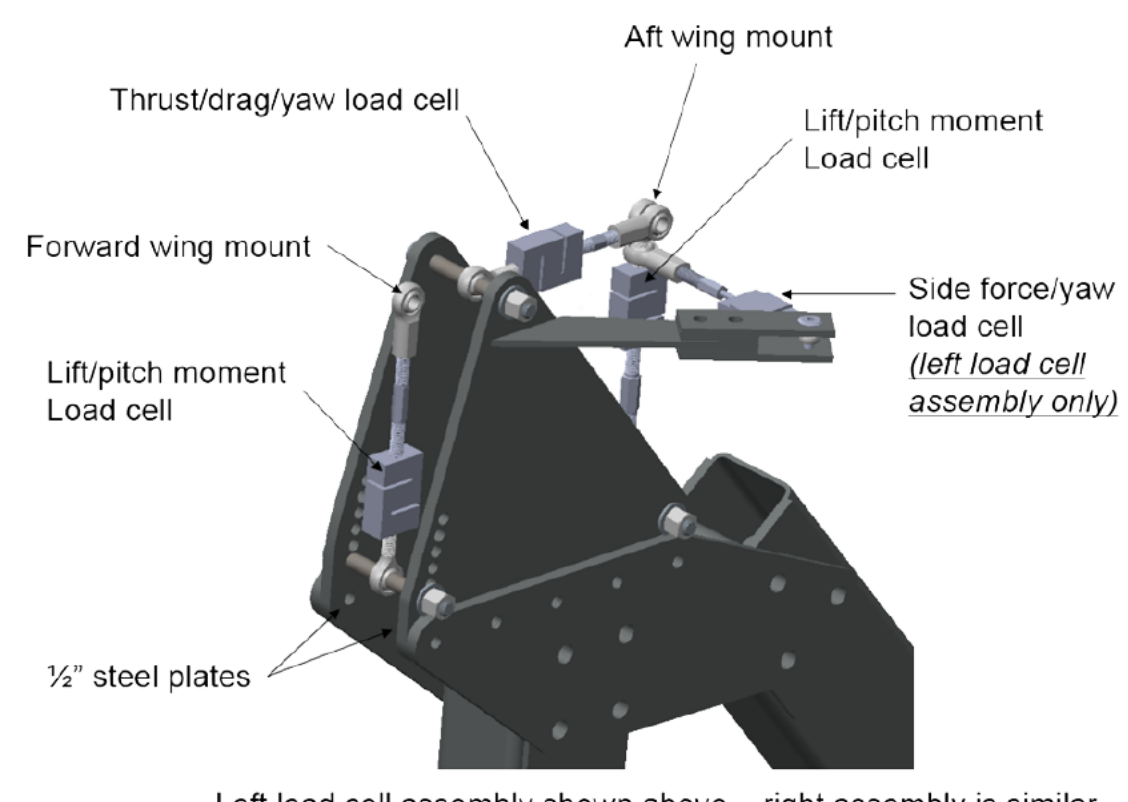

Left load cell assembly shown above - right assembly is similar

Figure 10. Load cell assembly (Stoll, 2015)

In a study by Murphy and Landman (2015), wind tunnel tests were conducted for the GL10 unmanned air vehicle in the NASA Langley 12-Foot Low Speed Wind Tunnel. Design of 
Experiments and Response Surface Methods were used to reduce test time and to get robust statistical regression models. Exploratory experiments were performed initially to understand the general characteristics of the aircraft. Other experiments were categorized in accordance with four modes of flight (cruise, loiter, transition and hover) for aerodynamic characterization of the GL-10. General regression models were created for all force and moment coefficients in all modes using up to 23 factors.

Transonic propulsive wing application of a distributed exhaust system underwent wind tunnel experiments at the University of Illinois in the 5x5 Supersonic Tunnel facility (Perry et al., 2016). The aim of the research was to design a new propulsive wing concept to meet the efficiency goals of the NASA generation N+3 aircraft. Trailing edge distributed cross-flow fans were used to provide suction/blowing for the airfoil as shown Figure 11. Experimental data illustrated that cross-flow fans could be effectively used for a transonic flow. Eventually, the propulsive wing concept was applied to the Boeing SUGAR (Subsonic Ultra Green Aircraft Research). Results show that $11.8 \%$ fuel reduction is achievable for this baseline aircraft with a propulsive wing.
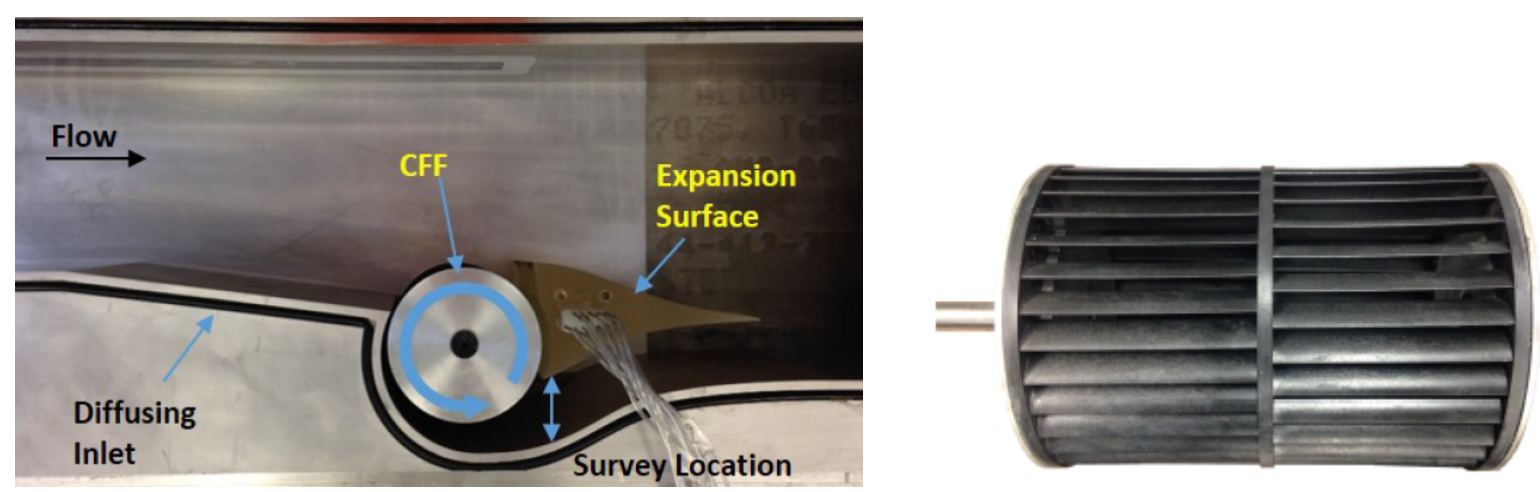

Figure 11.Cross flow fan tunnel set up and cross flow fan 


\section{CHAPTER 3}

\section{EXPERIMENTAL SETUP AND DESIGN}

\subsection{Wind Tunnel Facilities}

The Old Dominion University Low-Speed Wind Tunnel (ODU LSWT) is an atmospheric closed return tunnel equipped with a $93 \mathrm{~kW}$ electric motor. The tunnel has high speed and low speed test sections measuring $0.91 \times 1.22$ meters and $2.13 \times 2.44$ meters respectively, as seen below in Figure 12. The high speed test section is 2.43 meters long and has a top speed of 55 $\mathrm{m} / \mathrm{s}$. The low speed test section is 2.13 meters long and has a top speed of $12 \mathrm{~m} / \mathrm{s}$. The tunnel and model positioning systems are computer controlled using LABVIEW software. Pressure probes, pressure transducers, multiple force balances, particle image velocimetry, and hot wire anemometry are other capabilities of the ODU LSWT.

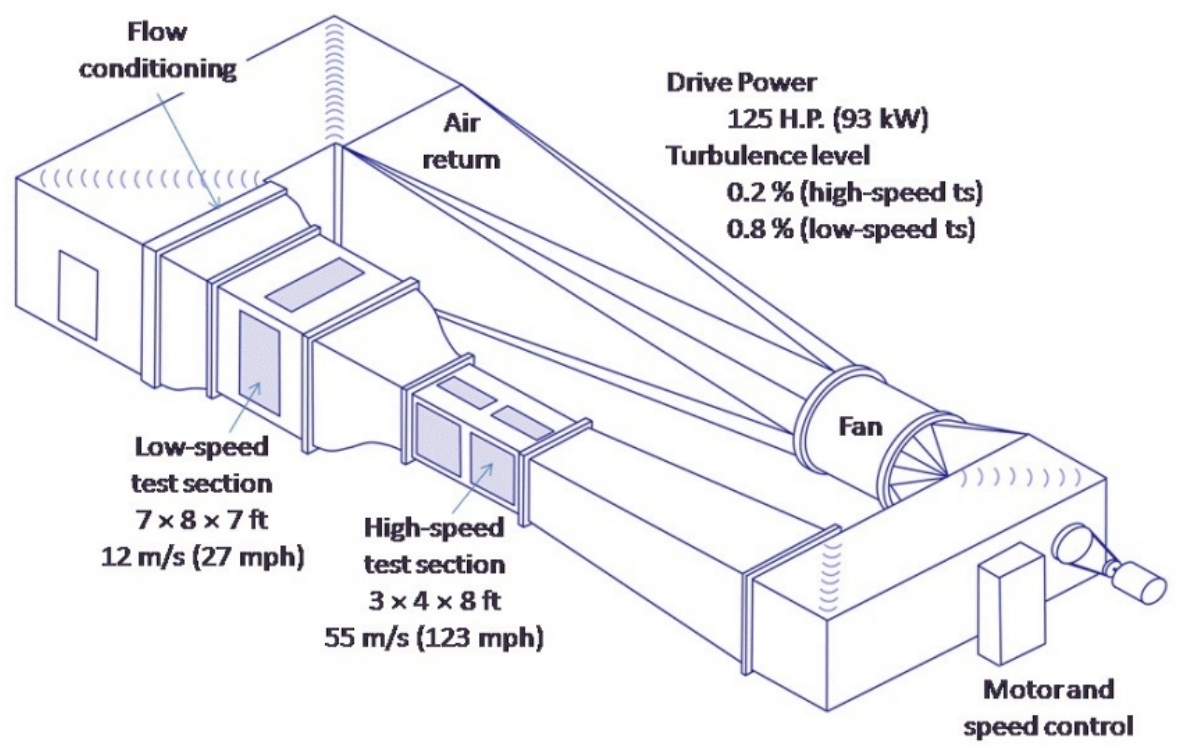

Figure 12. Old Dominion University Low Speed Wind Tunnel 


\subsection{Model Design}

The design of the fixed wing UAV was based on existing UAVs, available power, and wind tunnel test facility limits. These limits were wing span limits due to boundary effects, force limits due to the balance, free stream speed limits, and propeller choices. The allowable maximum wing span for the wind tunnel test section was 38-inches (Barlow, Rae, \& Pope, 1999). Therefore, a 34-inch wing span was determined for wind tunnel testing using available propellers. Balance force limits were considered for propeller and motor selection and determination of the model total weight. These balance moment center load limits were $70 \mathrm{lbs}$. for normal force and $15 \mathrm{lbs}$. for axial force. A detailed explanation of the force balance is given in an appendix.

An 8 propeller wing configuration was planned for the distributed propulsion system due to the wing span and power restriction. So, the maximum propeller diameter was chosen as 4 inches, when wingspan and propeller numbers were considered. Accordingly, a two blade GWS $4.0 \times 2.5$ propeller was selected from the University of Illinois at Champaign Urbana Propeller Data Base (Deters, Ananda, \& Selig, 2014) as seen in Figure 17. The value of 4.0 indicates propeller diameter and 2.5 indicates propeller pitch. Also, a Medusa MR-012-030-4000 brushless motor was used for the tests due to size, power output, and historical wind tunnel test data with the GWS 4.0 x 2.5 propeller (Deters et al., 2014).

A 5.5-inch chord length was determined for appropriate installation of the brushless inrunner electric motors in the wing. Two types of motor mountings (nacelles) were designed for the wing-tip and inboard motor locations and were 3D printed from ABS material. 


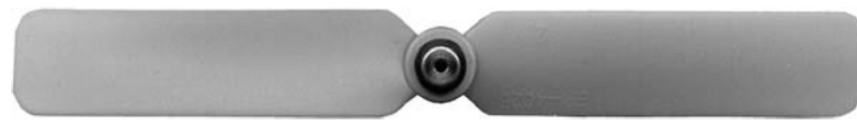

Front View

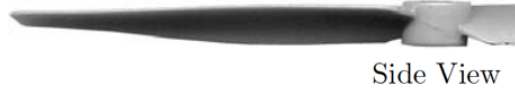

Figure 13. GWS $4.0 \times 2.5$ propeller (Deters \& Selig, 2008)

RPM and wind tunnel free stream velocity ranges were defined from historical $\mathrm{C}_{\mathrm{T}}$ and advance ratio $(\mathrm{J})$ data of the GWS $4.0 \times 2.5$ propeller to avoid the windmill condition(Deters et al., 2014). The plot is shown in Figure 14 for various propeller chord based Reynolds numbers. Zero thrust coefficient determined the windmill case. Therefore, a 0.62 advance ratio value was chosen for calculations and equation (1) was used to calculate the maximum tunnel velocity. In equation (1), V is tunnel free stream velocity, $\mathrm{n}_{\text {prop }}$ is the RPS value, and $\mathrm{D}_{\text {prop }}$ is propeller diameter. The velocity range was identified between $8 \mathrm{~m} / \mathrm{s}$ and $10 \mathrm{~m} / \mathrm{s}$. Also, RPM range was determined between 10000 and 13000. Additionally, the wing chord length based Re number range was computed between 76500 and 95650 by using equation (2). In equation (2) $\rho$ is air density, $\mu$ is dynamic viscosity, $\mathrm{c}$ is wing chord length, and $\mathrm{V}$ is tunnel velocity. 


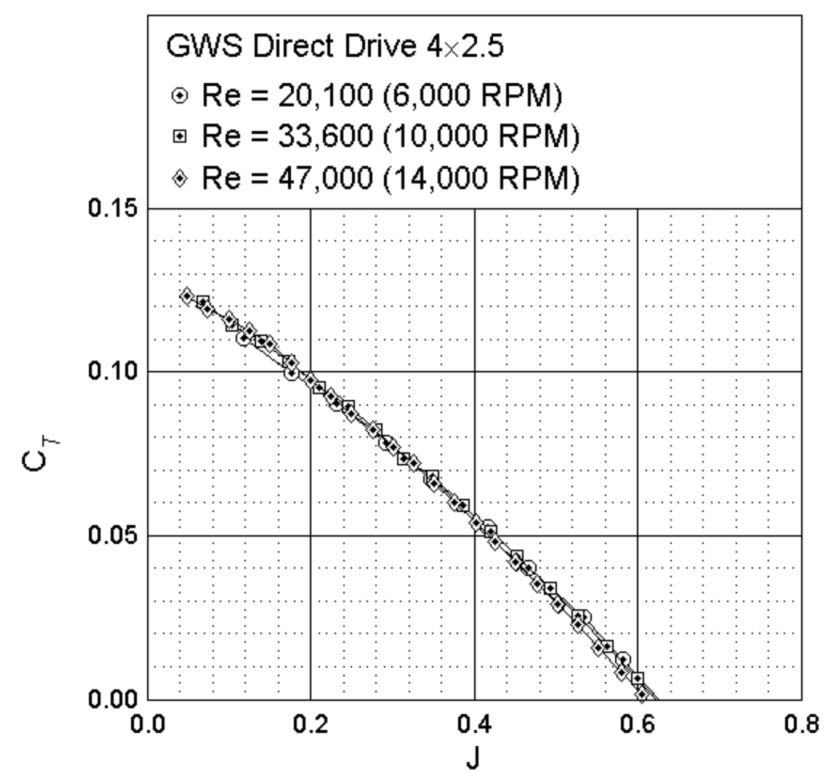

Figure 14. GWS 4.0 x 2.5 propeller thrust coefficient data (Deters et al., 2014)

$$
\begin{aligned}
& J=\frac{V}{n_{\text {prop }} D_{\text {prop }}} \\
& \operatorname{Re}=\frac{\rho V c}{\mu}
\end{aligned}
$$

The direction of the inboard propellers, which are clockwise and counter clockwise, were arranged in sequence based on wing tip-mounted propeller directions. The benefit of the leading edge mounted wing tip propellers is reducing induced drag when their rotation is opposite of the wing tip vortices (Miranda \& Brennan, 1986). Therefore, outward rotating directions were chosen for wing tip propellers.

In keeping with the goal of representing a UAV operating at a low Reynolds number, a SD7037 airfoil was selected from the Low Speed Airfoil Data (Lyon, Broeren, Giguere, 
Gopalarathnam, \& Selig, 1997) library as representative. The SD7037 airfoil is shown in Figure 15. The boundary layer trips were not used.

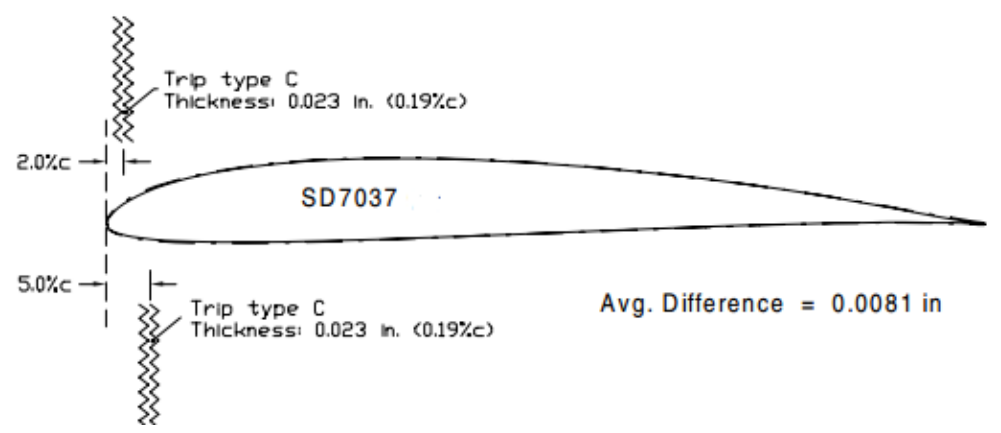

Figure 15. SD 7037 airfoil

The angle of attack range was chosen in a pre-stall region where the lift curve slope was relatively linear (Lyon et al., 1997). Hence, a 0-8 degree range was selected for angle of attack. Additionally, XFOIL analysis results for operating Reynolds numbers that are between 76000 and 96000 is shown below. The final assembled model CAD design is shown in Figure 17. Also, a detailed technical drawing of model assembly is given in the appendix.

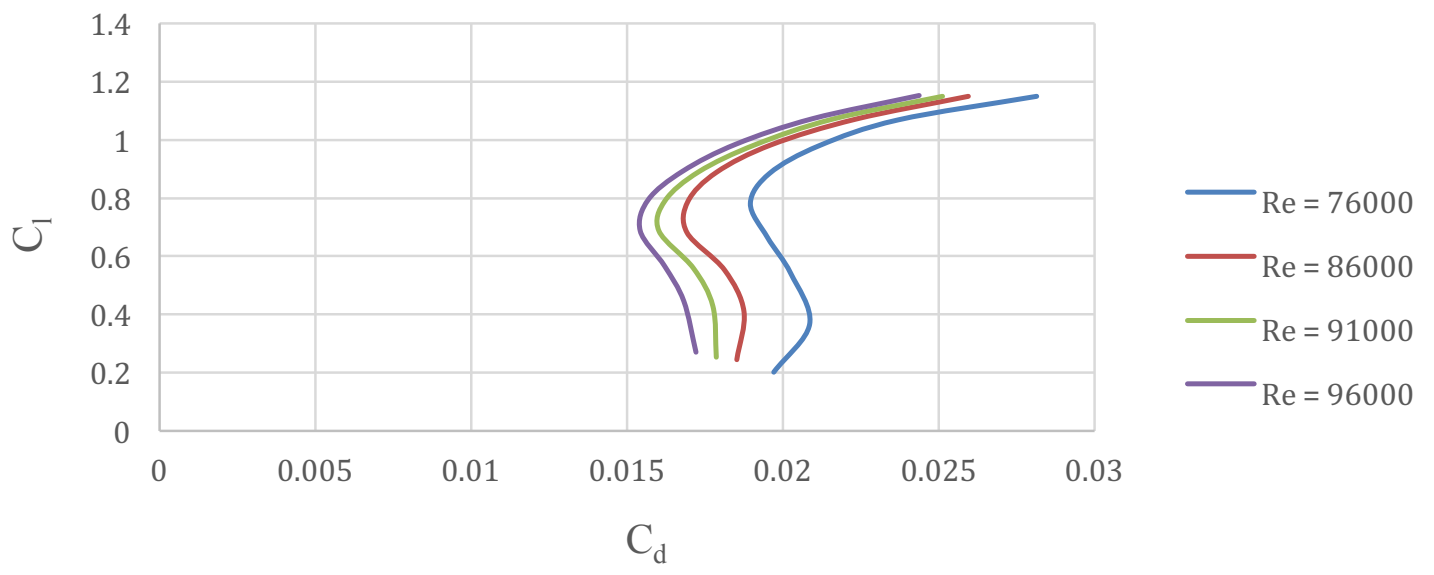

Figure 16. SD 7037 airfoil XFOIL analysis results 


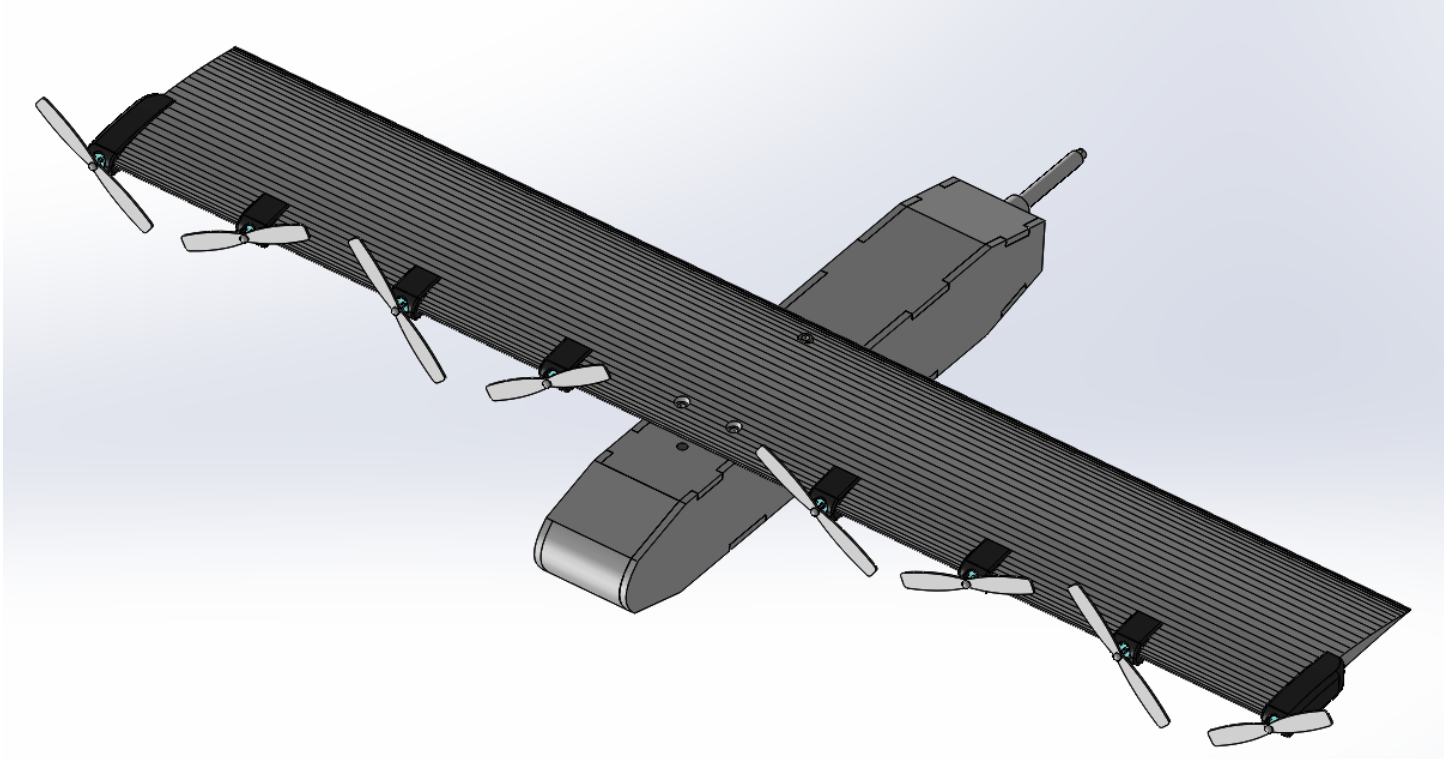

Figure 17. Small UAV CAD model

\subsection{Model Building}

The model utilized in the wind tunnel was hand fabricated in three manufacturing steps: wing building, simple fuselage building, and painting and final finish.

A hot wire cut blue foam core was used for wing construction. Also, a one-piece spruce spar was inserted into the wing along the wingspan and a thin carbon fiber strip was added to stiffen the trailing edge. The wing was next covered with fiberglass and resin as shown in Figure 18. West System 105 epoxy resin and West System 206 slow hardener were used for the covering operation. 


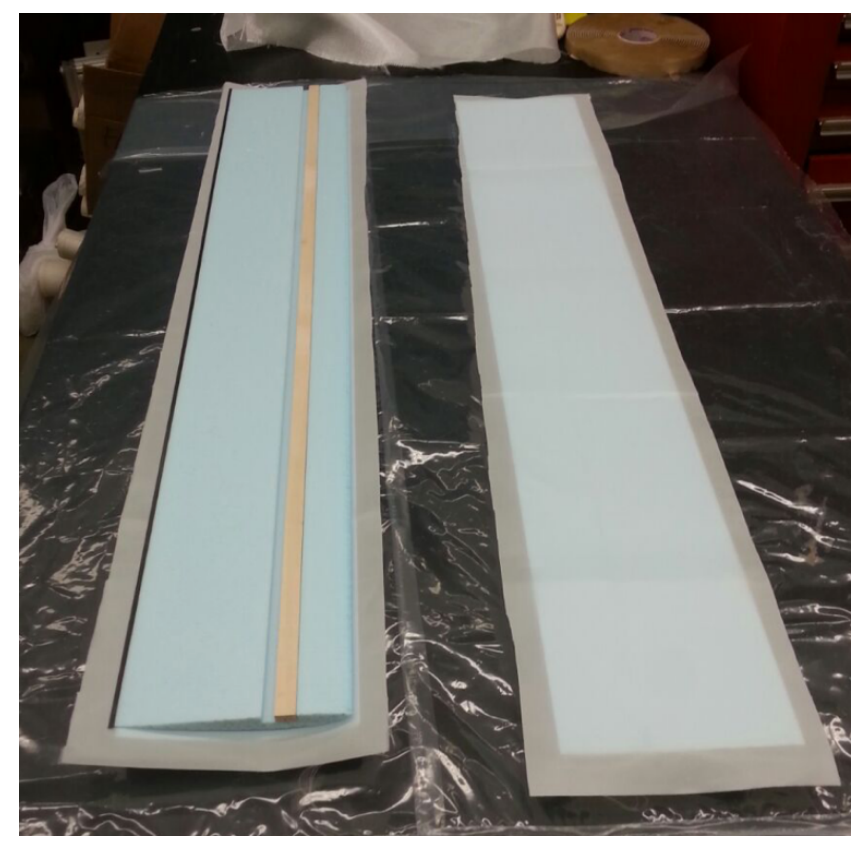

Figure 18. Blue foam wing core, strut, rod and fiberglass

The fiberglass-covered wing was put in a vacuum bag and the vacuum pump provided 24 hours of equal pressure distribution along the wing for the epoxy curing process. Figure 19 illustrates this process.

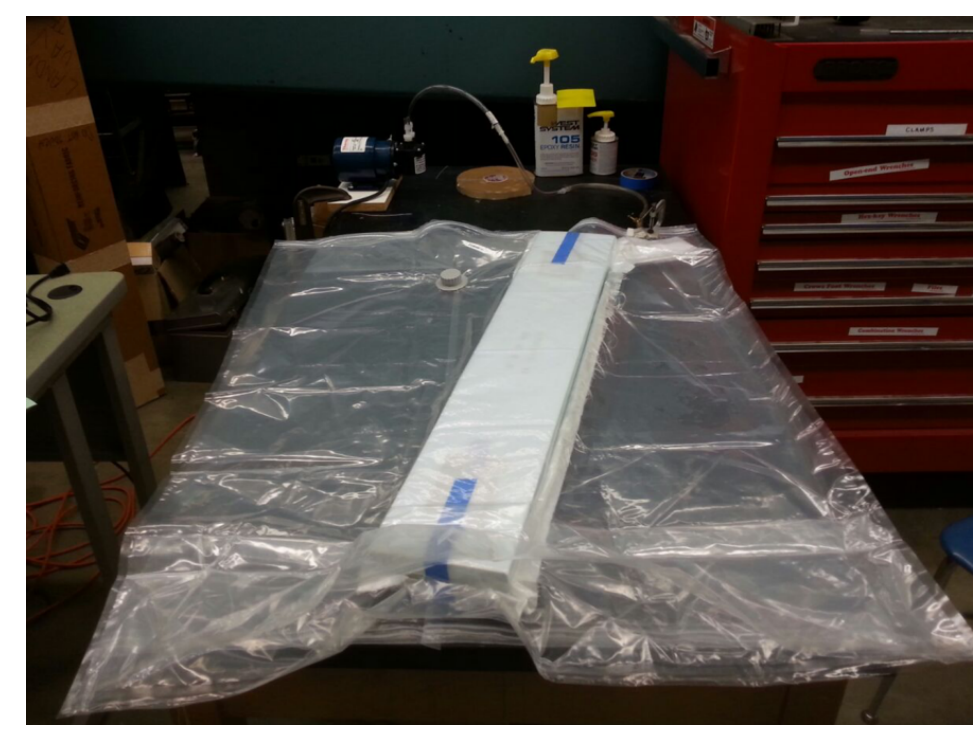

Figure 19. Vacuum process 
Afterwards, 8 equidistant motor mount holes were drilled throughout the leading edge. The vertical direction of the wing was adjusted with a spirit level, as seen in Figure 20.

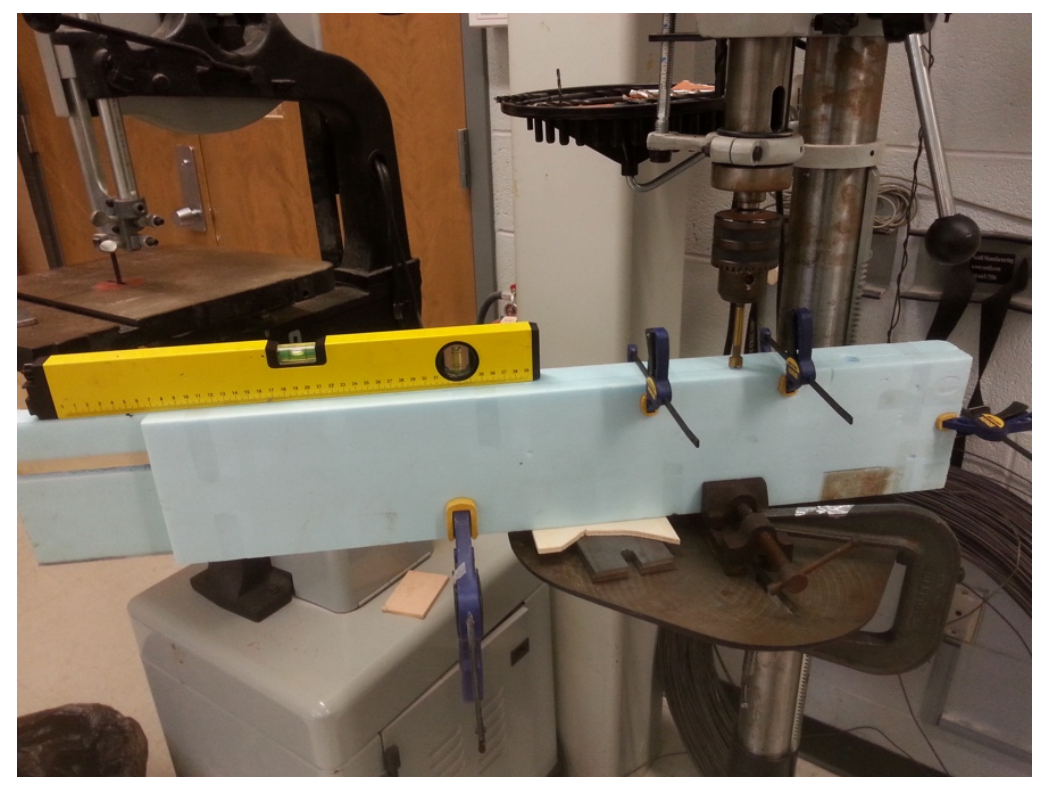

Figure 20. Drilling of the motor holes

Furthermore, eight motor mounts were produced with a 3D printing manufacturing technique from ABS material. These motor mounts were used to lock the motors in the leading edge holes, as shown in Figure 21.

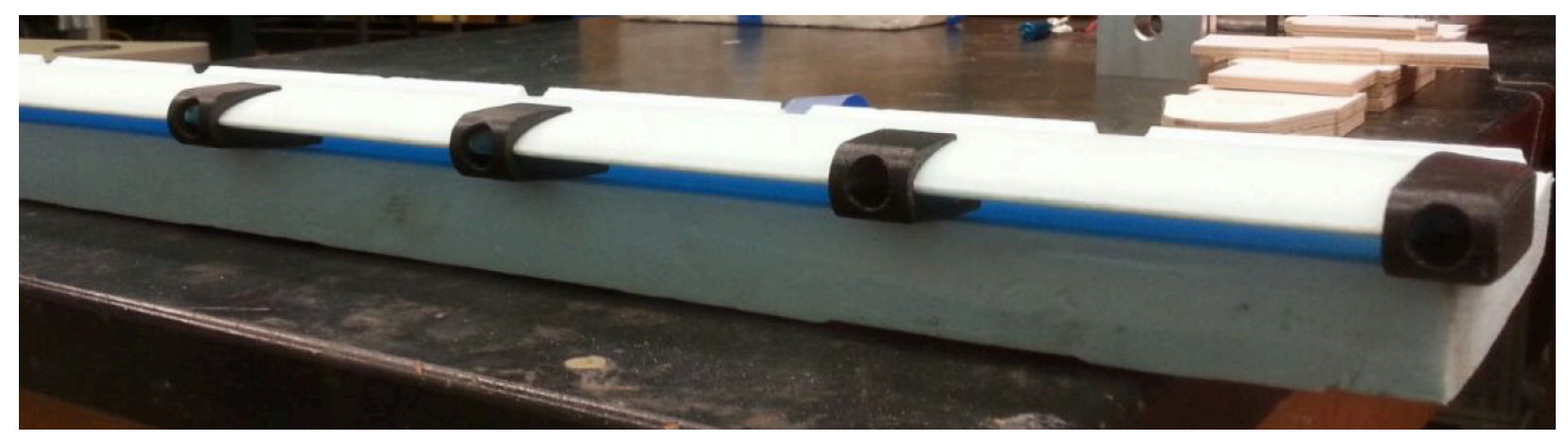

Figure 21. Motor mountings along the leading edge 
Afterward, motors and motor mounts were assembled to the wing, which is illustrated in Figure 22.

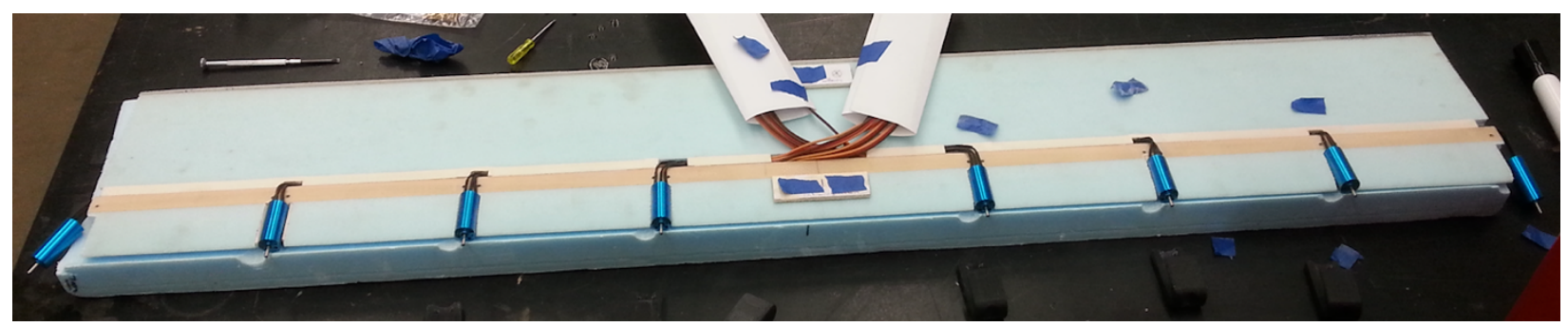

(a)

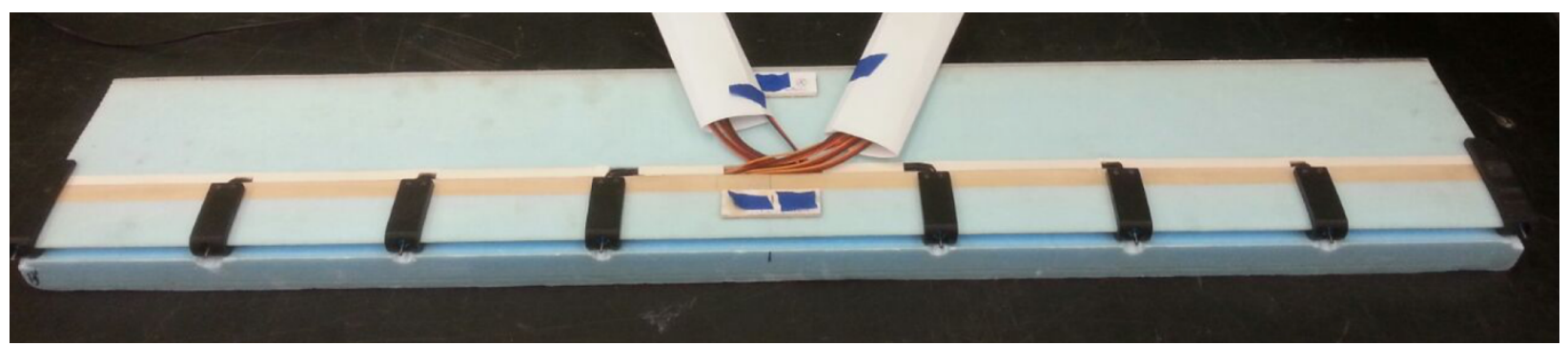

(b)

Figure 22. Bottom side of the wing (a) without motor mounting (b) with motor mounting

A simple fuselage was built from plywood and balsa wood to provide an interface between the balance and wing. All parts were assembled using epoxy. The gaps between the parts were filled with body filler and the entire fuselage was sanded smooth. The wing was attached to the fuselage with three screws. An aluminum machine bulkhead was placed in the fuselage to support the metric end of the balance. The fuselage and bulkhead are shown in Figure 23. 


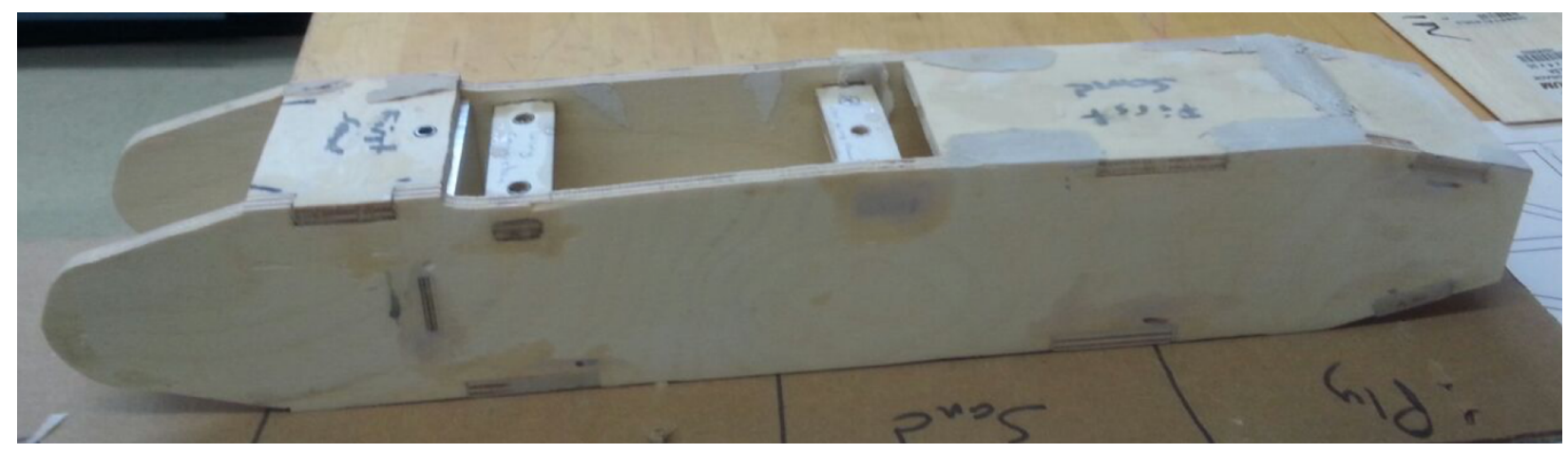

Figure 23. Fuselage and aluminum bulkhead before nose covering and sanding process

Finally, the wing, fuselage, and motor mounts were painted with filler and sandable primer. The wing was coated and sanded four times until it met the desired roughness. The painted and assembled small UAV model is illustrated in Figure 24.

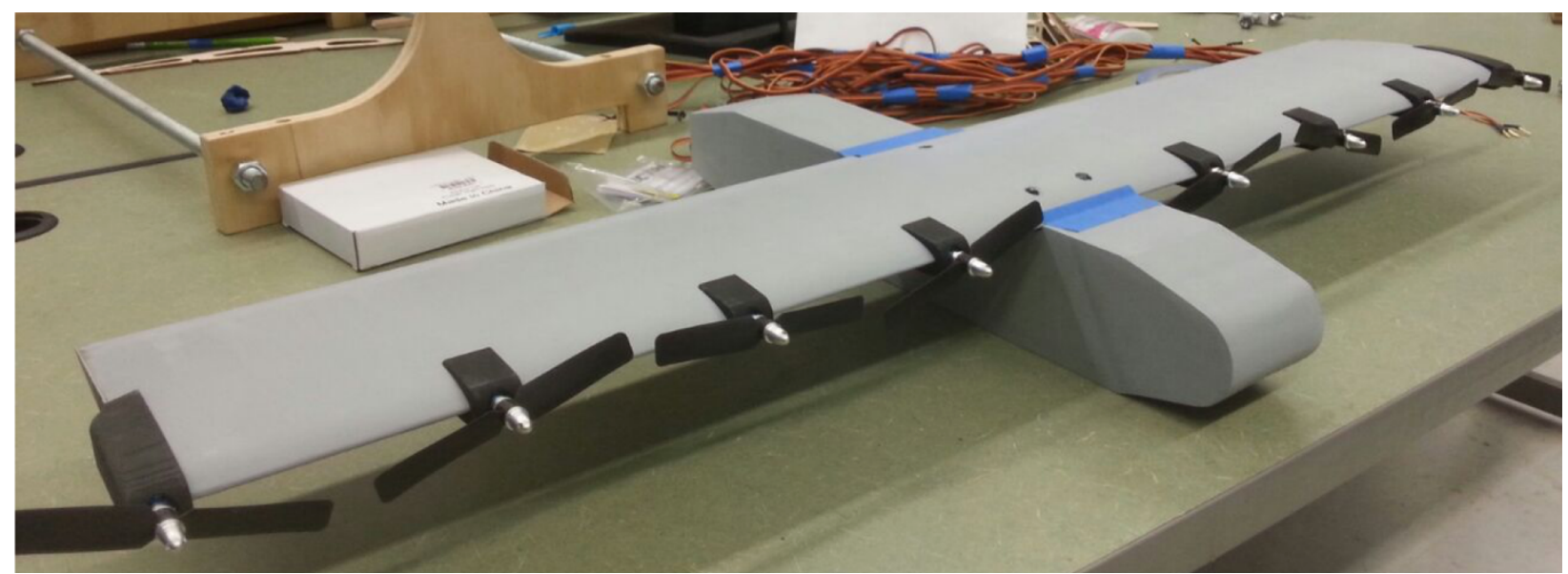

Figure 24. Small UAV model

\subsection{Force Balance}

A NASA 2044a force balance was used for wind tunnel testing. It is a 6 degree of freedom strain gage based internal balance. The metric end of the balance was inserted into the model aluminum bulkhead and was fixed by a dowel pin from the top of the fuselage. The moment center of the balance was placed at the quarter chord of the wing. The balance block 
diagram between electrical connections and National Instruments data acquisition system components is shown in Figure 25 (Philips, 2016). To reduce the electrical noise on the balance signal lines, low pass filters were installed on each channel. The balance force and moment ranges and other specifications are given in the appendix.

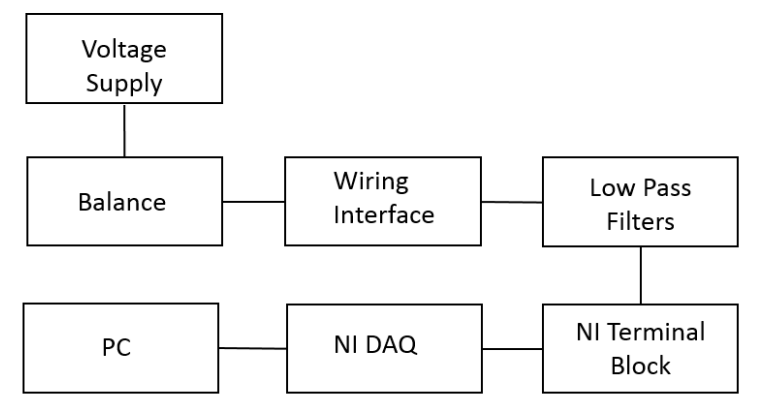

Figure 25. Balance block diagram (Philips, 2016)

\subsection{Model Support and Devices}

An existing twin lead screw model support system was used for wind tunnel testing. This system has full automation, remote pitch, and roll control capabilities. The model pitch position was adjusted with two sliders on lead screws. This slide positioning system kept the model on the tunnel centerline while pitching. The roll position was held constant for this study. The angle of attack adjustment and measurements were done by a high precision inclinometer. The picture of the overall assembly for the twin lead screw model support system is shown in Figure 26.

H-KING 10A electronic speed controllers were used for each Medusa MR-012-030-4000 brushless motor. To set the rotational speed of the motors, the speed controllers were connected to a Pololu Mini Maestro 12 Channel USB Servo Controller board. This servo controller has individual speed and acceleration control for each channel. The ESCs and servo controller were placed outside of the test section. 
Propeller RPM measurements were recorded with a Hangar-9 micro digital tachometer. An LED light source was used, opposite the side of the optical tachometer, to read the correct RPM value. The tachometer was attached on the wing for motor calibration. This setup is illustrated in Figure 27.

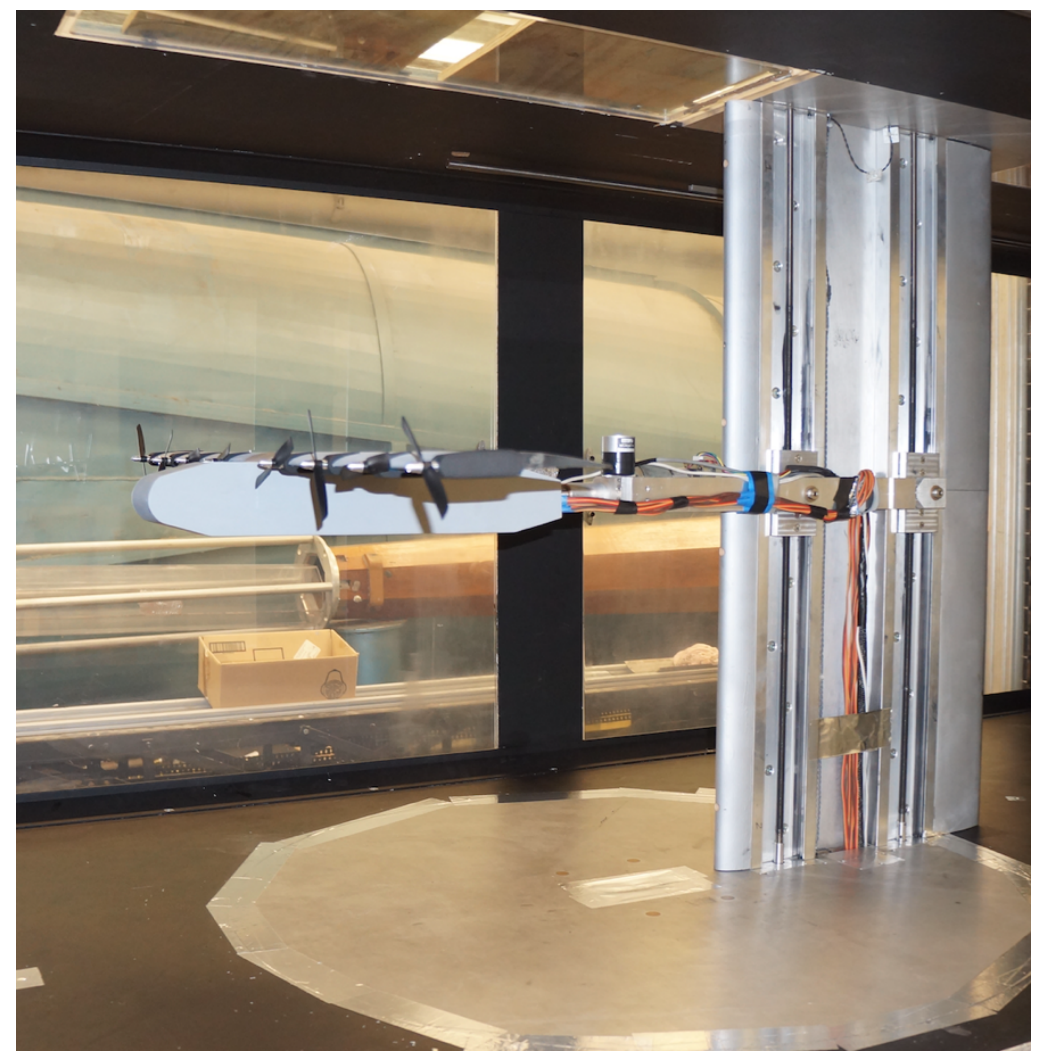

Figure 26. Model and support system in test section 


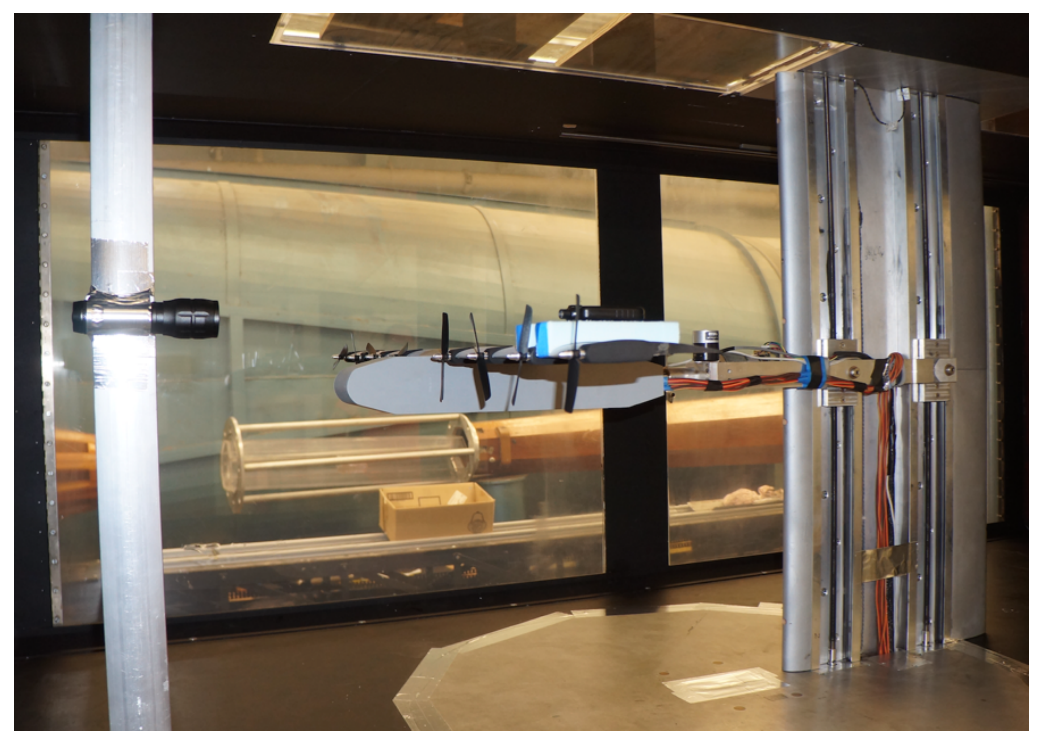

Figure 27. RPM recording setup

\subsection{Testing Procedure}

To reach thermal equilibrium for stable measurements, the balance and all the other electronic equipment were powered for at least 8 hours before beginning testing (Philips, 2016). The adjustment of the reference zero-degree angle of attack and zero degree roll angle were done by spirit level, as illustrated in Figure 28. Then, zero reference slide positions were saved.

An existing LabVIEW software program was used to control the model support and wind tunnel and to monitor the balance(Philips, 2016). The motor speed control was the only addition to the LabVIEW software.

A tare was taken before beginning testing for each case (all-propellers on, wing-alone, wing-tip propellers-alone etc.). The test matrix had tunnel velocity, angle of attack, and propeller RPM factors. Also, a randomized test matrix was created using design of experiments methodology, which is discussed in detail in Chapter 4. The tests were begun with the tunnel starting. As soon as tunnel velocity reached the desired condition, the angle of attack adjustment 
was done by the twin lead screw mechanism, and the motors were run with determined RPM

levels. When these three factor values matched the test matrix values, the data was taken over a 15 second sample time. After data recording, the model was sent to zero angle of attack and zero RPM level. This process was repeated over the entire text matrix.

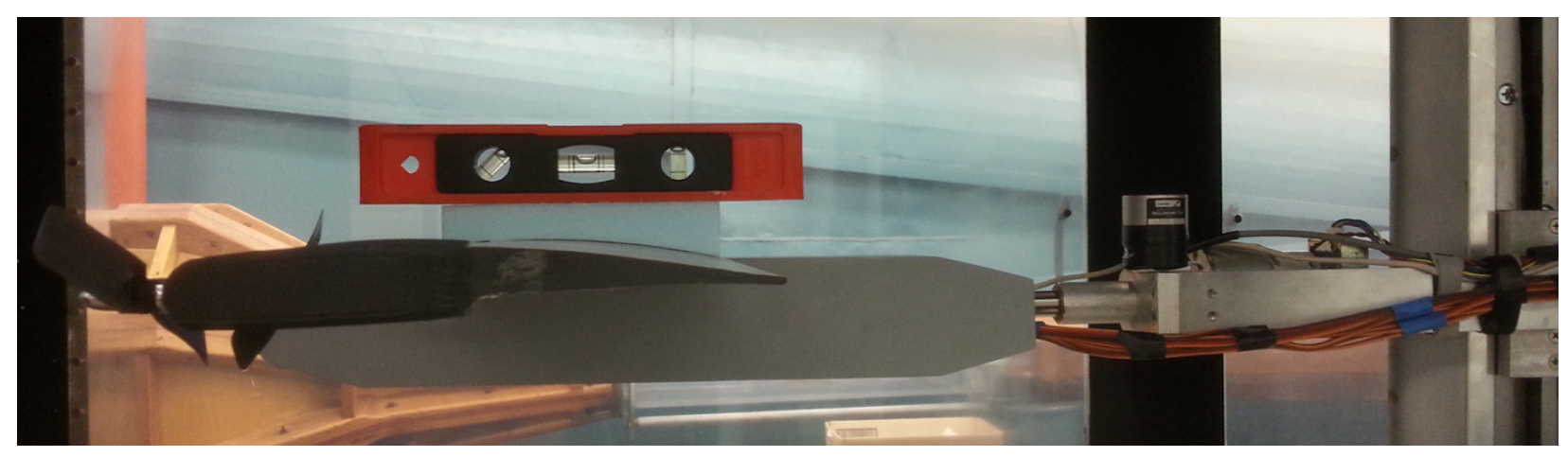

(a)

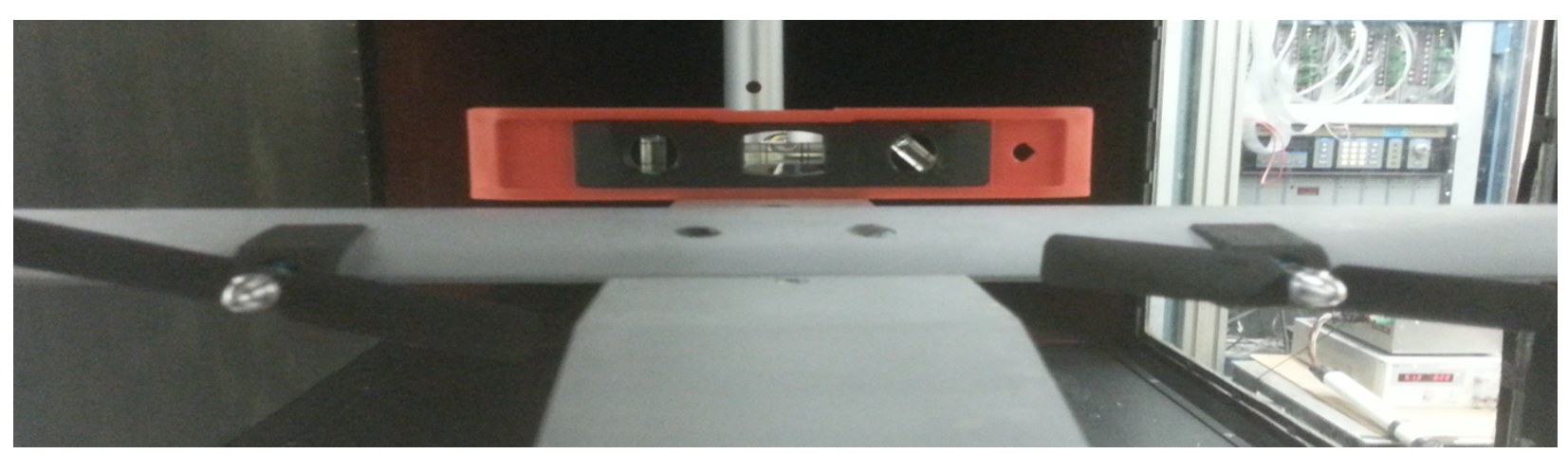

(b)

Figure 28. Reference angle (a) angle of attack (b) roll angle 


\subsection{Measurement Uncertainties}

Experimental measurements include uncertainties in both the input variables and responses. Generally, uncertainty has two types of error sources, called systematic standard uncertainties and random standard uncertainties (Coleman \& Steele, 2009). Instrument accuracy in the form of a bias is accounted for using the systematic standard uncertainties. Random standard uncertainties are related to standard errors of the measured responses (results). In general, where the result $r$ is a function of several variables,

$$
r=r\left(X_{1}, X_{2}, \ldots, X_{j}\right)
$$

combined standard uncertainty $\left(\mathrm{u}_{\mathrm{r}}\right)$ is defined by (Coleman \& Steele, 2009),

$$
u_{r}=\left(b_{r}^{2}+s_{r}^{2}\right)^{1 / 2}
$$

With the Taylor Series Method, where the systematic standard uncertainty of the result, $b_{r}$ is defined by,

$$
b_{r}^{2}=\left(\frac{\partial r}{\partial X_{1}}\right)^{2} b_{X_{1}}^{2}+\left(\frac{\partial r}{\partial X_{2}}\right)^{2} b_{X_{2}}^{2}+\ldots+\left(\frac{\partial r}{\partial X_{j}}\right)^{2} b_{X_{j}}^{2}+\ldots+2\left(\frac{\partial r}{\partial X_{i}}\right)\left(\frac{\partial r}{\partial X_{k}}\right) b_{X_{i}} b_{X_{k}}+\ldots
$$

and the random standard uncertainty of the result, $\mathrm{s}_{\mathrm{r}}$ is defined by,

$$
s_{r}^{2}=\frac{S^{2}}{n}
$$

The error distribution of $r$ usually shows a Gaussian distribution (supported by the Central Limit Theorem) which allows use of the $t$ distribution to obtain a confidence level for the overall uncertainty, as seen in equation 7.

$$
U_{r}=t_{\%} u_{r}
$$

where the $\pm U_{r}$ band around $r$ will include the true value of result for the chosen level of confidence. Most engineering and scientific applications consider $\mathrm{t}=2$ for an approximate $95 \%$ 
confidence level and assume there are no correlated random errors ${ }^{31}$. Therefore, equation (7) is redefined by,

$$
U_{95}=2\left(b_{r}^{2}+s_{r}^{2}\right)^{1 / 2}
$$

\subsubsection{Wind Tunnel Velocity Uncertainty Analysis}

The Taylor Series approach to uncertainty propagation was applied to assess the uncertainty associated with wind tunnel velocity measurements. Wind tunnel velocity is a function of the static pressure differential, atmospheric pressure and fluid temperature, as seen in equation (9). Related derivatives for uncertainty analysis are given in equations (10)-(12).

$$
\begin{gathered}
V=\sqrt{\frac{\frac{2 \Delta P}{P_{a t m}}}{R T}} \\
\frac{\partial V}{\partial \Delta P}=\frac{\sqrt{2}}{2} \frac{R T}{\sqrt{\Delta P R T P_{a t m}}} \\
\frac{\partial V}{\partial P_{a t m}}=-\frac{\sqrt{2}}{2} \frac{\Delta P R T}{\sqrt{\Delta P R T P_{a t m}^{3}}} \\
\frac{\partial V}{\partial T}=\frac{\sqrt{2}}{2} \frac{\Delta P R}{\sqrt{\Delta P R T P_{a t m}}}
\end{gathered}
$$

The systematic uncertainties of each measurement variable are given in Table 1.

\begin{tabular}{cc} 
Component & Uncertainty \\
\hline Differential Pressure & $\pm 0.01 \%$ Full Scale \\
Temperature & \pm 0.1 deg. C \\
Barometric Pressure & $\pm 0.01 \%$ of Reading \\
\hline
\end{tabular}

Table 1 . Systematic uncertainties of velocity measurement components 
The random uncertainty component for velocity was calculated using the standard error from replicated measurements of velocity. For this study, overall uncertainty in the estimations of wind tunnel velocities for nominal wind tunnel speeds of $9 \mathrm{~m} / \mathrm{s}$, atmospheric pressure of 101506 $\mathrm{Pa}$, and tunnel fluid temperature of $294 \mathrm{~K}$ were calculated and are shown in Table 2.

\begin{tabular}{cc} 
Component & Calculated Value \\
\hline $9 \mathrm{~m} / \mathrm{s}$ & \\
$\mathrm{s}_{\mathrm{r}}$ & $\pm 0.0111 \mathrm{~m} / \mathrm{s}$ \\
$\mathrm{b}_{\mathrm{r}}$ & $\pm 0.0346 \mathrm{~m} / \mathrm{s}$ \\
$\mathrm{U}_{95}$ & $\pm 0.0727 \mathrm{~m} / \mathrm{s}$ \\
\hline
\end{tabular}

Table 2. Overall uncertainty of wind tunnel speed

3.7.2 Normal and Axial Force Coefficients Uncertainty Analysis

The normal force coefficient is a function of normal force and static differential pressure (dynamic pressure), as seen equation (13). Applying the Taylor Series approach, related derivatives for uncertainty analysis are given in (14)-(15).

$$
\begin{gathered}
C_{N}=\frac{N}{\frac{1}{2} \rho V^{2} S_{r e f}}=\frac{N}{\frac{1}{2} \frac{P_{a t m}}{R T} \frac{2 \Delta P}{\frac{P_{a t m}}{R T}} S_{r e f}}=\frac{N}{\Delta P S_{\text {ref }}} \\
\frac{\partial C_{N}}{\partial N}=\frac{1}{\Delta P S_{r e f}} \\
\frac{\partial C_{N}}{\partial \Delta P}=-\frac{N}{\Delta P^{2} S_{r e f}}
\end{gathered}
$$


Axial force coefficient is function of axial force and static differential pressure as seen in equation (16). Applying the Taylor Series approach, related derivatives for uncertainty analysis are given in (17)-(18).

$$
\begin{gathered}
C_{A}=\frac{A}{\frac{1}{2} \rho V^{2} S_{\text {ref }}}=\frac{A}{\frac{1}{2} \frac{P_{a t m}}{R T} \frac{2 \Delta P}{\frac{P_{a t m}}{R T}} S_{r e f}}=\frac{A}{\Delta P S_{r e f}} \\
\frac{\partial C_{A}}{\partial A}=\frac{1}{\Delta P S_{r e f}} \\
\frac{\partial C_{A}}{\partial \Delta P}=-\frac{A}{\Delta P^{2} S_{r e f}}
\end{gathered}
$$

The uncertainties of each measurement variable are given in Table 3.

\begin{tabular}{cc} 
Component & Uncertainty \\
\hline Balance Normal Force & $\pm 0.05 \%$ \\
Balance Axial Force & $\pm 0.10 \%$ \\
\hline
\end{tabular}

Table 3. Systematic uncertainties of balance measurement components

For this study, overall uncertainty for nominal normal force of $3.832 \mathrm{~N}$ and nominal axial force of $-1.641 \mathrm{~N}$ are shown in Table 4, which is based on the nominal tunnel speed of $9 \mathrm{~m} / \mathrm{s}$, atmospheric pressure of $101506 \mathrm{~Pa}$ and wing reference area of $0.120 \mathrm{~m}^{2}$. 


\begin{tabular}{cc} 
Component & Calculated Value \\
\hline $\mathrm{C}_{\mathrm{N}}=0.6549$ & \pm 0.0006 \\
$\mathrm{~S}_{\mathrm{r}}$ & \pm 0.00007 \\
$\mathrm{~b}_{\mathrm{r}}$ & \pm 0.0012 \\
$\mathrm{U}_{95}$ & \\
$\mathrm{C}_{\mathrm{A}}=-0.2806$ & \pm 0.0003 \\
$\mathrm{~S}_{\mathrm{r}}$ & \pm 0.0002 \\
$\mathrm{~b}_{\mathrm{r}}$ & \pm 0.00007 \\
$\mathrm{U}_{95}$ &
\end{tabular}

Table 4. Overall uncertainty of force coefficients 


\section{CHAPTER 4}

\section{METHODOLOGY}

\subsection{Overview}

Design of experiments (DOE) methodology was used in this study even though one factor at a time (OFAT) was the traditional testing approach. OFAT testing allows only one factor to change while all other factors remain unchanged. Error sources (system errors and precision errors) cannot be separated from each other, and significant contributions of factor interaction terms (simultaneous factor changes cause interaction terms) on the response cannot be reliably determined with regression models; only main factor effects can be readily characterized. Due to these disadvantages of the OFAT procedure, the aerospace community has started to use DOE methodology in recent years.

The origin of the DOE methodology came from the study field of agriculture, with the work of Ronald A. Fisher (1935). The methodology was expanded to response surface methodology (RSM) by Box and Wilson (1951) for industrial applications in 1950s. Recently, computer programs have been developed for DOE and RSM; these make it simple to analyze complex designs. The goal of the DOE methodology is to create statistically rigorous regression models that predict the response with minimized prediction error. In other words, it determines the effect of input factors on process and response with their simultaneous changes. DOE has three main principles for experimental design: randomization, replication, and blocking (Montgomery, 2013).

Randomization is the cornerstone of the statistical methods and it applies to both run order and experimental factor level choices. It also assists in averaging out the unknown and 
uncontrolled extraneous factor effects. The randomization is supplied by using computer based random number generators.

Randomized, repeated runs of factor combinations are defined as replication. These allow the researcher to obtain an estimate of pure systematic experimental noise, independent from model fitting.

Blocking is an experiment design technique used to improve the precision with which comparisons among the factors of interest are made. Blocking reduces or eliminates the variability transmitted from known but uncontrollable nuisance factors, that is, factors that may influence the experimental response but are not directly of interest to the experiment.

In addition, orthogonality is addressed along with these three main DOE principles (Myers, Montgomery, \& Anderson-Cook, 2009). Orthogonality in an experimental design is one that minimizes the variances and uncorrelated orthogonal regressors to improve the parameter estimates.

RSM is a subset of DOE. It is a useful combination of statistical and mathematical techniques for process development, improvement, and optimization. In general, RSM is classified into three main categories in industrial experimentation: mapping a response surface over a particular region of interest, optimization of the responses, and selection of the operating conditions to achieve specifications or customer requirements (Myers et al., 2009).

\subsection{Test Matrix Design}

The fundamental classical experiment design in DOE is the 2-level factorial design. A factorial design allows all factor levels to be changed simultaneously for all possible combinations. Each factor has two levels (high and low limits). A first order plus interaction 
regression model can be developed with a factorial design. A full factorial design with center points for two factors is shown below in Figure 29. The center points provide a means to test for the need for quadratic model terms. Also, pure error calculation and scaled prediction variance reduction is afforded by center point replicates in DOE/RSM. The regression model representation of the factorial experiment with main effects and two factor interactions is shown in equation (19).

$$
y=B_{0}+\sum_{i} B_{i} x_{i}+\sum \sum_{i \neq j} B_{i j} x_{i} x_{j}+\ldots+\varepsilon \quad i=1,2, \ldots, k
$$

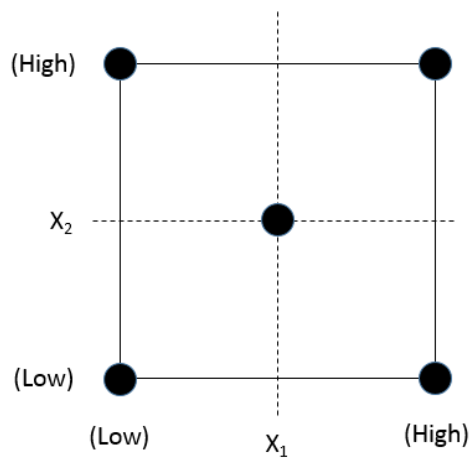

Figure 29. A full factorial design for two factors

$y$ is the response, B's are the fitted regression coefficients, x's are independent variables (factors) and the $\varepsilon$ is a random error term. This first order model can represent some mild curvature in the response function through the interaction terms. However, pure second order terms (quadratic effects) are usually required for curvature representation in the response function particularly for aircraft aerodynamic characterization. Therefore, a second order response surface model must be considered, as seen in equation (20).

$$
y=B_{0}+\sum_{i} B_{i} x_{i}+\sum_{i} B_{i i} x_{i}^{2}+\sum \sum_{i \neq j} B_{i j} x_{i} x_{j}+\varepsilon \quad i=1,2, \ldots, k
$$


To fit the second order model, the classical factorial design is augmented with axial points. This design is called a central composite design (CCD). The CCD has high run number efficiency with excellent prediction qualities. It has five level factor settings to cover the region of interest. When axial points are at the same distance as factorial points, a variant of the CCD is called the face centered central composite design (FCD). These designs are shown in Figure 30. The FCD has three factor levels. Although three factor level settings are adequate to predict the responses for some applications, sometimes the model can be inadequate to cover the experimental region for estimating responses. Therefore, a nested FCD was developed by Landman, Simpson, Mariani, Ortiz, and Britcher (2007) as seen in Figure 35, which features five factor levels and the ability to include pure cubic terms in the regression model.

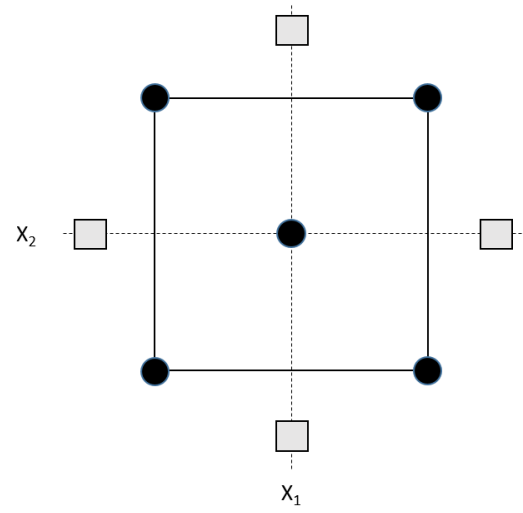

(a)

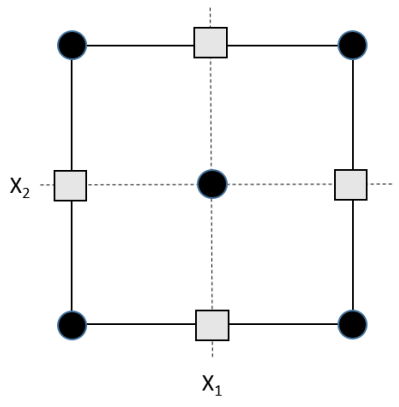

(b)

Figure 30. (a) CCD and (b) FCD for two factors 


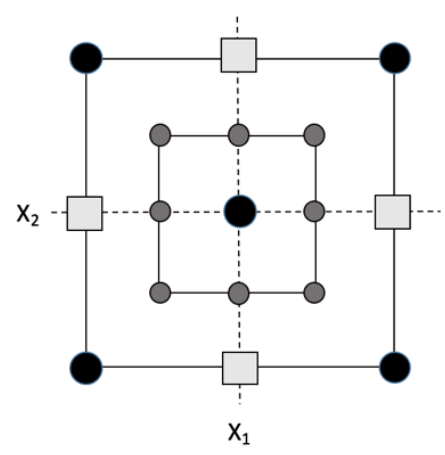

Figure 31. Nested FCD for two factors

Also, these designs can be fractionated if the experimenter can make some logical assumptions about omitting high order interaction terms (Montgomery, 2013). This reduces run numbers in the experiment. The one-half fraction factorial design and the alternate fraction of three factors $(a, b, c)$ are illustrated in Figure 32.

In this experimental study, a full nested FCD response surface method with center points was selected for the wing-alone and wing-tip-propellers-alone-on configurations. A fractionated (minimum-run Resolution V) nested FCD design with center points was selected for the allpropellers-on configuration. Resolution is a degree measurement of confounded or aliased regression terms. Main effects or two factor interactions are not aliased with any other main effects or two factor interactions in resolution $\mathrm{V}$ design, meaning they may be uniquely estimated (Myers et al., 2009). 


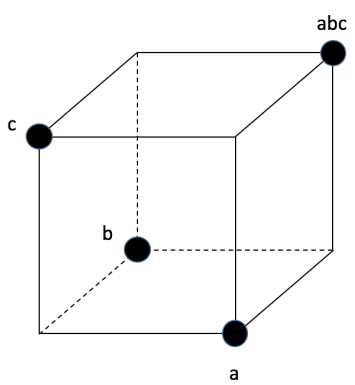

(a)

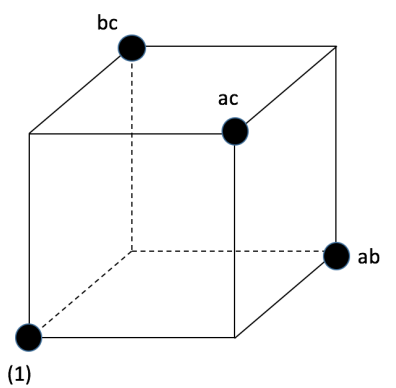

(b)

Figure 32. One-half fraction of three factors (a) principle (b) alternate fraction Actual test matrix designs are shown in the Appendix for all configurations. 


\section{CHAPTER 5}

\section{ANALYSIS OF RESULTS}

\subsection{Analysis of Variance (ANOVA)}

In this study, the test matrix design and collected data analysis were accomplished with the help of Design Expert ${ }^{\mathrm{TM}}$ software. ANOVA is used to evaluate regression model term significance and error. Generally, a multiple linear regression model is used to fit a response surface as illustrated in equation (20) in Section 4.2 and the ordinary least squares fitting method is used to estimate the regression coefficients in the model (Myers et al., 2009). Therefore, the model can be written in matrix notation as seen in equation (21),

$$
y=X \beta+\varepsilon
$$

where $y$ is an $n \times 1$ vector of observations, $X$ is an $n \times p$ model matrix, $\beta$ is a $p \times 1$ vector of the regression coefficients, and $\varepsilon$ is an $\mathrm{n} \times 1$ vector of random errors. Then, the least square estimator of regression coefficients $(\beta)$ is calculated, as shown in equation (22), to develop the regression model (Myers et al., 2009).

$$
\beta=\left(X^{\prime} X\right)^{-1} X^{\prime} y
$$

Hence. the fitted regression model becomes:

$$
\hat{y}=X \beta+\varepsilon
$$

If there is a linear relationship between the response variable and a subset of the regressor variables, then the model is significant (Myers et al., 2009). An ANOVA determines this relationship with hypothesis testing as seen below. 


$$
\begin{aligned}
& H_{0}=\beta_{1}=\beta_{2}=\ldots=\beta_{k}=0 \\
& H_{1}=\beta_{j} \neq 0 \text { for at least one } j
\end{aligned}
$$

The rejected null hypothesis implies that at least one of the regressor variables contributes significantly to the model. This test procedure starts by noting the relationship of the total variability (sum of squares) to that explained by the model and that due to error (25).

$$
S S_{T}=S S_{R}+S S_{E}
$$

$\mathrm{SS}_{\mathrm{T}}$ is a total sum of squares which represents total variability in the observations, $\mathrm{SS}_{\mathrm{R}}$ is a regression sum of squares which represents variability related to the regression model and $\mathrm{SS}_{\mathrm{E}}$ is an error sum of squares which represents variability related to the residual error(Montgomery, 2013). The formulas for calculating these terms are illustrated in the equations below and are found in any regression text:

$$
\begin{aligned}
& S S_{T}=y^{\prime} y-\frac{\left(\sum_{i=1}^{n} y_{i}\right)^{2}}{n} \\
& S S_{R}=b^{\prime} X^{\prime} y-\frac{\left(\sum_{i=1}^{n} y_{i}\right)^{2}}{n} \\
& S S_{E}=y^{\prime} y-b^{\prime} X^{\prime} y
\end{aligned}
$$

Then, overall variance can be estimated by calculating mean square values in equations (29) and (30) (Montgomery, 2013).

$$
\begin{aligned}
& M S_{E}=\frac{S S_{E}}{n-k-p} \\
& M S_{R}=\frac{S S_{R}}{k}
\end{aligned}
$$


In equations (30) and (31), $\mathrm{n}$ is the total number of observations, $\mathrm{k}$ is the total number of regression variables included in the model, and $\mathrm{p}$ is the number of parameters. The mean squares are variance quantities. Finally, the acceptance or rejection of the null hypothesis is determined using the $\mathrm{F}_{0}$ test statistic for equality of variances, as shown in equation (31).

$$
F_{0}=\frac{M S_{R}}{M S_{E}}
$$

To reject the null hypothesis (model is significant), $F_{0}$ must be greater than $F_{\alpha, k, n-k-1}\left(F_{\text {critical }}\right)$. The $\alpha$ is a determined significance level where $1-\alpha$ is the desired confidence. Although the F test provides information about the significance of the overall model, it cannot give any knowledge about the significant level of any given term. Therefore, each term in the model is tested individually versus error.

Furthermore, the $\mathrm{SS}_{\mathrm{E}}$ term is composed of two terms: lack of fit $\left(\mathrm{SS}_{\mathrm{LOF}}\right)$ and pure error $\left(\mathrm{SS}_{\mathrm{PE}}\right)$. Lack of fit implies how well the regression model fits the experimental observations and pure error quantifies the error in repeated experimental measurements.

$$
S S_{L O F}=S S_{E}+S S_{P E}
$$

Mean squares are calculated for lack of fit testing, as seen in equation (33) and (34),

$$
\begin{gathered}
M S_{L O F}=\frac{S S_{L O F}}{(m-p)} \\
M S_{P E}=\frac{S S_{P E}}{(n-m)}
\end{gathered}
$$

where $\mathrm{m}-\mathrm{p}$ is degrees of freedom for $\mathrm{SS}_{\mathrm{LOF}}, \mathrm{p}$ is the number of model parameters, and there are n-m degrees of freedom for SSPE. Detailed calculations can be seen in Myers et al. (2009).

Similarly, the $\mathrm{F}_{0}$ test statistic is applied for lack of fit testing, as shown in equation (35). 


$$
F_{0}=\frac{M S_{L O F}}{M S_{P E}}
$$

If $\mathrm{F}_{0}$ is greater than $\mathrm{F}_{\alpha, \mathrm{m}-\mathrm{p}, \mathrm{n}-\mathrm{m}}$, then lack of fit is significant. In general, this is not a desired situation. However, in some cases where noise levels are very low (wind tunnel testing), lack of fit can be significant while the model is significant and fit is acceptable. Thus, another family of fit statistics ( $\mathrm{R}^{2}$ family) must be considered to draw a complete conclusion about the goodness of the fit.

Residual diagnostics are used to determine the validation of error distribution assumptions: normality, independence, and constant variance (Montgomery, 2013). The residuals (e) are the difference between the measured response $(y)$ and the predicted response $(\hat{y})$.

$$
e=y-\hat{y}
$$

A normal probability plot of residuals is used for checking the normality assumption. If the residuals resemble a straight line, the normality assumption is valid. In addition, a plot of residuals in time sequence is used for verifying the independence assumption. If the residuals have a structureless distribution, the independence assumption is valid. Lastly, plotting the residuals versus fitted values and factor levels for the constant variance assumption is checked. If the residuals are bounded and have no cone or barrel shape, the constant variance assumption is verified $^{35}$

The $\mathrm{R}^{2}$ family $\left(\mathrm{R}^{2}, \mathrm{R}_{\text {adj }}^{2}, \mathrm{R}^{2}\right.$ pred $)$ allows an assessment of the model quality. $\mathrm{R}^{2}$ represents the total variability in the response that is explained by the model(Montgomery, 2013). The $\mathrm{R}^{2}$ value range is between zero and one $(100 \%)$. In general, $95 \%$ or greater values of $\mathrm{R}^{2}$ are desired for wind tunnel experimentation. However, this statistic always increases when either significant 
or insignificant terms are added to model. Thus, the $\mathrm{R}_{\text {adj }}^{2}$ statistic can be considered for better estimation of the model's variability explanation related with observed response because the $\mathrm{R}_{\text {adj }}^{2}$ value decreases when insignificant terms are added to the regression model (Montgomery, 2013). The computation of these statistics is shown in equations (37) and (38).

$$
\begin{gathered}
R^{2}=\frac{S S_{R}}{S S_{T}}=1-\frac{S S_{E}}{S S_{T}} \\
R_{a d j}^{2}=1-\frac{n-1}{n-p}\left(1-R^{2}\right)
\end{gathered}
$$

In addition to the model fit statistics above, a prediction error sum of squares (PRESS) and $\mathrm{R}_{\text {pred }}^{2}$ can be used to examine predictive capability of the regression model for future observations (Montgomery, 2013). The computation of PRESS is based on residual error (e) and diagonal elements of the hat matrix $(\mathrm{H})$. $\mathrm{H}$ maps the vector of observed values into a vector of fitted values as seen in equation (39) (Myers et al., 2009).

$$
\begin{gathered}
H=X\left(X^{\prime} X\right)^{-1} X^{\prime} \\
\text { PRESS }=\sum_{i=1}^{n}\left(\frac{e_{i}}{1-h_{i i}}\right)^{2}
\end{gathered}
$$

$\mathrm{R}_{\text {pred }}^{2}$ is calculated with using PRESS value, as shown in equation (41). The $\mathrm{R}_{\text {pred values range is }}^{2}$ between zero and one. The value of $\mathrm{R}_{\text {pred }}^{2}$ is desired to be close to one to explain the variability in predicting new observations.

$$
R_{\mathrm{Pred}}^{2}=1-\frac{P R E S S}{S S_{\text {Total }}}
$$


A confidence interval (C.I.) can be identified for individual regression coefficients, mean response, and the prediction of future responses (Myers et al., 2009). The 100(1- $\alpha) \%$ confidence interval for individual regression coefficients is illustrated below in equation (42).

$$
b_{j}-t_{\alpha / 2, n-p} \sqrt{\hat{\sigma}^{2} C_{j j}} \leq \beta_{j} \leq b_{j}+t_{\alpha / 2, n-p} \sqrt{\hat{\sigma}^{2} C_{j j}}
$$

The $b_{j}$ is the predicted regression coefficient, $\beta_{j}$ is the true value for the regression coefficient, $C_{j j}$ is the diagonal element of the $\left(\mathrm{X}^{\prime} \mathrm{X}\right)^{-1}$ matrix, $1-\alpha$ is the confidence level, $\mathrm{n}$ is the number of observations, $\mathrm{t}_{\alpha / 2, \mathrm{n}-\mathrm{p}}$ is the $\mathrm{t}$ statistic, $\sigma$ is the error variance, and $\mathrm{p}$ is the number of model parameters (Montgomery, 2013).

Similarly, the $100(1-\alpha) \%$ confidence interval for the mean response is shown below.

$$
\hat{y}\left(x_{0}\right)-t_{\alpha / 2, n-p} \sqrt{\hat{\sigma} x_{0}^{\prime}\left(X^{\prime} X\right)^{-1} x_{0}} \leq \mu_{y\left(x_{0}\right)} \leq \hat{y}\left(x_{0}\right)+t_{\alpha / 2, n-p} \sqrt{\hat{\sigma} x_{0}^{\prime}\left(X^{\prime} X\right)^{-1} x_{0}}
$$

$\mu_{\mathrm{y}(\mathrm{x} 0)}$ is the actual mean response, $\mathrm{y}\left(\mathrm{x}_{0}\right)$ is the estimated mean response at the design point $\mathrm{x}_{0}, \mathrm{X}$ is the model matrix, $1-\alpha$ is the confidence level, $n$ is the number of observations, $t_{\alpha / 2, n-p}$ is the $t$ statistic, $\sigma$ is the error variance, and $\mathrm{p}$ is the number of model parameters.

Finally, the $100(1-\alpha) \%$ confidence interval for the prediction of future observations (prediction interval) is given in equation (44) (Myers et al., 2009).

$$
\hat{y}\left(x_{0}\right)-t_{\alpha / 2, n-p} \sqrt{\hat{\sigma}\left(1+x_{0}^{\prime}\left(X^{\prime} X\right)^{-1} x_{0}\right)} \leq \mu_{y\left(x_{0}\right)} \leq \hat{y}\left(x_{0}\right)+t_{\alpha / 2, n-p} \sqrt{\hat{\sigma}\left(1+x_{0}^{\prime}\left(X^{\prime} X\right)^{-1} x_{0}\right)}
$$

The additional $\sigma^{2}$ term is due to the variability of observations around the predicted mean at that location (Myers et al., 2009). 


\subsection{All-Propellers-On Mode}

The all-propellers-on configuration has six factors (angle of attack, velocity, motor-1, motor-2, motor-3, motor-4) instead of ten factors. This is because the symmetry assumption was made for the motors, as seen in Figure 33. Matched motors were set to identical RPM.

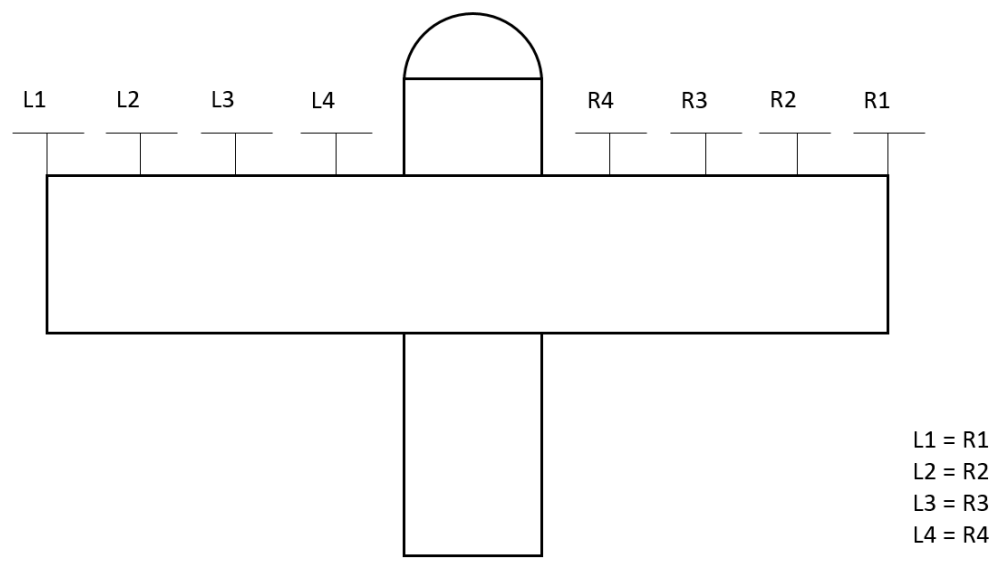

Figure 33. Motor name convention and symmetry

Factors and factor limits are shown in Table 5 for the all-propellers-on mode.

\begin{tabular}{|cc|c|c|}
\hline \multicolumn{2}{|c|}{ Factors } & Low Limit & High Limit \\
\hline A-o-A & Angle of attack (degree) & 0 & 8 \\
\hline V & Velocity (m/s) & 8 & 10 \\
\hline L1 & Left Motor 1 (RPM) & 10000 & 13000 \\
\hline L2 & Left Motor 2 (RPM) & 10000 & 13000 \\
\hline L3 & Left Motor 3 (RPM) & 10000 & 13000 \\
\hline L4 & Left Motor 4 (RPM) & 10000 & 13000 \\
\hline
\end{tabular}

Table 5. Factors and factor limits for all-propellers-on mode

\subsubsection{Normal Force Coefficient}

A second order quadratic model was considered in this case to predict normal force coefficient as a function of six factors. ANOVA was used to determine significant and 
insignificant model terms for building the final response model. The model included only significant terms. This reduction was made by the P-value approach. Due to the choice of $\alpha=$ 0.05 (95\% confidence), $\mathrm{P}<0.05$ indicates significance. A reduced second order polynomial model was identified by the ANOVA, as shown in Table 6.

\begin{tabular}{|c|c|c|c|c|c|}
\hline Source & $\begin{array}{c}\text { Sum of } \\
\text { Squares }\end{array}$ & df & $\begin{array}{c}\text { Mean } \\
\text { Square }\end{array}$ & $\begin{array}{c}\text { F } \\
\text { Value }\end{array}$ & $\begin{array}{c}\text { p-value } \\
\text { Prob }>\text { F }\end{array}$ \\
\hline Block & $1.003 \mathrm{E}-003$ & 1 & $1.003 \mathrm{E}-003$ & & \\
\hline Model & 4.49 & 12 & 0.37 & 15827.77 & $<0.0001$ \\
\hline A-A-o-A & 4.35 & 1 & 4.35 & $1.842 \mathrm{E}+005$ & $<0.0001$ \\
\hline B-Velocity & 0.046 & 1 & 0.046 & 1952.40 & $<0.0001$ \\
\hline C-L1 & $5.658 \mathrm{E}-003$ & 1 & $5.658 \mathrm{E}-003$ & 239.59 & $<0.0001$ \\
\hline D-L2 & $1.831 \mathrm{E}-003$ & 1 & $1.831 \mathrm{E}-003$ & 77.52 & $<0.0001$ \\
\hline E-L3 & $4.668 \mathrm{E}-003$ & 1 & $4.668 \mathrm{E}-003$ & 197.64 & $<0.0001$ \\
\hline F-L4 & $4.360 \mathrm{E}-003$ & 1 & $4.360 \mathrm{E}-003$ & 184.63 & $<0.0001$ \\
\hline $\mathrm{AB}$ & 7.239E-003 & 1 & $7.239 \mathrm{E}-003$ & 306.50 & $<0.0001$ \\
\hline $\mathrm{AC}$ & $1.008 \mathrm{E}-004$ & 1 & $1.008 \mathrm{E}-004$ & 4.27 & 0.0428 \\
\hline $\mathrm{AD}$ & $9.773 \mathrm{E}-005$ & 1 & $9.773 \mathrm{E}-005$ & 4.14 & 0.0460 \\
\hline $\mathrm{AE}$ & $4.861 \mathrm{E}-004$ & 1 & $4.861 \mathrm{E}-004$ & 20.58 & $<0.0001$ \\
\hline $\mathrm{AF}$ & $1.302 \mathrm{E}-003$ & 1 & $1.302 \mathrm{E}-003$ & 55.13 & $<0.0001$ \\
\hline $\mathrm{E}^{2}$ & $4.505 \mathrm{E}-004$ & 1 & $4.505 \mathrm{E}-004$ & 19.08 & $<0.0001$ \\
\hline Residual & $1.535 \mathrm{E}-003$ & 65 & $2.362 \mathrm{E}-005$ & & \\
\hline Lack of Fit & $1.467 \mathrm{E}-003$ & 56 & $2.620 \mathrm{E}-005$ & 3.47 & 0.0246 \\
\hline Pure Error & $6.789 \mathrm{E}-005$ & 9 & $7.543 \mathrm{E}-006$ & & \\
\hline Cor Total & 4.49 & 78 & & & \\
\hline
\end{tabular}

Table 6. ANOVA for all-propellers-on $\mathrm{C}_{\mathrm{N}}$

The fit statistics were used for examining model fit and prediction capabilities. The desired values for $\mathrm{R}^{2}$ statistics is one or close to one as discussed in Section 5.1. The results indicate that the model described and predicted $99 \%$ of variability in the response due to changing the factors, as seen in Table 7.

\begin{tabular}{|l|l|l|l|}
\hline Std. Dev. & $4.860 \mathrm{E}-003$ & R-Squared & 0.9997 \\
\hline Mean & 0.66 & Adj R-Squared & 0.9996 \\
\hline C.V. \% & 0.74 & Pred R-Squared & 0.9994 \\
\hline PRESS & $2.731 \mathrm{E}-003$ & Adeq Precision & 456.395 \\
\hline
\end{tabular}

Table 7. Fit statistics for all-propellers-on $\mathrm{C}_{\mathrm{N}}$ 
To check the normality, independence, and constant variance assumptions, residual diagnostics were used. The normal probability plot of the residuals for the developed model is shown in Figure 34 (a). In this plot, all residuals lie along a straight line representing a normal distribution due to transformed axes. This illustrates that all residuals were normally distributed and the normality assumption was validated. Figure 34 (b) shows a plot of residuals versus run order that was used to identify independence of the responses from time. The plot oscillates randomly around zero with no trend. Thus, the independence assumption is valid. Lastly, a plot of residuals versus predicted values is shown in Figure 34 (c) for checking the constant variance assumption. The plot has no cone or barrel shape and is well bounded within normal limits; therefore, the constant variance assumption is satisfied. 


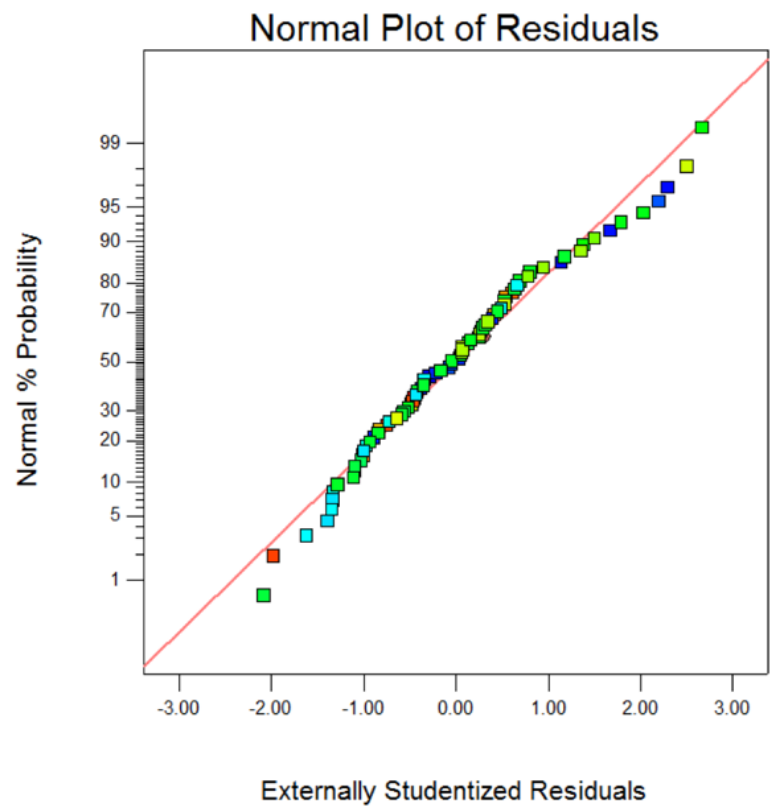

(a)

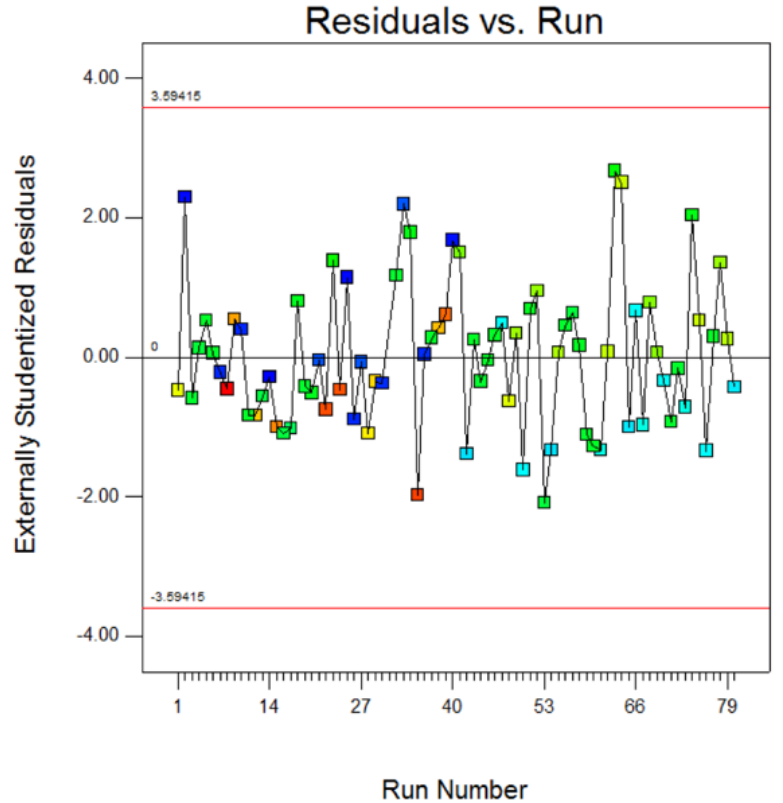

(b)

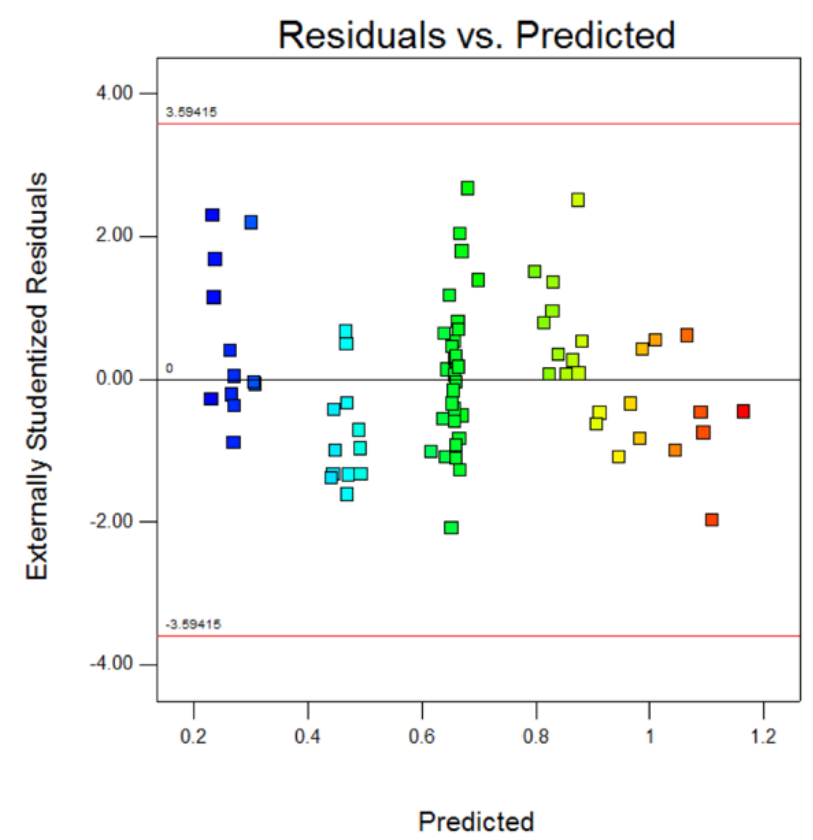

(c)

Figure 34. (a) Normality (b) Independence (c) Constant variance for all-propellers-on $\mathrm{C}_{\mathrm{N}}$

The model term coefficients for the second order response surface are illustrated in Table 8 . 


\begin{tabular}{|l|r|}
\hline \multicolumn{1}{|c|}{ Factor } & \multicolumn{1}{c|}{$\begin{array}{c}\text { Coefficient } \\
\text { Estimate }\end{array}$} \\
\hline Intercept & -0.16660 \\
\hline A-A-o-A & 0.10608 \\
\hline B-Velocity & -0.022784 \\
\hline C-L1 & $8.20235 \mathrm{E}-006$ \\
\hline D-L2 & $4.05705 \mathrm{E}-006$ \\
\hline E-L3 & $7.52859 \mathrm{E}-005$ \\
\hline F-L4 & $3.22497 \mathrm{E}-006$ \\
\hline AB & $-4.65124 \mathrm{E}-003$ \\
\hline AC & $3.65923 \mathrm{E}-007$ \\
\hline AD & $3.60294 \mathrm{E}-007$ \\
\hline AE & $8.03548 \mathrm{E}-007$ \\
\hline AF & $1.31506 \mathrm{E}-006$ \\
\hline $\mathrm{E}^{2}$ & $-3.03135 \mathrm{E}-009$ \\
\hline
\end{tabular}

Table 8. Model term coefficients for all-propellers-on $\mathrm{C}_{\mathrm{N}}$

The final equation in terms of actual factors is given.

$$
\begin{aligned}
C_{N} & =-0.16660+0.10608 * A-0.022784 * B+8.20235 * 10^{-6} * C+4.05705 * 10^{-6} * D+7.52859 * 10^{-5} \\
& * E+3.22497 * 10^{-6} * F-4.65124 * 10^{-3} * A * B+3.65923 * 10^{-7} * A * C+3.60294 * 10^{-7} * A * D \\
& +8.03548 * 10^{-7} * A * E+1.31506 * 10^{-6} * A * F-3.03135 * 10^{-9} * E^{2}
\end{aligned}
$$

The response surface plots for minimum and maximum RPM levels (10000-13000) are shown in Figures 35 and 36. These surface plots visualize the responses to help understand the characterization process. The normal force coefficient $\left(\mathrm{C}_{\mathrm{N}}\right)$ is seen as a weak function of velocity and as expected, a strong function of angle-of-attack. 


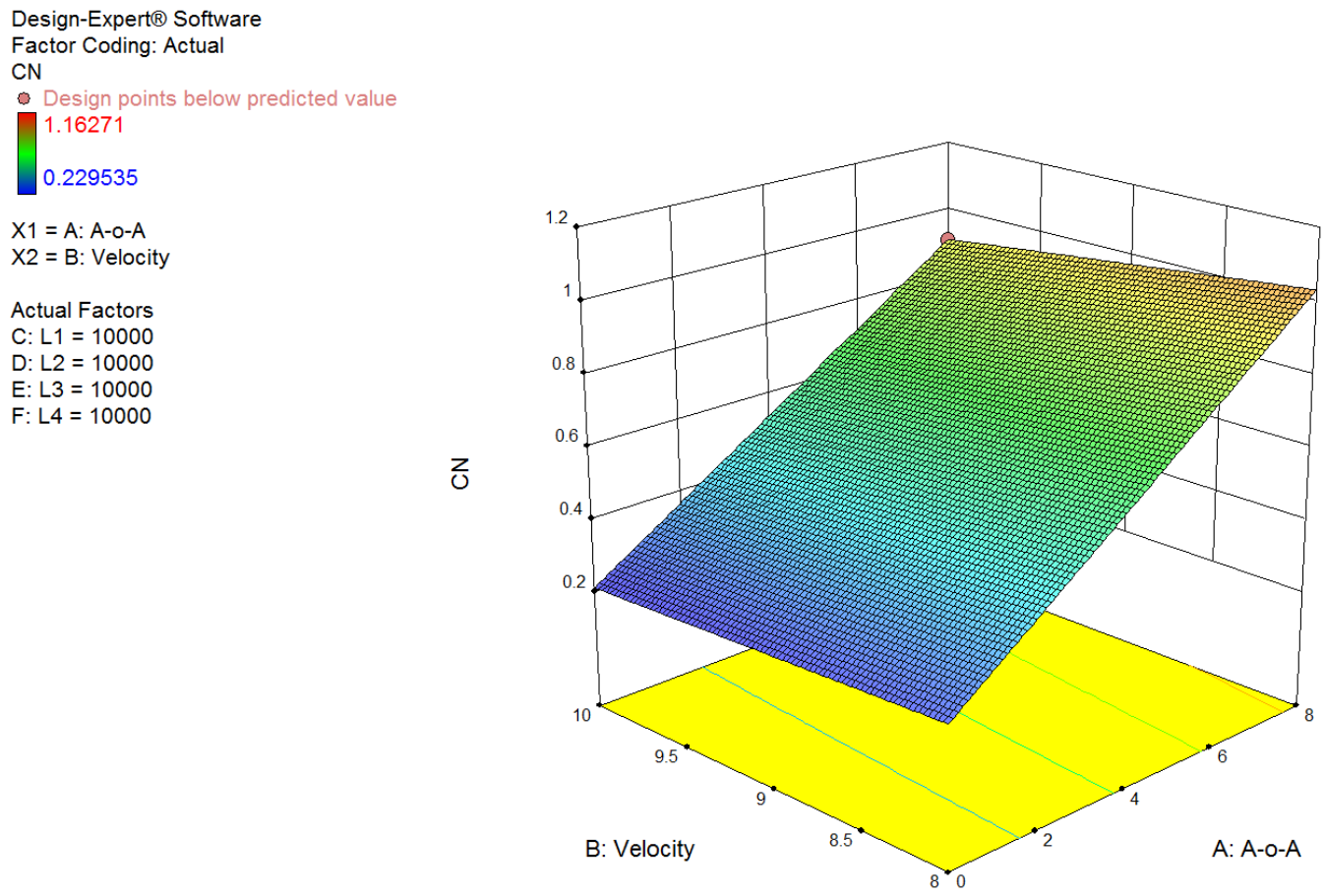

Figure 35. Response surface for all-propellers-on $C_{N}$ at minimum RPM level

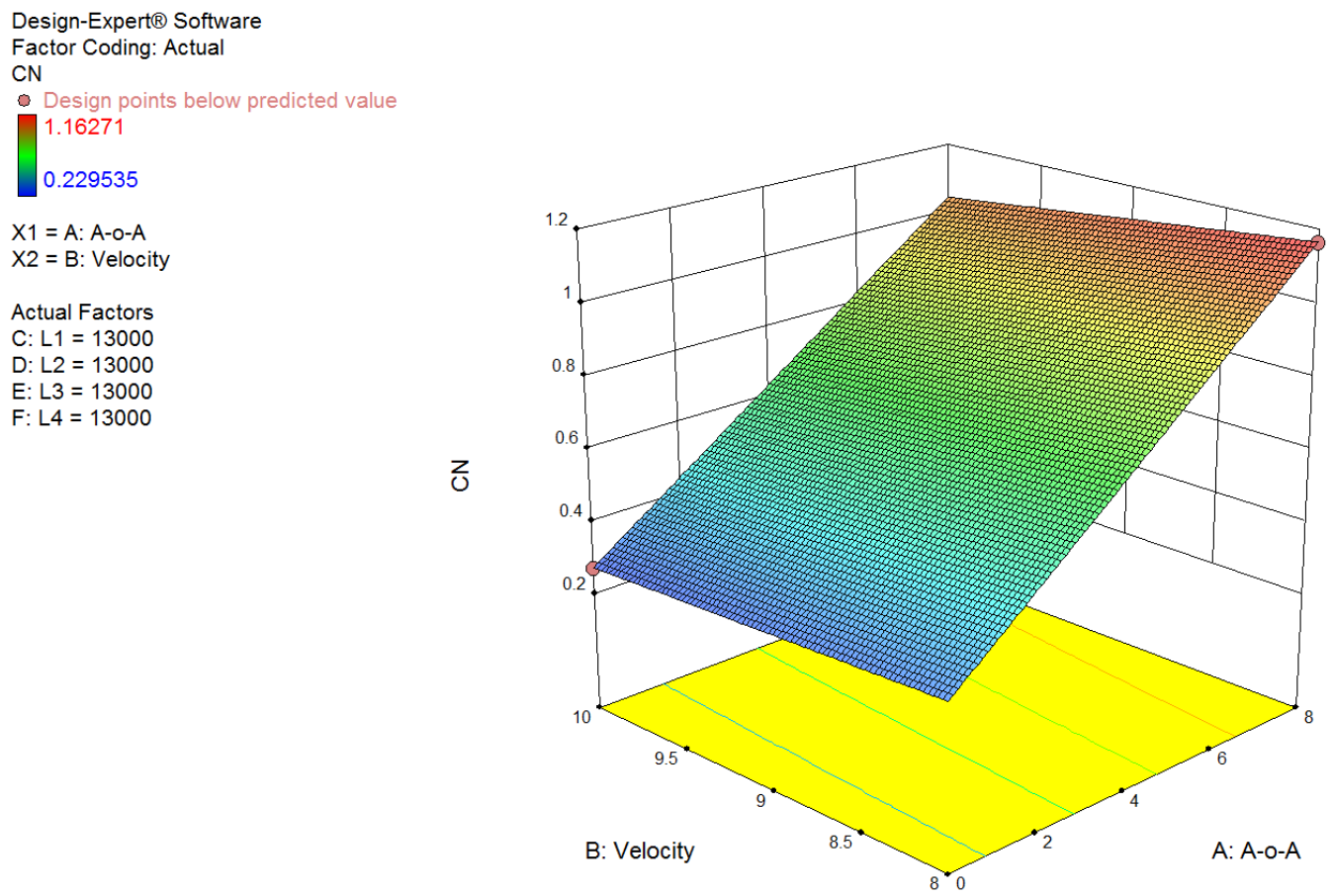

Figure 36. Response surface all-propellers-on $\mathrm{C}_{\mathrm{N}}$ at maximum RPM level 
A two-factor interaction plot for $\mathrm{AB}, \mathrm{AE}$ and $\mathrm{AF}$ is presented in Figures 37, 38 and 39. The $\mathrm{AB}$ interaction term represents the normal force versus angle of attack for a velocity range between $8-10 \mathrm{~m} / \mathrm{s}$ at highest RPM. Also, AE and AF interaction terms represent the normal force versus angle of attack for L3 and L4 RPM ranges between 10000 - 13000 at the lowest velocity. The plots of these interactions are not parallel, so they contribute to the final model significantly, although the latter two interactions are weak, as seen in the p-values.
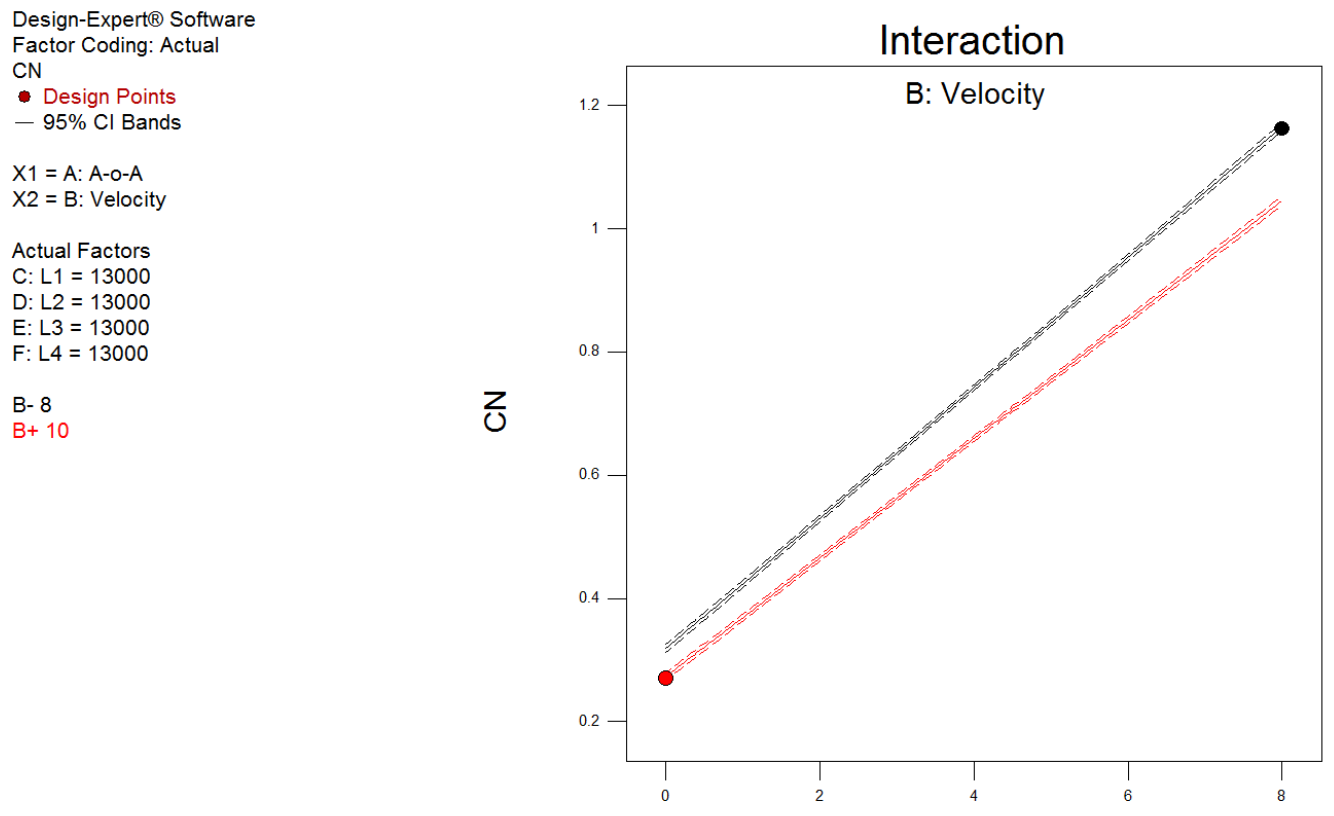

A: A-o-A

Figure 37. $\mathrm{C}_{\mathrm{N}}$ as a function of angle of attack and velocity for all-propellers-on mode 


Design-Expert 8 Software
Factor Coding: Actual
CN
Design Points
$-95 \%$ CI Bands
X1 = A: A-o-A
X2 = E: L3
Actual Factors
B: Velocity = 8
C: L1 $=13000$
D: L2 $=13000$
F: L4 $=13000$
E- 10000
E+ 13000

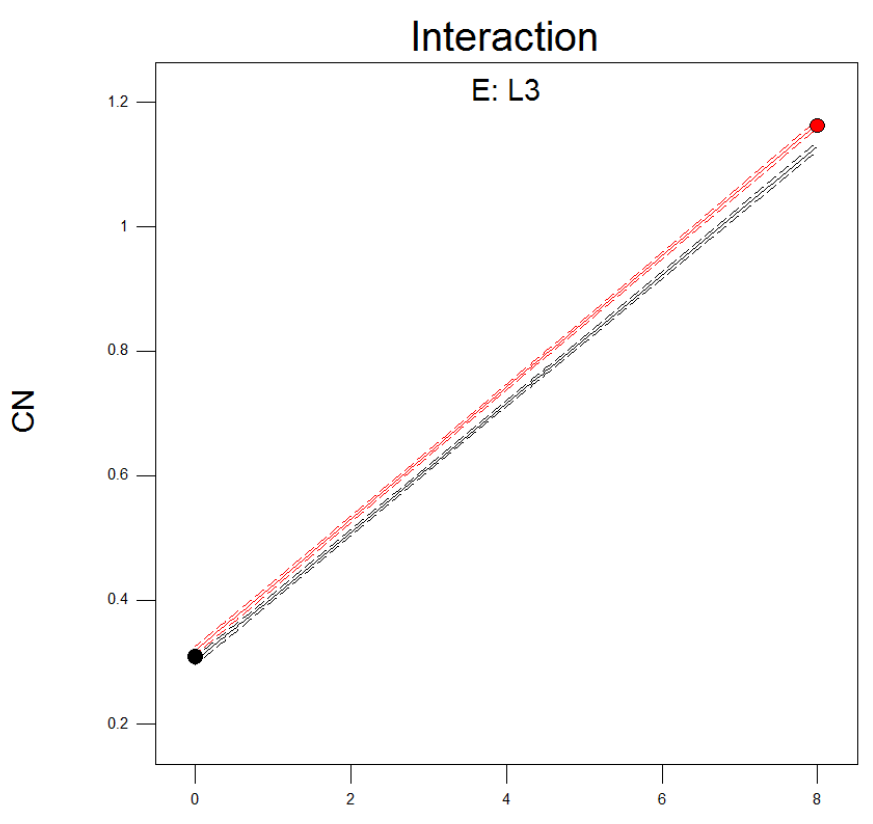

A: A-o-A

Figure $38 . \mathrm{C}_{\mathrm{N}}$ as a function of angle of attack and L3 for all-propellers-on mode

Design-Expert $\circledast$ Software
Factor Coding: Actual
CN
Design Points
$-95 \%$ CI Bands
X1 = A: A-o-A
X2 $=$ F: L4
Actual Factors
B: Velocity $=8$
C: $L 1=13000$
D: $L 2=13000$
E: L3 $=13000$
F- 10000
F+ 13000

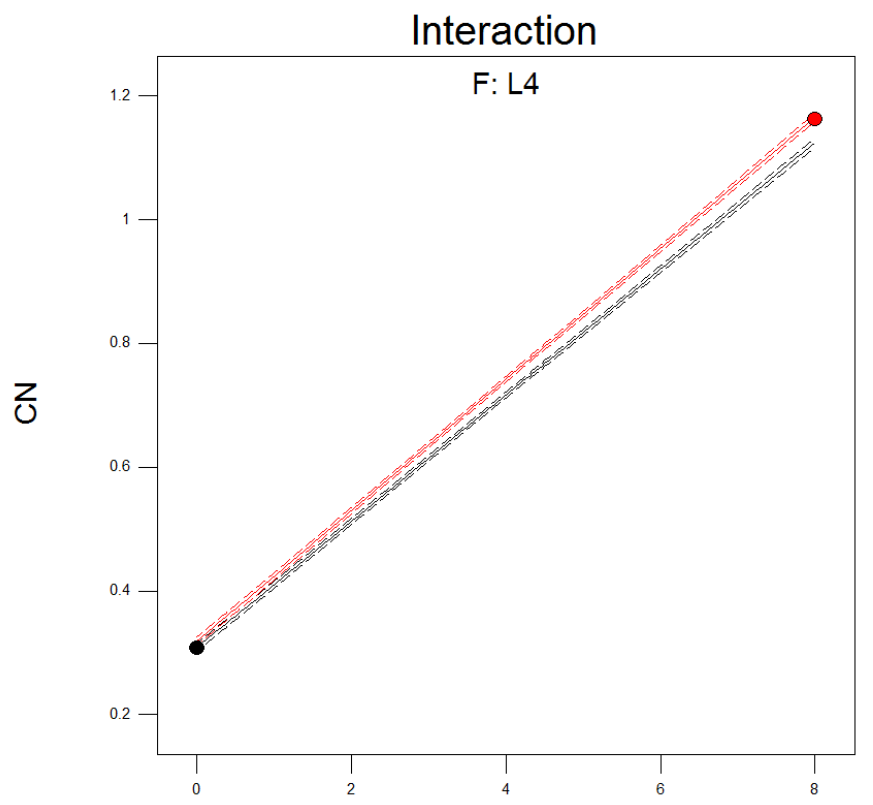

A: A-o-A

Figure 39. $\mathrm{C}_{\mathrm{N}}$ as a function of angle of attack and L4 for all-propellers-on mode 
To conclude that the response surface adequately models the observed data, normal force coefficient was measured at confirmation points. These confirmation points were independent of design point locations and help to make an assessment of the prediction capability of the model. The results of the confirmation point measurements are shown in Table 9. Measured and predicted normal force coefficients and the $95 \%$ prediction interval are shown in the table. All confirmation point results fell into a $95 \%$ prediction interval. Thus, the model adequately represents the observed data.

\begin{tabular}{|c|c|c|c|c|c|}
\hline Run & & 95\%PI Low & Predicted & Measured & 95\%PI High \\
\hline $\mathbf{1}$ & & 0.481 & 0.491 & 0.485 & 0.501 \\
$\mathbf{2}$ & & 0.793 & 0.804 & 0.810 & 0.814 \\
$\mathbf{3}$ & & 0.593 & 0.604 & 0.614 & 0.614 \\
$\mathbf{4}$ & $\mathbf{C}_{\mathbf{N}}$ & 0.753 & 0.763 & 0.773 & 0.773 \\
$\mathbf{5}$ & & 0.885 & 0.896 & 0.905 & 0.907 \\
$\mathbf{6}$ & & 0.285 & 0.296 & 0.302 & 0.306 \\
$\mathbf{7}$ & & 0.410 & 0.421 & 0.426 & 0.431 \\
\hline
\end{tabular}

Table 9. Prediction capability of the all-propellers-on $\mathrm{C}_{\mathrm{N}}$ model

\subsubsection{Axial Force Coefficient}

A second order quadratic model was considered in this case to predict axial force coefficient as a function of six factors. The reduced second order polynomial model was identified as significant by ANOVA using the same procedure as described in section 5.2.1. The ANOVA results are provided in Table 10. 


\begin{tabular}{|c|c|c|c|c|c|}
\hline Source & $\begin{array}{c}\text { Sum of } \\
\text { Squares }\end{array}$ & df & $\begin{array}{c}\text { Mean } \\
\text { Square }\end{array}$ & $\begin{array}{c}\text { F } \\
\text { Value }\end{array}$ & $\begin{array}{c}\text { p-value } \\
\text { Prob }>\text { F }\end{array}$ \\
\hline Block & $3.749 \mathrm{E}-003$ & 1 & $3.749 \mathrm{E}-003$ & & \\
\hline Model & 0.77 & 19 & 0.040 & 2306.66 & $<0.0001$ \\
\hline A-A-o-A & 0.049 & 1 & 0.049 & 2786.88 & $<0.0001$ \\
\hline B-Velocity & 0.44 & 1 & 0.44 & 25057.81 & $<0.0001$ \\
\hline C-L1 & 0.035 & 1 & 0.035 & 1998.27 & $<0.0001$ \\
\hline D-L2 & 0.021 & 1 & 0.021 & 1199.48 & $<0.0001$ \\
\hline E-L3 & 0.026 & 1 & 0.026 & 1486.99 & $<0.0001$ \\
\hline F-L4 & 0.031 & 1 & 0.031 & 1787.34 & $<0.0001$ \\
\hline $\mathrm{AB}$ & $3.171 \mathrm{E}-004$ & 1 & $3.171 \mathrm{E}-004$ & 18.11 & $<0.0001$ \\
\hline $\mathrm{AE}$ & $1.125 \mathrm{E}-004$ & 1 & $1.125 \mathrm{E}-004$ & 6.42 & 0.0140 \\
\hline $\mathrm{AF}$ & $1.996 \mathrm{E}-004$ & 1 & $1.996 \mathrm{E}-004$ & 11.40 & 0.0013 \\
\hline $\mathrm{BC}$ & $2.757 \mathrm{E}-003$ & 1 & $2.757 \mathrm{E}-003$ & 157.46 & $<0.0001$ \\
\hline $\mathrm{BD}$ & $5.193 \mathrm{E}-004$ & 1 & $5.193 \mathrm{E}-004$ & 29.65 & $<0.0001$ \\
\hline $\mathrm{BE}$ & $8.455 \mathrm{E}-004$ & 1 & $8.455 \mathrm{E}-004$ & 48.28 & $<0.0001$ \\
\hline $\mathrm{BF}$ & 7.971E-004 & 1 & $7.971 \mathrm{E}-004$ & 45.52 & $<0.0001$ \\
\hline $\mathrm{CE}$ & $1.010 \mathrm{E}-004$ & 1 & $1.010 \mathrm{E}-004$ & 5.77 & 0.0196 \\
\hline $\mathrm{CF}$ & 7.611E-005 & 1 & $7.611 \mathrm{E}-005$ & 4.35 & 0.0415 \\
\hline $\mathrm{DE}$ & $1.353 \mathrm{E}-004$ & 1 & $1.353 \mathrm{E}-004$ & 7.72 & 0.0073 \\
\hline EF & $2.912 \mathrm{E}-004$ & 1 & $2.912 \mathrm{E}-004$ & 16.63 & 0.0001 \\
\hline $\mathrm{A}^{2}$ & $1.121 \mathrm{E}-003$ & 1 & $1.121 \mathrm{E}-003$ & 64.01 & $<0.0001$ \\
\hline $\mathrm{B}^{2}$ & $2.225 \mathrm{E}-003$ & 1 & $2.225 \mathrm{E}-003$ & 127.07 & $<0.0001$ \\
\hline Residual & $1.016 \mathrm{E}-003$ & 58 & $1.751 \mathrm{E}-005$ & & \\
\hline Lack of Fit & $8.773 \mathrm{E}-004$ & 49 & $1.790 \mathrm{E}-005$ & 1.16 & 0.4329 \\
\hline Pure Error & $1.384 \mathrm{E}-004$ & 9 & $1.538 \mathrm{E}-005$ & & \\
\hline Cor Total & 0.77 & 78 & & & \\
\hline Block & $3.749 \mathrm{E}-003$ & 1 & $3.749 \mathrm{E}-003$ & & \\
\hline
\end{tabular}

Table 10. ANOVA for all-propellers-on $\mathrm{C}_{\mathrm{A}}$

The fit statistics are seen in Table 11 and completely support the regression model.

\begin{tabular}{|l|r|l|r|}
\hline Std. Dev. & $4.185 \mathrm{E}-003$ & R-Squared & 0.9987 \\
\hline Mean & -0.30 & Adj R-Squared & 0.9982 \\
\hline C.V. \% & 1.39 & Pred R-Squared & 0.9973 \\
\hline PRESS & $2.108 \mathrm{E}-003$ & Adeq Precision & 267.359 \\
\hline
\end{tabular}

Table 11. Fit Statistics for all-propellers-on $\mathrm{C}_{\mathrm{A}}$

Normality, independence and constant variance assumptions were validated as described in section 5.2.1. A normal probability plot of the residuals for the developed model is shown in Figure 40 (a). Figure 40 (b) shows a plot of residuals versus run order that was used to validate 
independence. Lastly, a plot of residuals versus predicted values is shown in Figure 40 (c) for checking the constant variance assumption. All residual diagnostic plots are seen as acceptable.

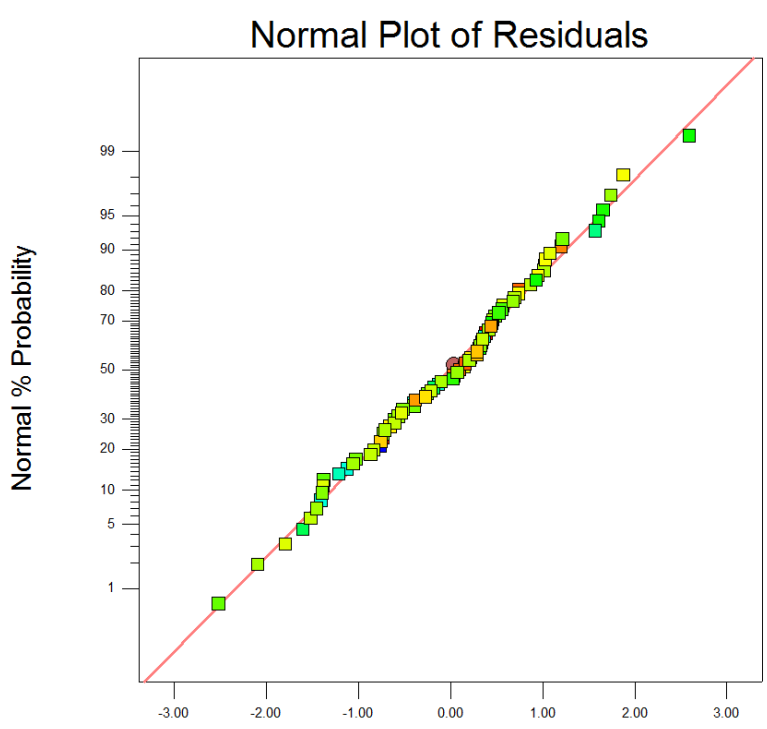

Externally Studentized Residuals

(a)

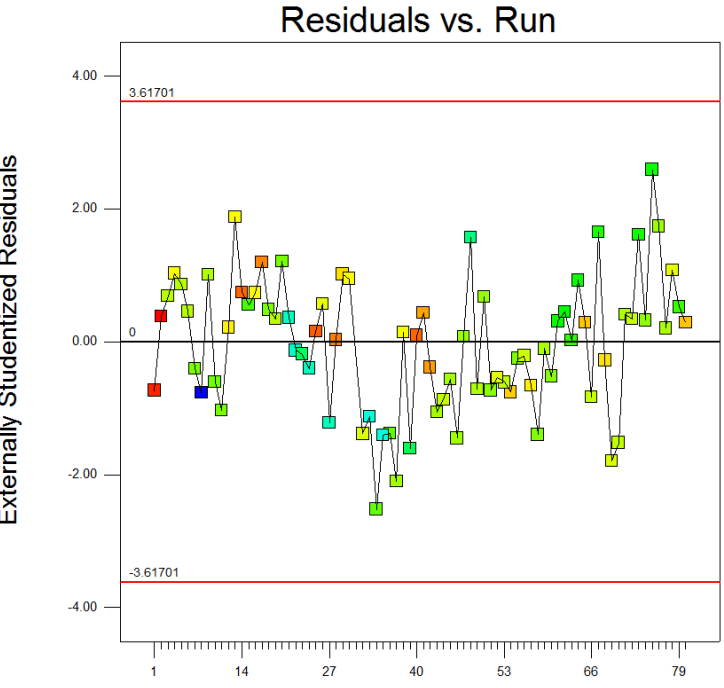

Run Number

(b)

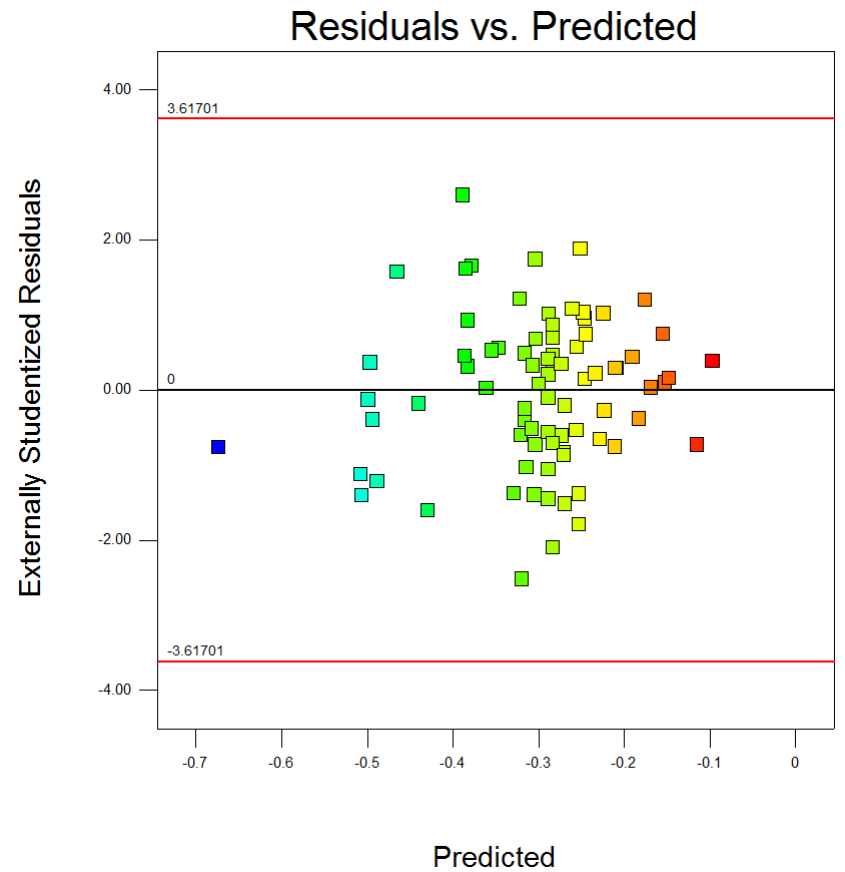

(c)

Figure 40. (a) Normality (b) Independence (c) Constant variance for all-propellers-on $\mathrm{C}_{\mathrm{A}}$ 
The model term coefficients for the second order response surface are given in Table 12.

\begin{tabular}{|l|r|}
\hline \multicolumn{1}{|c|}{ Factor } & \multicolumn{1}{c|}{$\begin{array}{c}\text { Coefficient } \\
\text { Estimate }\end{array}$} \\
\hline Intercept & 0.11683 \\
\hline A-A-o-A & $-1.01054 \mathrm{E}-003$ \\
\hline B-Velocity & 0.33421 \\
\hline C-L1 & $-9.95128 \mathrm{E}-005$ \\
\hline D-L2 & $-6.61061 \mathrm{E}-005$ \\
\hline E-L3 & $-1.04246 \mathrm{E}-004$ \\
\hline F-L4 & $-6.93875 \mathrm{E}-005$ \\
\hline AB & $1.02190 \mathrm{E}-003$ \\
\hline AE & $-4.05693 \mathrm{E}-007$ \\
\hline AF & $-5.48548 \mathrm{E}-007$ \\
\hline BC & $8.03554 \mathrm{E}-006$ \\
\hline BD & $3.54175 \mathrm{E}-006$ \\
\hline BE & $4.33477 \mathrm{E}-006$ \\
\hline BF & $4.25708 \mathrm{E}-006$ \\
\hline CE & $1.02516 \mathrm{E}-009$ \\
\hline CF & $-9.03277 \mathrm{E}-010$ \\
\hline DE & $1.20507 \mathrm{E}-009$ \\
\hline EF & $1.71531 \mathrm{E}-009$ \\
\hline $\mathrm{A}^{2}$ & $-1.07932 \mathrm{E}-003$ \\
\hline $\mathrm{B}^{2}$ & -0.024332 \\
\hline
\end{tabular}

Table 12. Model Term Coefficients for all-propellers-on $\mathrm{C}_{\mathrm{A}}$

The final equation in terms of actual factors is given.

$$
\begin{aligned}
C_{A} & =0.11683-1.01054 * 10^{-3} * A+0.33421 * B-9.95128 * 10^{-5} * C-6.61061 * 10^{-5} * D-1.04246 * 10^{-4} \\
& * E-6.93875 * 10^{-5} * F+1.02190 * 10^{-3} * A * B-4.05693 * 10^{-7} * A * E-5.48548 * 10^{-7} * A * F \\
& +8.03554 * 10^{-6} * B * C+3.54175 * 10^{-6} * B * D+4.33477 * 10^{-6} * B * E+4.25708 * 10^{-6} * B * F \\
& +1.02516 * 10^{-9} * C^{*} E-9.03277 * 10^{-10} * C^{*} F+1.20507 * 10^{-9} * D^{*} E+1.71531 * 10^{-9} * E * F \\
& -1.07932 * 10^{-3} * A^{2}-0.024332 * B^{2}
\end{aligned}
$$

The response surface plots for minimum and maximum RPM levels (10000-13000) were shown in Figures 41 and 42. 
Design-Expert $\circledast$ Software

Factor Coding: Actual

$\mathrm{Ca}$

- Design points above predicted value

$-0.0958695$

$-0.675712$

$\mathrm{X} 1=\mathrm{A}: \mathrm{A}-\mathrm{o}-\mathrm{A}$

$\mathrm{X} 2$ = B: Velocity

Actual Factors

C: $L 1=10000$

$D: L 2=10000$

$E: L 3=10000$

$F: L 4=10000$

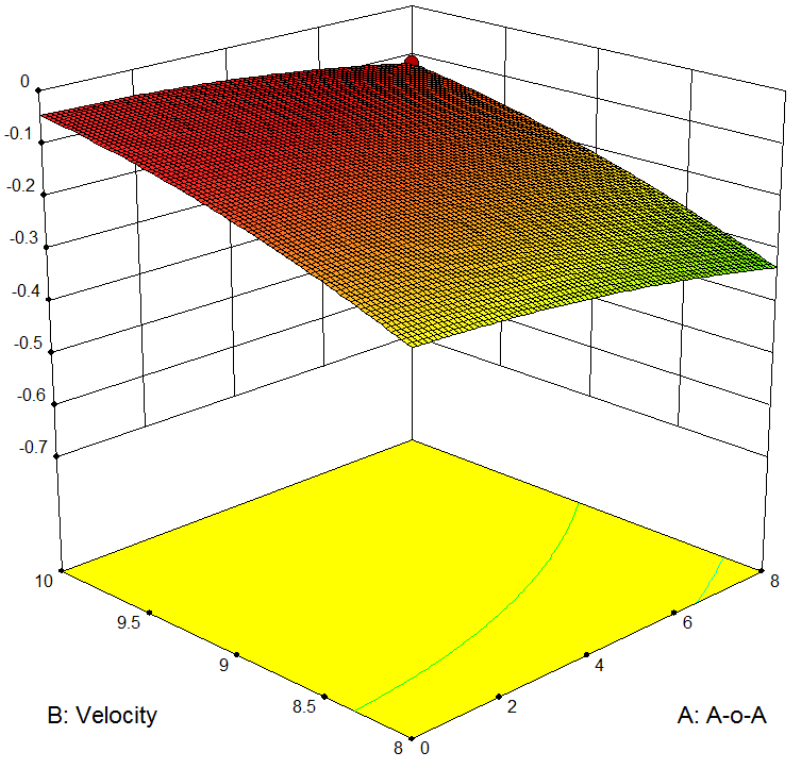

Figure 41. Response surface for all-propellers-on $C_{A}$ at minimum RPM

Design-Expert $囚$ Software
Factor Coding: Actual
Ca
Design points above predicted value
-0.0958695
-0.675712
$X 1=$ A: A-o-A
X2 $=$ B: Velocity
Actual Factors
C: $L 1=13000$
D: $L 2=13000$
E: $L 3=13000$
F: $L 4=13000$

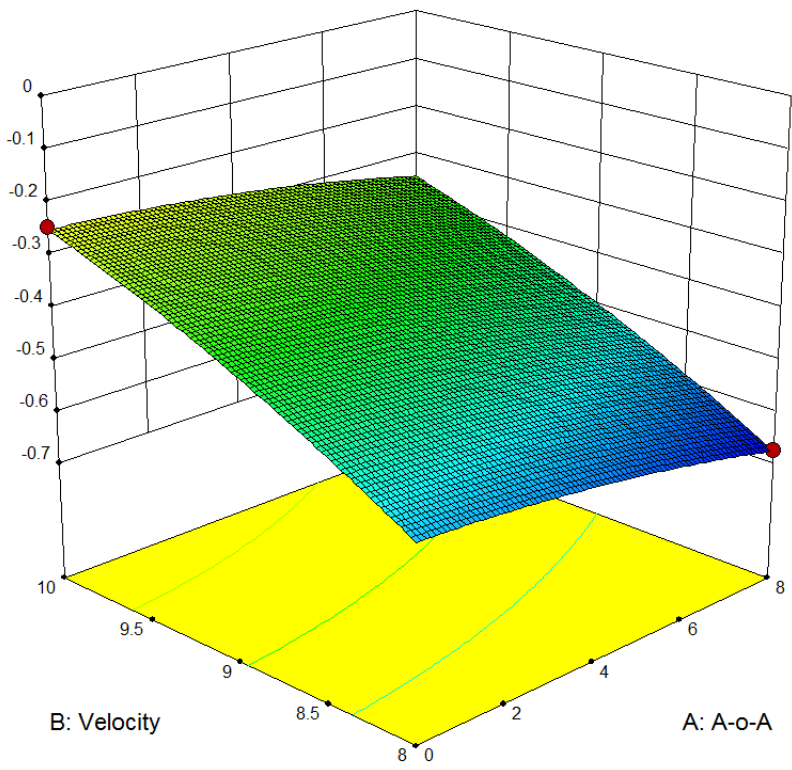

Figure 42. Response surface for all-propellers-on $C_{A}$ at maximum RPM 
A two-factor interaction graph for $\mathrm{BC}$ is shown below. The $\mathrm{BC}$ interaction term represents the Velocity x RPM interaction. Figure 43 shows axial force versus velocity for a L1 RPM range between 10000 - 13000, while other RPM levels are at the maximum level. This result shows that L1 had a more significant effect on axial force at low velocity versus high. This is felt to be due to reduction in induced drag, which coincided with a reduction on total drag; hence, in the axial force.
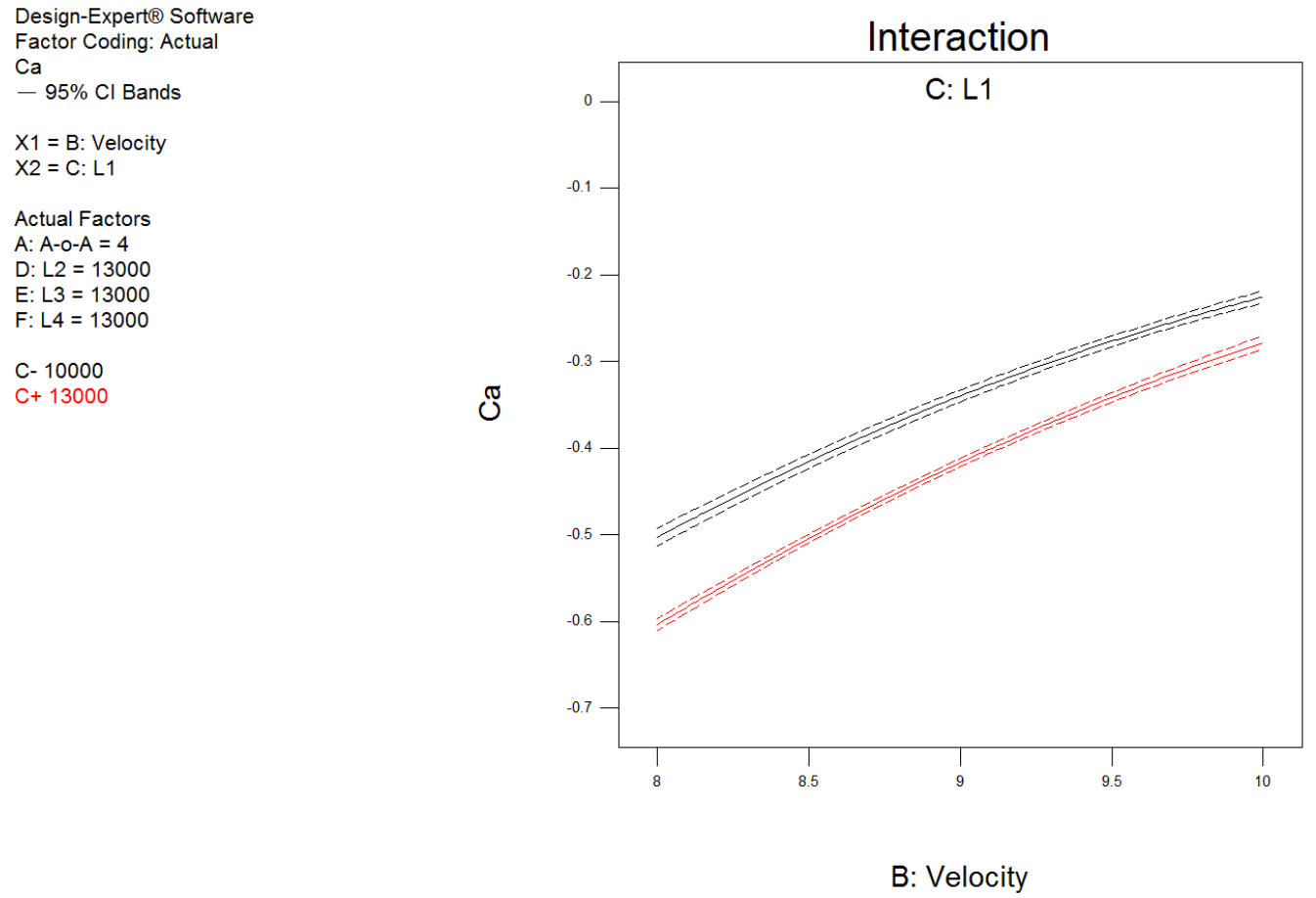

Figure $43 . \mathrm{C}_{\mathrm{A}}$ as a function of velocity and $\mathrm{L} 1$ for all-propellers-on mode

Confirmation point measurements are shown in Table 13. All confirmation point results fell into the $95 \%$ prediction interval. Thus, the regression model adequately represents the observed data. 


\begin{tabular}{|c|c|c|c|c|c|}
\hline Run & & 95\%PI Low & Predicted & Measured & 95\%PI High \\
\hline $\mathbf{1}$ & & -0.408 & -0.399 & -0.405 & -0.390 \\
$\mathbf{2}$ & & -0.232 & -0.222 & -0.224 & -0.211 \\
$\mathbf{3}$ & & -0.460 & -0.450 & -0.453 & -0.440 \\
$\mathbf{4}$ & \multirow{2}{*}{$\mathbf{C}_{\mathbf{A}}$} & -0.328 & -0.320 & -0.322 & -0.311 \\
$\mathbf{5}$ & & -0.248 & -0.237 & -0.236 & -0.227 \\
$\mathbf{6}$ & & -0.413 & -0.403 & -0.399 & -0.393 \\
$\mathbf{7}$ & & -0.146 & -0.136 & -0.129 & -0.126 \\
\hline
\end{tabular}

Table 13. Prediction capability of all-propellers-on $\mathrm{C}_{\mathrm{A}}$ model

\subsection{Wing-Alone Mode}

Wing-alone mode has two factors are shown in the table below.

\begin{tabular}{|cc|c|c|}
\hline \multicolumn{2}{|c|}{ Factors } & Low Limit & High Limit \\
\hline A-o-A & Angle of attack (degree) & 0 & 8 \\
\hline V & Velocity (m/s) & 8 & 10 \\
\hline
\end{tabular}

Table 14. Factors and factor limits for wing-alone mode

\subsubsection{Normal Force Coefficient}

A second order quadratic model was considered in this case to predict the normal force coefficient as a function angle of attack. ANOVA was used to determine significant and insignificant model terms for building a final response model. The model included only significant terms. This reduction was again made by the P-value approach. The ANOVA results are provided in Table 15. 


\begin{tabular}{|c|c|c|c|c|c|}
\hline Source & $\begin{array}{c}\text { Sum of } \\
\text { Squares }\end{array}$ & df & $\begin{array}{c}\text { Mean } \\
\text { Square }\end{array}$ & $\begin{array}{c}\mathbf{F} \\
\text { Value }\end{array}$ & $\begin{array}{c}\text { p-value } \\
\text { Prob }>\text { F }\end{array}$ \\
\hline Block & 1.704E-004 & 1 & $1.704 \mathrm{E}-004$ & & \\
\hline Model & 0.73 & 2 & 0.37 & 23945.49 & $<0.0001$ \\
\hline A-A-o-A & 0.73 & 1 & 0.73 & 47824.79 & $<0.0001$ \\
\hline $\mathrm{A}^{2}$ & $1.012 \mathrm{E}-003$ & 1 & $1.012 \mathrm{E}-003$ & 66.20 & $<0.0001$ \\
\hline Residual & $3.362 \mathrm{E}-004$ & 22 & $1.528 \mathrm{E}-005$ & & \\
\hline Lack of Fit & $2.075 \mathrm{E}-004$ & 14 & $1.482 \mathrm{E}-005$ & 0.92 & 0.5738 \\
\hline Pure Error & $1.287 \mathrm{E}-004$ & 8 & $1.609 \mathrm{E}-005$ & & \\
\hline Cor Total & 0.73 & 25 & & & \\
\hline
\end{tabular}

Table 15. ANOVA for wing-alone $\mathrm{C}_{\mathrm{N}}$

The fit statistics values for $\mathrm{R}^{2}$ are shown in Table 16 .

\begin{tabular}{|l|r|l|r|}
\hline Std. Dev. & $3.909 E-003$ & R-Squared & 0.9995 \\
\hline Mean & 0.57 & Adj R-Squared & 0.9995 \\
\hline C.V. \% & 0.68 & Pred R-Squared & 0.9993 \\
\hline PRESS & $5.094 E-004$ & Adeq Precision & 407.176 \\
\hline
\end{tabular}

Table 16. Fit statistics for wing-alone $C_{N}$

Figure 44 summarizes the residual diagnostics, no problems were found. 


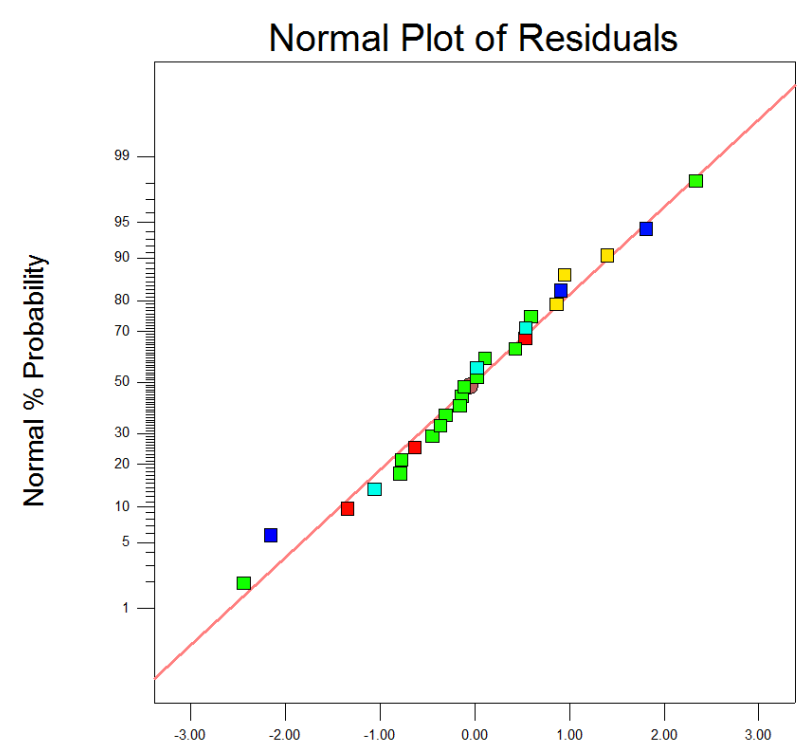

Externally Studentized Residuals

(a)

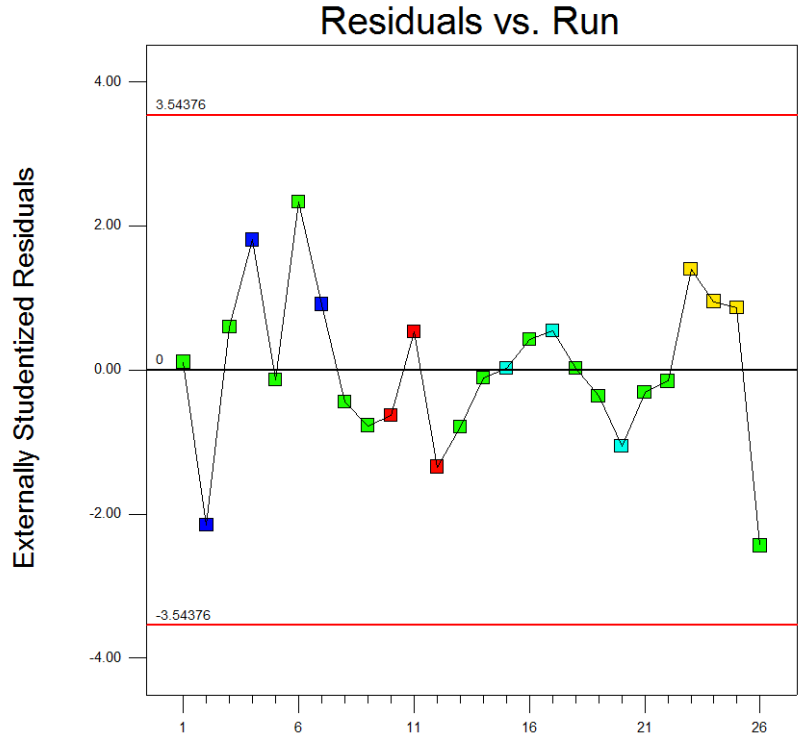

Run Number

(b)

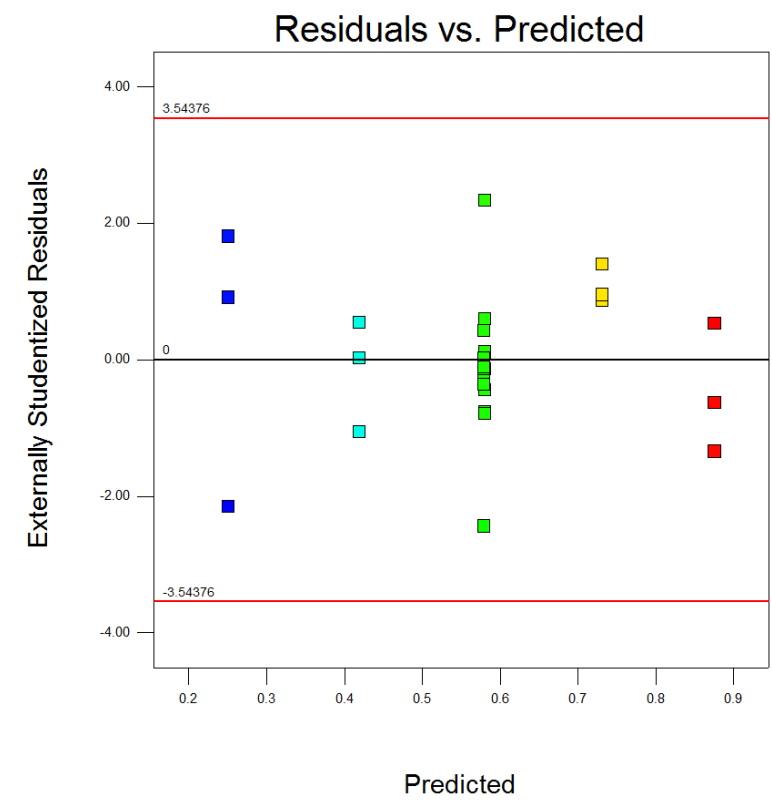

(c)

Figure 44. (a) Normality (b) Independence (c) Constant variance for wing-alone $\mathrm{C}_{\mathrm{N}}$

The model term coefficients for the second order response surface are illustrated in Table 17. 


\begin{tabular}{|l|r|}
\hline \multicolumn{1}{|c|}{ Factor } & \multicolumn{1}{c|}{$\begin{array}{c}\text { Coefficient } \\
\text { Estimate }\end{array}$} \\
\hline Intercept & 0.25060 \\
\hline $\mathrm{A}-\mathrm{A}-\mathrm{o}-\mathrm{A}$ & 0.086625 \\
\hline $\mathrm{A}^{2}$ & $-1.07294 \mathrm{E}-003$ \\
\hline
\end{tabular}

Table 17. Model term coefficients for wing-alone $\mathrm{C}_{\mathrm{N}}$

Therefore, the final equation, in terms of actual factors, is given.

$$
C_{N}=0.25060+0.086625 * A-1.07294 * 10^{-3} * A^{2}
$$

The response surface plot is shown in Figure 45.

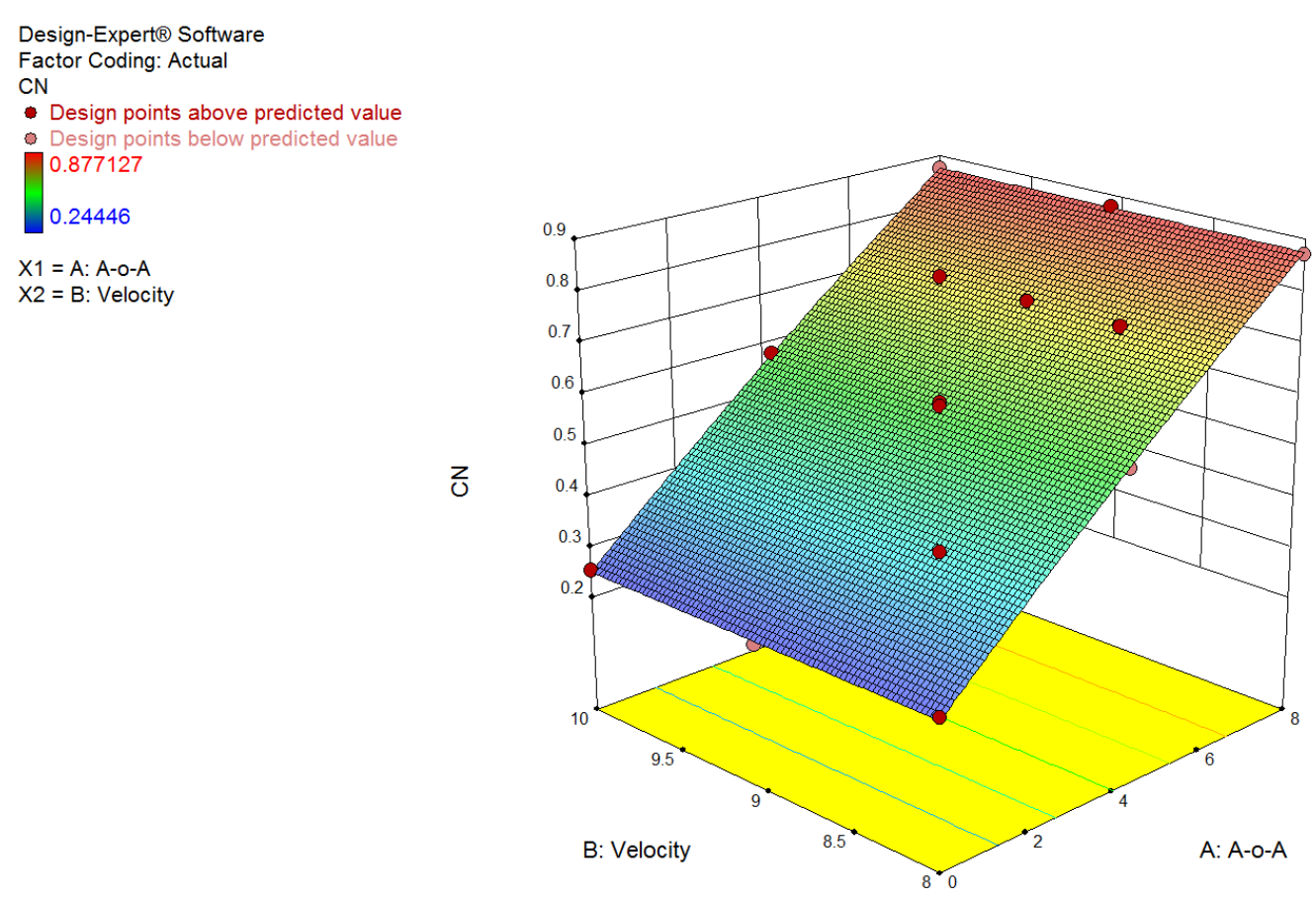

Figure 45. Response surface for wing-alone $C_{N}$

There is no interaction term for wing alone $\mathrm{C}_{\mathrm{N}}$. $\mathrm{C}_{\mathrm{N}}$ is just a function of angle of attack.

The results of the confirmation point measurements are shown in Table 18. All confirmation point results fell into a $95 \%$ prediction interval. Thus, model adequately represents the observed data. 


\begin{tabular}{|c|l|c|c|c|c|}
\hline Run & & 95\%PI Low & Predicted & Measured & 95\%PI High \\
\hline $\mathbf{1}$ & & 0.492 & 0.500 & 0.499 & 0.509 \\
$\mathbf{2}$ & $\mathbf{C}_{\mathbf{N}}$ & 0.648 & 0.656 & 0.665 & 0.665 \\
$\mathbf{3}$ & & 0.648 & 0.656 & 0.658 & 0.665 \\
\hline
\end{tabular}

Table 18. Prediction capability of the wing-alone $\mathrm{C}_{\mathrm{N}}$ model

\subsubsection{Axial Force Coefficient}

A second order quadratic model was considered in this case to predict axial force coefficient as a function of two factors, angle of attack and velocity. ANOVA was used to determine significant and insignificant model terms for building the response model. The ANOVA results are provided in Table 19.

\begin{tabular}{|l|r|r|r|r|r|}
\hline \multicolumn{1}{|c|}{ Source } & \multicolumn{1}{c|}{$\begin{array}{c}\text { Sum of } \\
\text { Squares }\end{array}$} & \multicolumn{1}{c|}{ df } & \multicolumn{1}{c|}{$\begin{array}{c}\text { Mean } \\
\text { Square }\end{array}$} & \multicolumn{1}{c|}{$\begin{array}{c}\text { F } \\
\text { Value }\end{array}$} & \multicolumn{1}{c|}{$\begin{array}{c}\text { p-value } \\
\text { Prob }>\text { F }\end{array}$} \\
\hline Block & $2.973 \mathrm{E}-005$ & 1 & $2.973 \mathrm{E}-005$ & & \\
\hline Model & 0.011 & 3 & $3.753 \mathrm{E}-003$ & 1445.28 & $<0.0001$ \\
\hline A-A-o-A & 0.011 & 1 & 0.011 & 4097.33 & $<0.0001$ \\
\hline B-Velocity & $1.352 \mathrm{E}-005$ & 1 & $1.352 \mathrm{E}-005$ & 5.21 & 0.0331 \\
\hline $\mathrm{A}^{2}$ & $6.057 \mathrm{E}-004$ & 1 & $6.057 \mathrm{E}-004$ & 233.30 & $<0.0001$ \\
\hline Residual & $5.452 \mathrm{E}-005$ & 21 & $2.596 \mathrm{E}-006$ & & \\
\hline Lack of Fit & $2.857 \mathrm{E}-005$ & 13 & $2.198 \mathrm{E}-006$ & 0.68 & 0.7442 \\
\hline Pure Error & $2.595 \mathrm{E}-005$ & 8 & $3.244 \mathrm{E}-006$ & & \\
\hline Cor Total & 0.011 & 25 & & & \\
\hline
\end{tabular}

Table 19. ANOVA for wing-alone $C_{A}$

The fit statistics are shown in Table 20 .

\begin{tabular}{|l|r|l|r|}
\hline Std. Dev. & $1.611 \mathrm{E}-003$ & R-Squared & 0.9952 \\
\hline Mean & 0.012 & Adj R-Squared & 0.9945 \\
\hline C.V. \% & 13.84 & Pred R-Squared & 0.9930 \\
\hline PRESS & $7.865 \mathrm{E}-005$ & Adeq Precision & 110.398 \\
\hline
\end{tabular}

Table 20. Fit Statistics for wing-alone $\mathrm{C}_{\mathrm{A}}$

The normality, independence and constant variance assumptions were validated as shown in Figure 46. All assumptions were validated. 


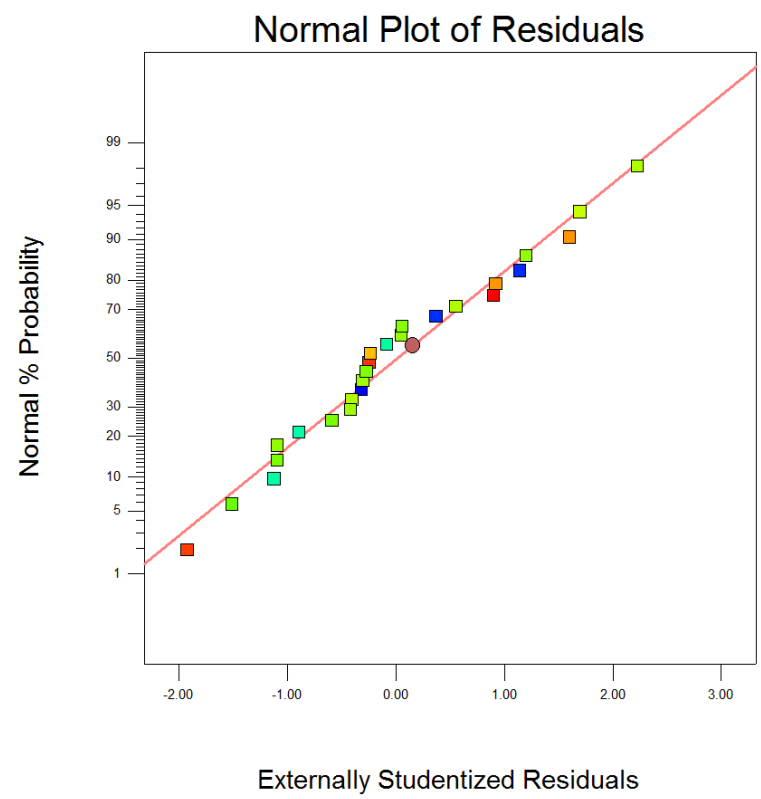

(a)

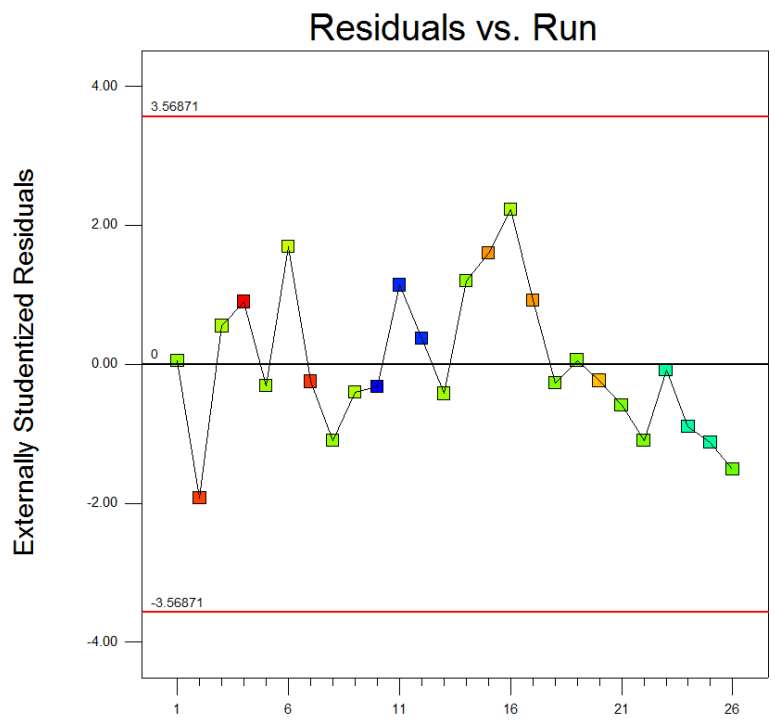

Run Number

(b)

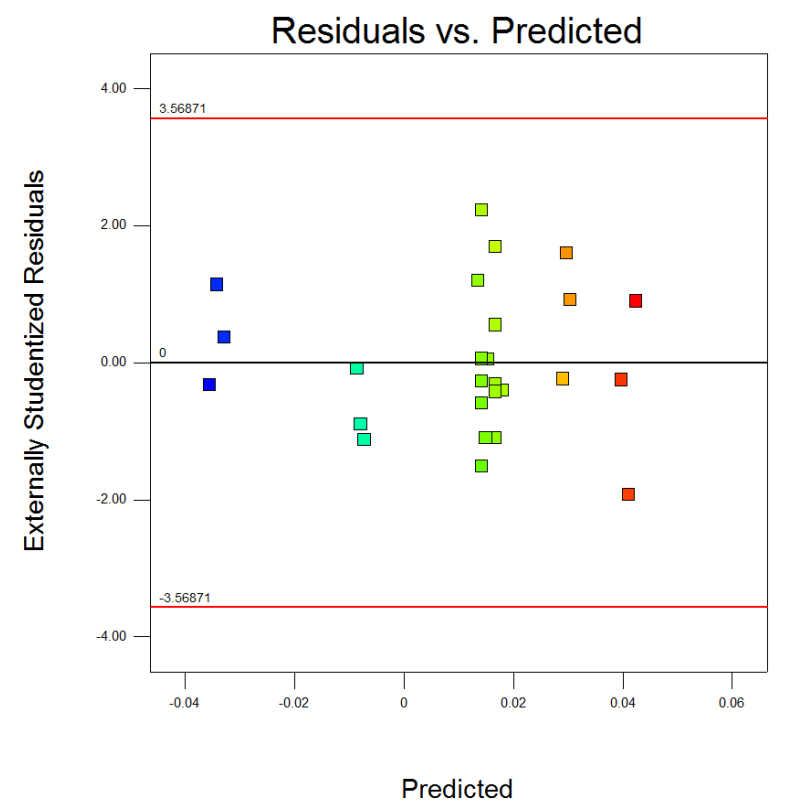

(c)

Figure 46. (a) Normality (b) Independence (c) constant variance for wing-alone $\mathrm{C}_{\mathrm{A}}$

The model term coefficients for the second order response surface is illustrated in Table 21 . 


\begin{tabular}{|l|r|}
\hline Factor & $\begin{array}{r}\text { Coefficient } \\
\text { Estimate }\end{array}$ \\
\hline Intercept & 0.051931 \\
\hline A-A-o-A & $-2.77360 \mathrm{E}-003$ \\
\hline $\mathrm{B}-$ Velocity & $-1.34242 \mathrm{E}-003$ \\
\hline $\mathrm{A}^{2}$ & $-8.30249 \mathrm{E}-004$ \\
\hline
\end{tabular}

Table 21. Model term coefficients for wing-alone $\mathrm{C}_{\mathrm{A}}$

The final equation in terms of actual factors is given.

$$
C_{A}=0.051931-2.77360 * 10^{-3} * A-1.34242 * 10^{-3} * B-8.30249 * 10^{-4} * A^{2}
$$

The response surface plot is shown in Figure 47.
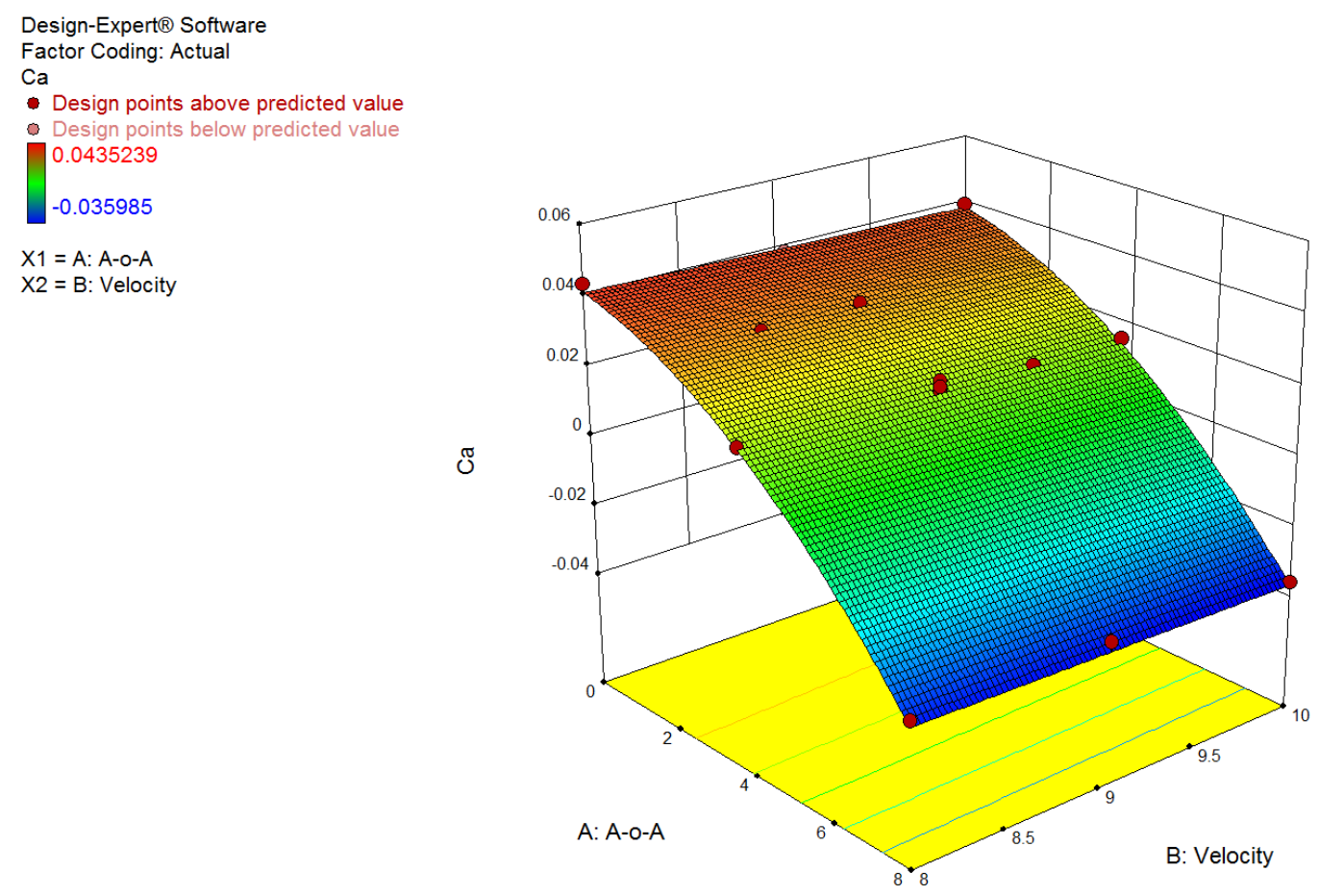

Figure 47. Response surface for wing-alone $C_{A}$

There is no interaction term for wing-alone $\mathrm{C}_{\mathrm{A}} \cdot \mathrm{C}_{\mathrm{A}}$ is a just a function of angle of attack. 
The results of the confirmation point measurements are shown in Table 22. All confirmation point results fell into a $95 \%$ prediction interval. Thus, model adequately represents the observed data.

\begin{tabular}{|c|c|c|c|c|c|}
\hline Run & & 95\%PI Low & Predicted & Measured & 95\%PI High \\
\hline $\mathbf{1}$ & & 0.021 & 0.025 & 0.021 & 0.029 \\
$\mathbf{2}$ & $\mathbf{C}_{\mathbf{A}}$ & 0.0002 & 0.003 & 0.002 & 0.007 \\
$\mathbf{3}$ & & 0.001 & 0.004 & 0.003 & 0.008 \\
\hline
\end{tabular}

Table 22. Prediction capability of the wing-alone $\mathrm{C}_{\mathrm{A}}$ model

\subsection{Wing-Tip-Propellers-Alone Mode}

Wingtip-propellers-alone mode has three factors, as seen in Table 23.

\begin{tabular}{|cc|c|c|}
\hline \multicolumn{2}{|c|}{ Factors } & Low Limit & High Limit \\
\hline A-o-A & Angle of attack (degree) & 0 & 8 \\
\hline V & Velocity (m/s) & 8 & 10 \\
\hline L1 & Left Motor 1 (RPM) & 10000 & 13000 \\
\hline
\end{tabular}

Table 23. Factors and factor limits for wingtip-alone mode

\subsubsection{Normal Force Coefficient}

Again, a reduced second order polynomial model was identified as significant by ANOVA. The ANOVA results are provided in Table 24. 


\begin{tabular}{|l|r|r|r|r|r|}
\hline \multicolumn{1}{|c|}{ Source } & \multicolumn{1}{c|}{$\begin{array}{c}\text { Sum of } \\
\text { Squares }\end{array}$} & \multicolumn{1}{c|}{ df } & \multicolumn{1}{c|}{$\begin{array}{c}\text { Mean } \\
\text { Square }\end{array}$} & \multicolumn{1}{c|}{$\begin{array}{c}\text { F } \\
\text { Value }\end{array}$} & $\begin{array}{c}\text { p-value } \\
\text { Prob }>\text { F }\end{array}$ \\
\hline Block & $1.952 \mathrm{E}-004$ & 1 & $1.952 \mathrm{E}-004$ & & \\
\hline Model & 1.36 & 5 & 0.27 & 4435.93 & $<0.0001$ \\
\hline A-A-o-A & 1.36 & 1 & 1.36 & 22098.14 & $<0.0001$ \\
\hline B-Velocity & $1.041 \mathrm{E}-003$ & 1 & $1.041 \mathrm{E}-003$ & 16.94 & 0.0002 \\
\hline C-L1 & $2.653 \mathrm{E}-003$ & 1 & $2.653 \mathrm{E}-003$ & 43.19 & $<0.0001$ \\
\hline AB & $3.465 \mathrm{E}-004$ & 1 & $3.465 \mathrm{E}-004$ & 5.64 & 0.0235 \\
\hline A $^{2}$ & $9.669 \mathrm{E}-004$ & 1 & $9.669 \mathrm{E}-004$ & 15.74 & 0.0004 \\
\hline Residual & $2.027 \mathrm{E}-003$ & 33 & $6.143 \mathrm{E}-005$ & & \\
\hline Lack of Fit & $1.569 \mathrm{E}-003$ & 23 & $6.823 \mathrm{E}-005$ & 1.49 & 0.2608 \\
\hline Pure Error & $4.580 \mathrm{E}-004$ & 10 & $4.580 \mathrm{E}-005$ & & \\
\hline Cor Total & 1.36 & 39 & & & \\
\hline
\end{tabular}

Table 24. ANOVA for wing-tip-propellers-alone $\mathrm{C}_{\mathrm{N}}$

The fit statistics results indicated that the model describes and can predict over $99 \%$ of the variability in the response due to factor changes, as seen in Table 25.

\begin{tabular}{|l|r|l|r|}
\hline Std. Dev. & $7.838 \mathrm{E}-003$ & R-Squared & 0.9985 \\
\hline Mean & 0.60 & Adj R-Squared & 0.9983 \\
\hline C.V. \% & 1.31 & Pred R-Squared & 0.9973 \\
\hline PRESS & $3.626 \mathrm{E}-003$ & Adeq Precision & 215.469 \\
\hline
\end{tabular}

Table 25. Fit Statistics for wing-tip-propellers-alone $C_{N}$

Residual diagnostics for the developed regression model are shown in Figure 48. No problems were found. 


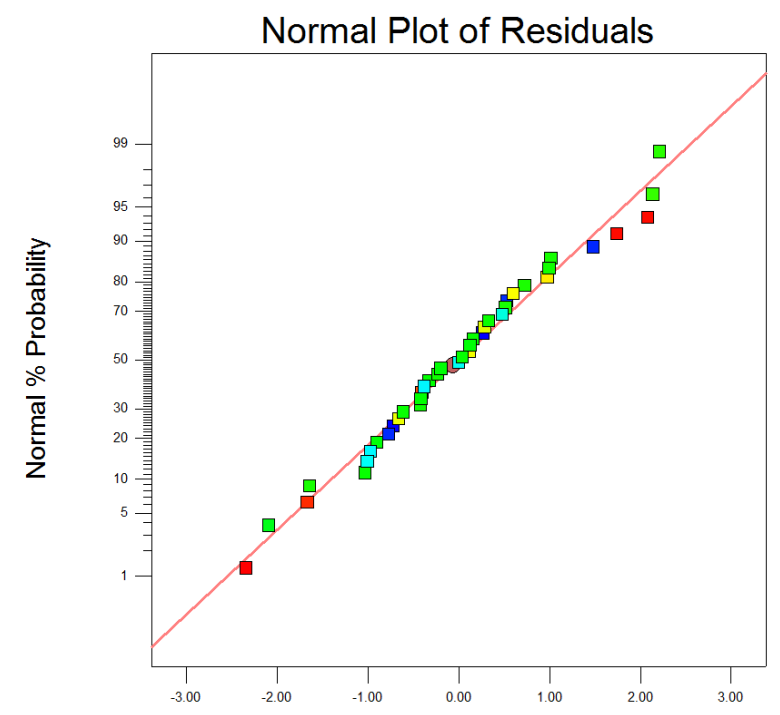

Externally Studentized Residuals

(a)

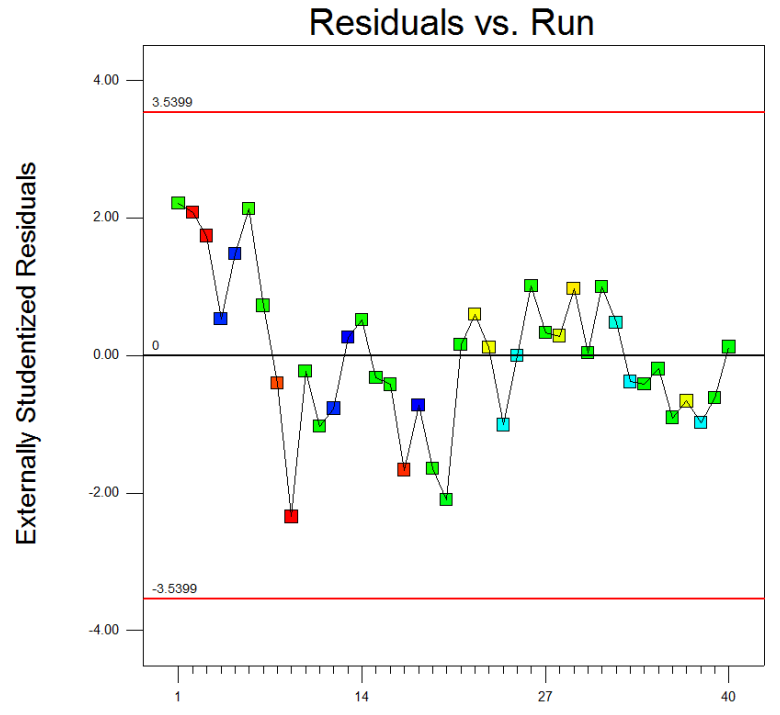

Run Number

(b)

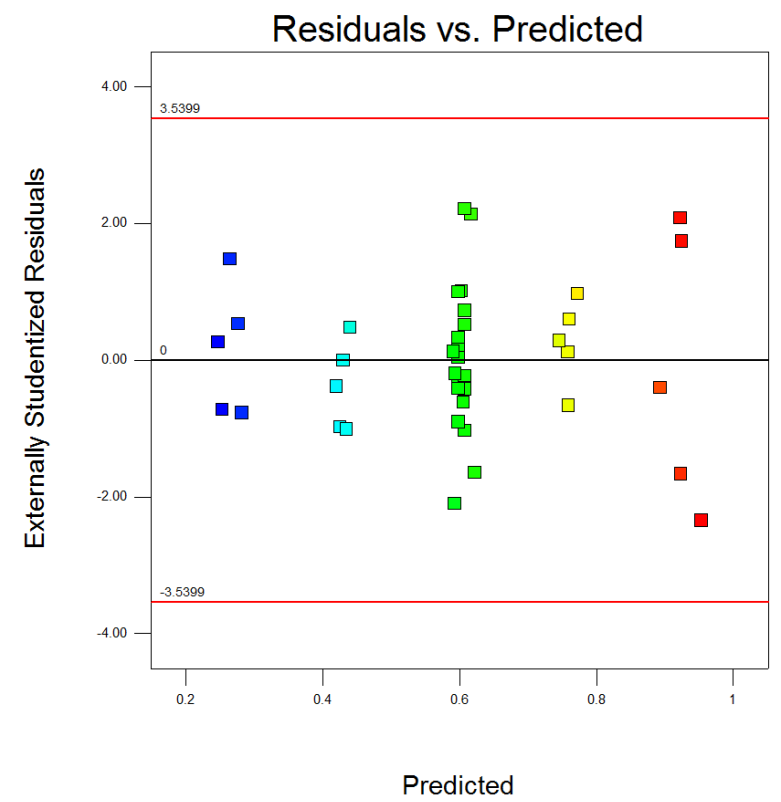

(c)

Figure 48. (a) Normality (b) Independence (c) Constant variance for wing-tip-propellers $\mathrm{C}_{\mathrm{N}}$

The model term coefficients for the second order response surface is illustrated in the table below. 


\begin{tabular}{|l|r|}
\hline Factor & $\begin{array}{r}\text { Coefficient } \\
\text { Estimate }\end{array}$ \\
\hline Intercept & 0.17265 \\
\hline A-A-o-A & 0.10350 \\
\hline B-Velocity & $-2.73947 \mathrm{E}-003$ \\
\hline C-L1 and R1 & $9.71212 \mathrm{E}-006$ \\
\hline $\mathrm{AB}$ & $-1.59610 \mathrm{E}-003$ \\
\hline $\mathrm{A}^{2}$ & $-8.43165 \mathrm{E}-004$ \\
\hline
\end{tabular}

Table 26. Model term coefficients for wing-tip-propellers-alone $\mathrm{C}_{\mathrm{N}}$

The final equation in terms of actual factors is given.

$$
\begin{aligned}
C_{N} & =0.17265+0.10350 * A-2.73947 * 10^{-3} * B+9.71212 * 10^{-6} * C-1.59610 * 10^{-3} * A * B \\
& -8.43165 * 10^{-4} * A^{2}
\end{aligned}
$$

The response surface plots for minimum and maximum RPM levels (10000-13000) are shown in Figures 49 and 50.

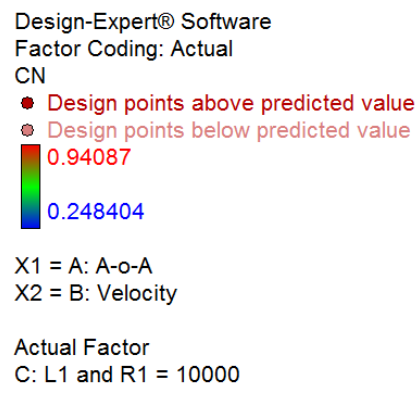

- Design points above predicted value Design points below predicted value 0.94087

0.248404

$\mathrm{X} 1=\mathrm{A}: \mathrm{A}-\mathrm{O}-\mathrm{A}$ $\mathrm{X} 2$ = B: Velocity

Actual Factor

C: $L 1$ and $R 1=10000$

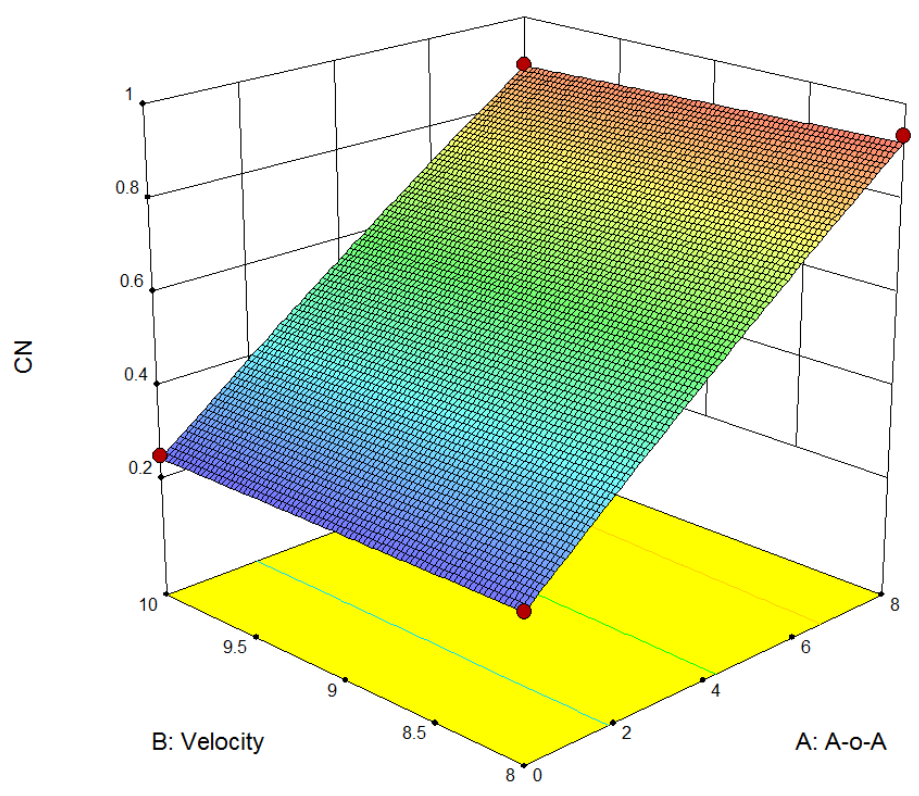

Figure 49. Response surface for wing-tip-propellers-alone $C_{N}$ at minimum RPM 


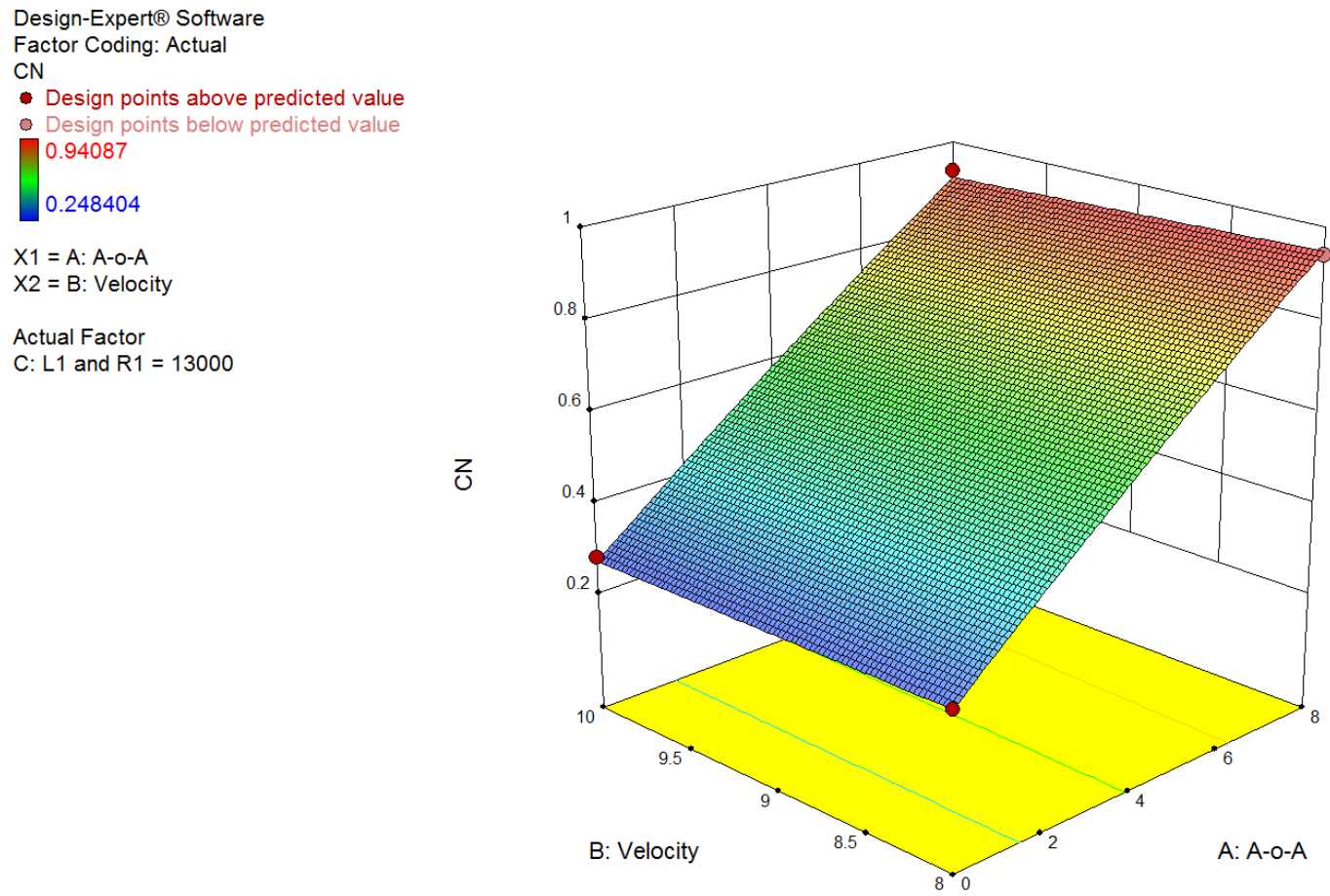

Figure 50. Response surface for wing-tip-propellers-alone $C_{N}$ at maximum RPM

Angle of attack and velocity are the only interaction terms for the wing-tip-propellers-alone $\mathrm{C}_{\mathrm{N}}$, as seen in Figure 51. 

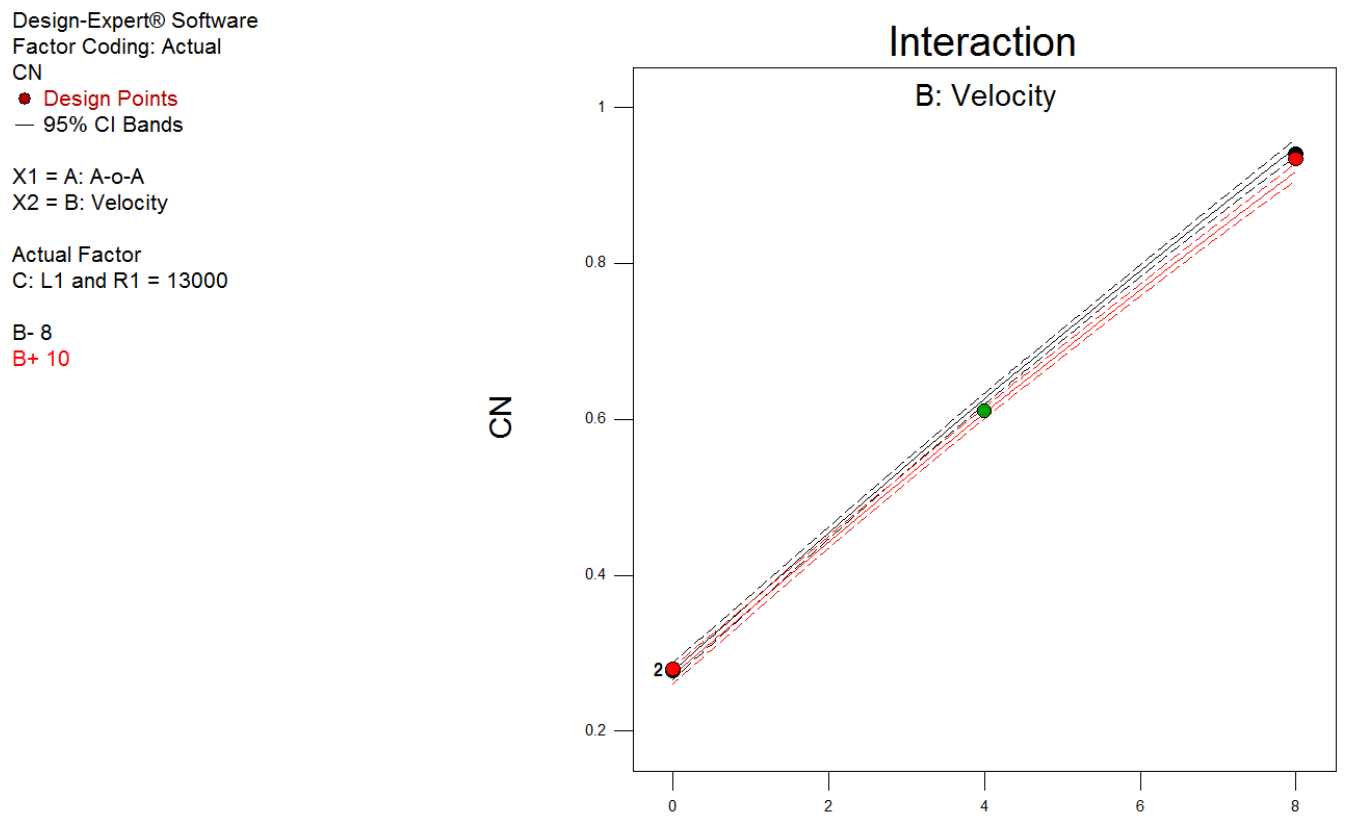

A: A-o-A

Figure $51 . \mathrm{C}_{\mathrm{N}}$ as a function of velocity and angle of attack for wingtip-propellers-alone mode

The results of the confirmation point measurements are shown in Table 27. All confirmation point results fell into a 95\% prediction interval. Thus, the model adequately represents the observed data.

\begin{tabular}{|c|c|c|c|c|c|}
\hline Run & & 95\%PI Low & Predicted & Measured & 95\%PI High \\
\hline $\mathbf{1}$ & & 0.419 & 0.436 & 0.424 & 0.453 \\
$\mathbf{2}$ & & 0.734 & 0.751 & 0.753 & 0.768 \\
$\mathbf{3}$ & \multirow{2}{*}{$\mathbf{C}_{\mathbf{N}}$} & 0.524 & 0.541 & 0.535 & 0.559 \\
$\mathbf{4}$ & & 0.667 & 0.684 & 0.681 & 0.700 \\
$\mathbf{5}$ & & 0.810 & 0.828 & 0.829 & 0.846 \\
$\mathbf{6}$ & & 0.250 & 0.269 & 0.254 & 0.288 \\
\hline
\end{tabular}

Table 27. Prediction capability of the wing-tip-propellers-alone $\mathrm{C}_{\mathrm{N}}$ 


\subsubsection{Axial Force Coefficient}

A second order quadratic model was considered in this case to predict the axial force coefficient as a function of three factors, angle of attack, velocity, and tip motor rpm. The ANOVA results are provided in Table 28.

\begin{tabular}{|l|r|r|r|r|r|}
\hline \multicolumn{1}{|c|}{ Source } & \multicolumn{1}{c|}{$\begin{array}{c}\text { Sum of } \\
\text { Squares }\end{array}$} & \multicolumn{1}{c|}{ df } & \multicolumn{1}{c|}{$\begin{array}{c}\text { Mean } \\
\text { Square }\end{array}$} & \multicolumn{1}{c|}{$\begin{array}{c}\text { F } \\
\text { Value }\end{array}$} & $\begin{array}{c}\text { p-value } \\
\text { Prob }>\text { F }\end{array}$ \\
\hline Block & $6.191 \mathrm{E}-004$ & 1 & $6.191 \mathrm{E}-004$ & & \\
\hline Model & 0.055 & 6 & $9.122 \mathrm{E}-003$ & 1510.35 & $<0.0001$ \\
\hline A-A-o-A & 0.020 & 1 & 0.020 & 3265.32 & $<0.0001$ \\
\hline B-Velocity & 0.013 & 1 & 0.013 & 2131.57 & $<0.0001$ \\
\hline C-L1 & 0.020 & 1 & 0.020 & 3284.61 & $<0.0001$ \\
\hline BC & $7.002 \mathrm{E}-004$ & 1 & $7.002 \mathrm{E}-004$ & 115.93 & $<0.0001$ \\
\hline $\mathrm{A}^{2}$ & $6.676 \mathrm{E}-004$ & 1 & $6.676 \mathrm{E}-004$ & 110.55 & $<0.0001$ \\
\hline $\mathrm{B}^{2}$ & $7.926 \mathrm{E}-005$ & 1 & $7.926 \mathrm{E}-005$ & 13.12 & 0.0010 \\
\hline Residual & $1.933 \mathrm{E}-004$ & 32 & $6.039 \mathrm{E}-006$ & & \\
\hline Lack of Fit & $1.834 \mathrm{E}-004$ & 22 & $8.335 \mathrm{E}-006$ & & 8.42 \\
\hline Pure Error & $9.903 \mathrm{E}-006$ & 10 & $9.903 \mathrm{E}-007$ & & 0.0007 \\
\hline Cor Total & 0.056 & 39 & & & \\
\hline
\end{tabular}

Table 28. ANOVA for wing-tip-propellers-alone $\mathrm{C}_{\mathrm{A}}$

The fit statistics are seen in Table 29.

\begin{tabular}{|l|r|l|r|}
\hline Std. Dev. & $2.458 \mathrm{E}-003$ & R-Squared & 0.9965 \\
\hline Mean & -0.062 & Adj R-Squared & 0.9958 \\
\hline C.V. \% & 3.99 & Pred R-Squared & 0.9930 \\
\hline PRESS & $3.839 \mathrm{E}-004$ & Adeq Precision & 203.174 \\
\hline
\end{tabular}

Table 29. Fit Statistics for wing-tip-propellers-alone $C_{A}$

Residual diagnostic results are shown in Figure 52. While some residuals were seen near limits, no problems were cited from the inclusion of all data in the model build. 


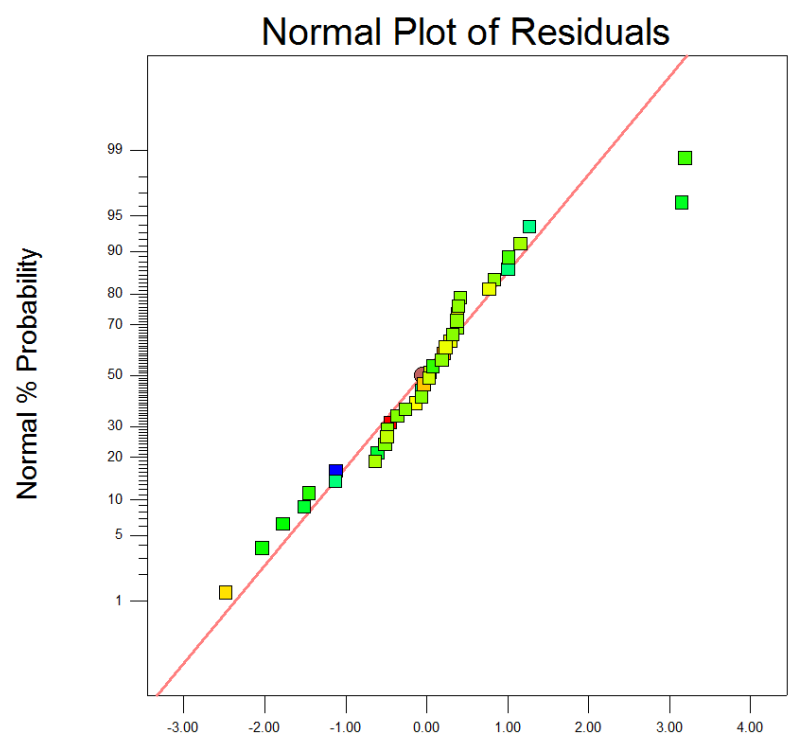

Externally Studentized Residuals

(a)

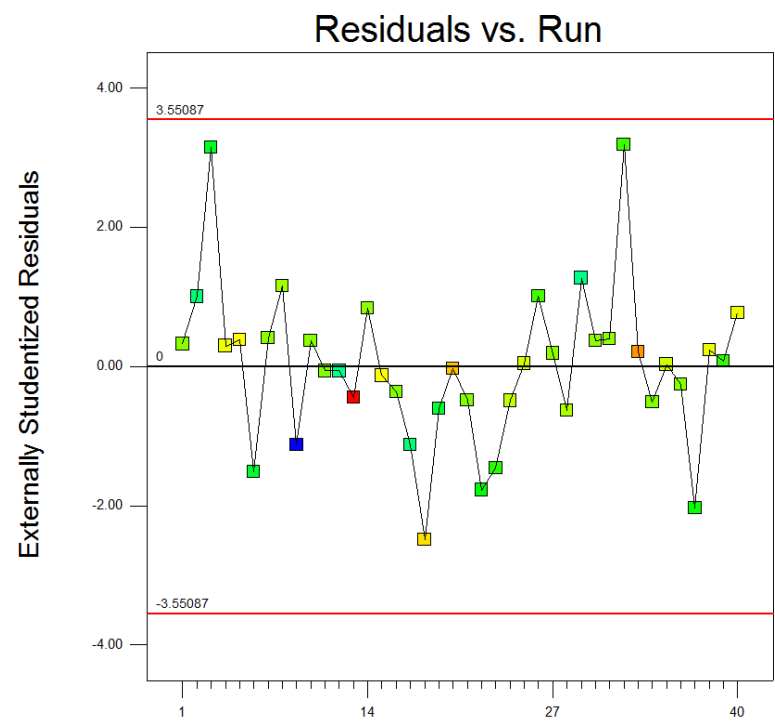

Run Number

(b)

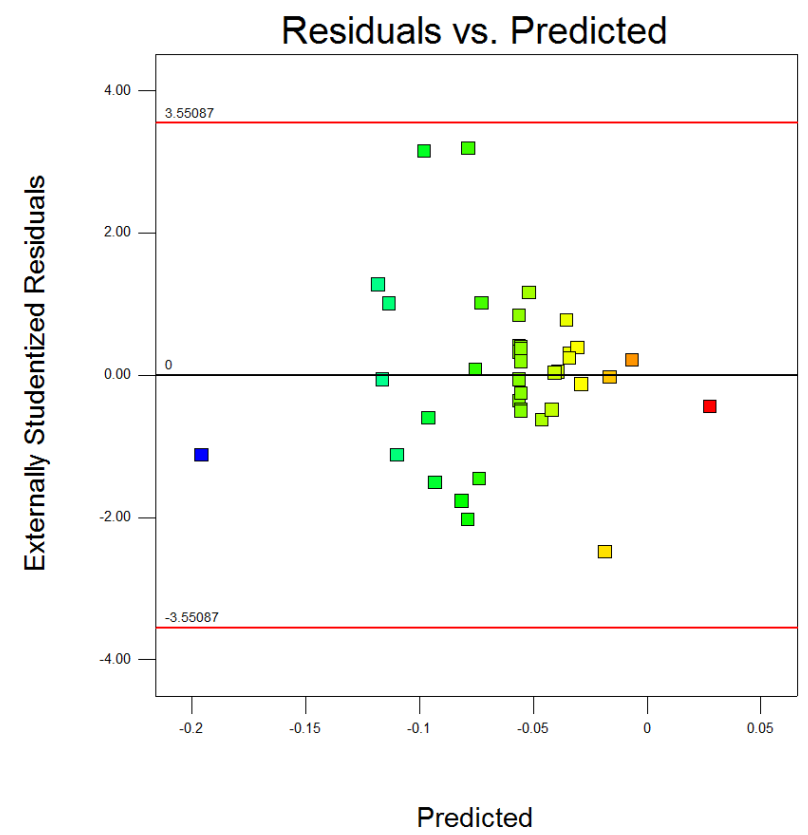

(c)

Figure 52. (a) Normality (b) Independence (c) Constant variance for wing-tip-propellers $C_{A}$

The model term coefficients for second order response surface is illustrated in Table 30 . 


\begin{tabular}{|l|r|}
\hline Factor & $\begin{array}{r}\text { Coefficient } \\
\text { Estimate }\end{array}$ \\
\hline Intercept & 0.22170 \\
\hline $\mathrm{A}-\mathrm{A}-\mathrm{O}-\mathrm{A}$ & $-2.92348 \mathrm{E}-003$ \\
\hline $\mathrm{B}-$ Velocity & 0.049418 \\
\hline $\mathrm{C}-\mathrm{L} 1$ & $-8.10142 \mathrm{E}-005$ \\
\hline $\mathrm{BC}$ & $6.05069 \mathrm{E}-006$ \\
\hline $\mathrm{A}^{2}$ & $-8.75809 \mathrm{E}-004$ \\
\hline $\mathrm{B}^{2}$ & $-4.82829 \mathrm{E}-003$ \\
\hline
\end{tabular}

Table 30. Model term coefficients for wing-tip-propellers-alone $\mathrm{C}_{\mathrm{A}}$

The final equation in terms of actual factors is given.

$$
\begin{aligned}
C_{A} & =0.22170-2.92348 * 10^{-3} * A+0.049418 * B \\
& -8.10142 * 10^{-5} * C+6.05069 * 10^{-6} * B * C-8.75809 * 10^{-4} * A^{2}-4.82829 * 10^{-3} * B^{2}
\end{aligned}
$$

The response surface plots for minimum and maximum angle-of-attack levels (0-8) are shown in Figures 53 and 54.
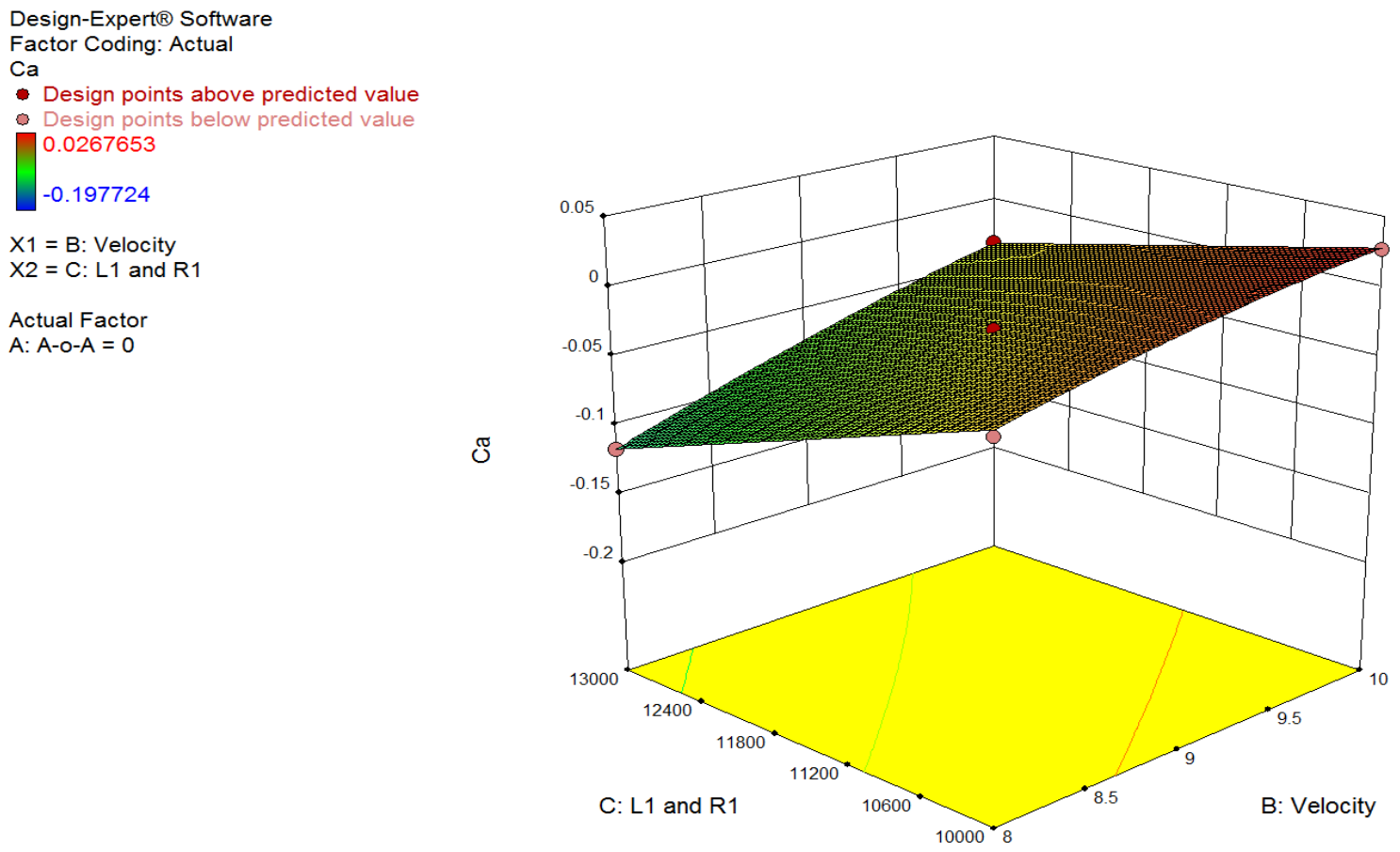

Figure 53. Response surface for wing-tip-propellers-alone $\mathrm{C}_{\mathrm{A}}$ at zero angle of attack 
Design-Expert $\circledast$ Software

Factor Coding: Actual

$\mathrm{Ca}$

- Design points above predicted value

Design points below predicted value

0.0267653

$-0.197724$

$\mathrm{X} 1=\mathrm{B}:$ Velocity

$\mathrm{X} 2=\mathrm{C}: \mathrm{L} 1$ and $\mathrm{R} 1$

Actual Factor

A: $A-0-A=8$

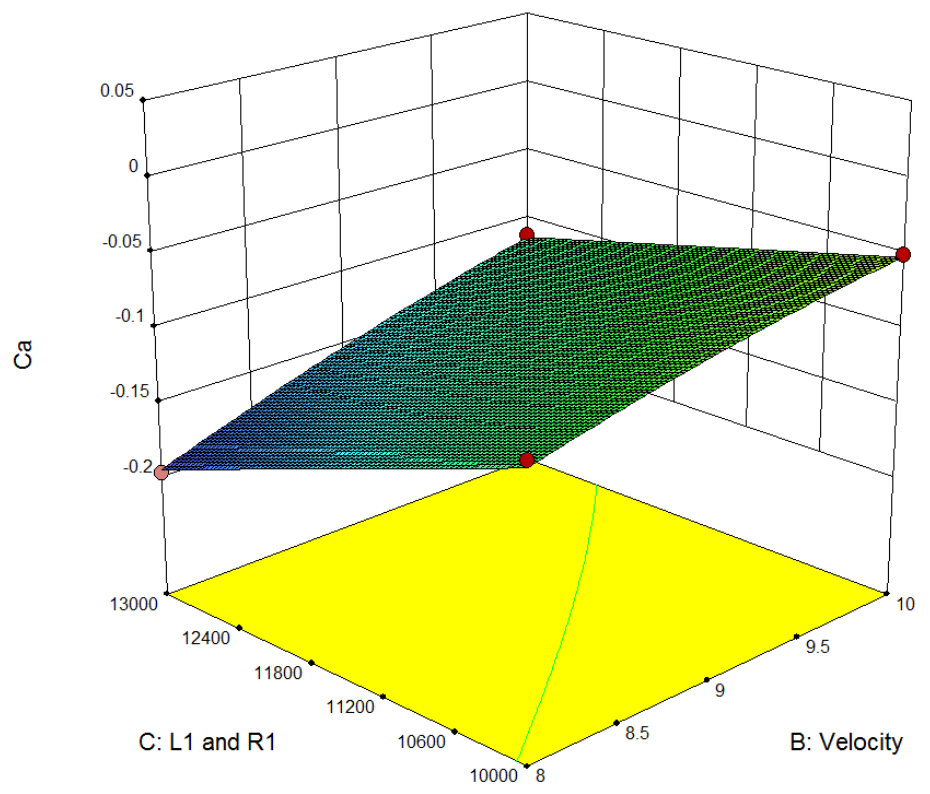

Figure 54. Response surface for wing-tip-propellers-alone $\mathrm{C}_{\mathrm{A}}$ at eight angle of attack

Although the $\mathrm{C}_{\mathrm{N}}$ model has no interaction term with $\mathrm{L} 1$ and $\mathrm{R} 1$, the $\mathrm{C}_{\mathrm{A}}$ model has a significant interaction term between velocity and $\mathrm{L} 1$ and $\mathrm{R} 1$, which is expected due to the induced drag reduction. 

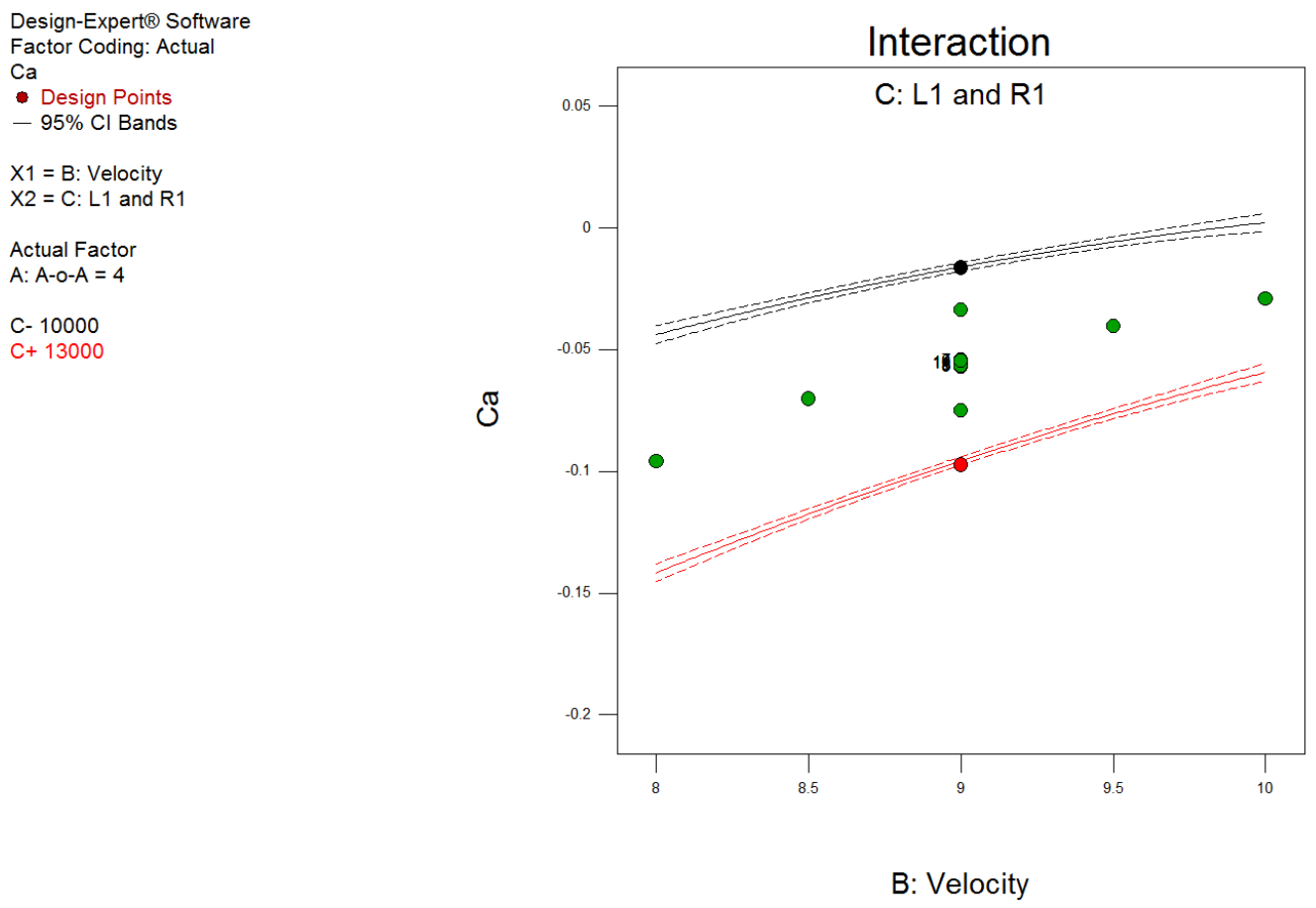

Figure $55 . \mathrm{C}_{\mathrm{A}}$ as a function of velocity and L1 and R1 for wing-tip-propellers-alone mode

The results of the confirmation point measurements are shown in Table 31. All confirmation point results fell into the $95 \%$ prediction interval. Thus, the model adequately represents the observed data.

\begin{tabular}{|c|c|c|c|c|c|}
\hline Run & & 95\%PI Low & Predicted & Measured & 95\%PI High \\
\hline $\mathbf{1}$ & & -0.068 & -0.062 & -0.061 & -0.056 \\
$\mathbf{2}$ & & -0.057 & -0.051 & -0.052 & -0.046 \\
$\mathbf{3}$ & \multirow{3}{*}{$\mathbf{C}_{\mathbf{A}}$} & -0.138 & -0.132 & -0.131 & -0.126 \\
$\mathbf{4}$ & & -0.071 & -0.066 & -0.062 & -0.061 \\
$\mathbf{5}$ & & -0.071 & -0.066 & -0.066 & -0.060 \\
$\mathbf{6}$ & & -0.097 & -0.091 & -0.090 & -0.085 \\
\hline
\end{tabular}

Table 31. Prediction capability of the wing-tip-propellers-alone $\mathrm{C}_{\mathrm{A}}$ model

\subsection{Wing-Tip-Propellers-Alone and Two-Inboard-Propellers-Alone Comparison}

Experiments were performed on the wing-tip-propellers-alone and two-inboardpropellers-alone modes to observe the effect of the wing-tip-propellers configuration on induced 
drag at low Reynolds numbers. Data was taken at $9 \mathrm{~m} / \mathrm{s}$ free-stream velocity, $11500 \mathrm{rpm}$ level conditions at specified angles-of-attack (2-4-6-8 degrees) with three replicates. Experimental results show that the wing-tip propellers model had low drag with increasing angle of attack at the low Reynolds number of 86000 , as seen in the figure below (Snyder, 1967).

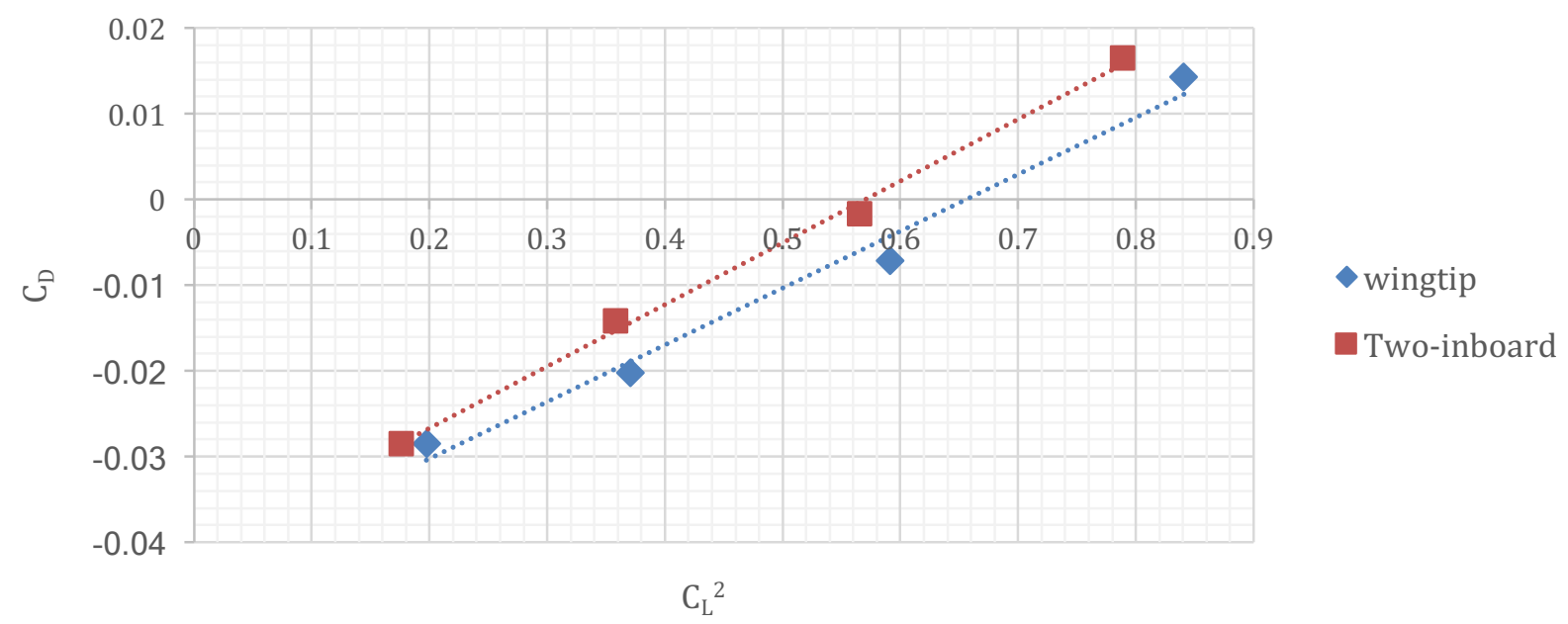

Figure 56. $\mathrm{C}_{\mathrm{D}}$ vs $\mathrm{C}_{\mathrm{L}}^{2}$

Induced drag reduction is separated from total drag by using the equation below (Snyder, 1967),

$$
C_{D}=C_{D_{P}}+m C_{L}^{2}
$$

where $C_{D p}$ is the parasitic drag term, $\mathrm{mC}_{\mathrm{L}}^{2}$ is the induced drag term, and $\mathrm{m}$ is the slope of the $\mathrm{C}_{\mathrm{D}}$ vs $\mathrm{C}_{\mathrm{L}}^{2}$ plots.

$$
m=\frac{d C_{D}}{d C_{L}^{2}}
$$


The induced drag contribution to drag reduction is shown in Figure 57. Although the wingtippropellers mode had lower induced drag with increasing angle of attack, the amount of reduction could be enhanced through the use of larger diameter and optimally designed propellers.

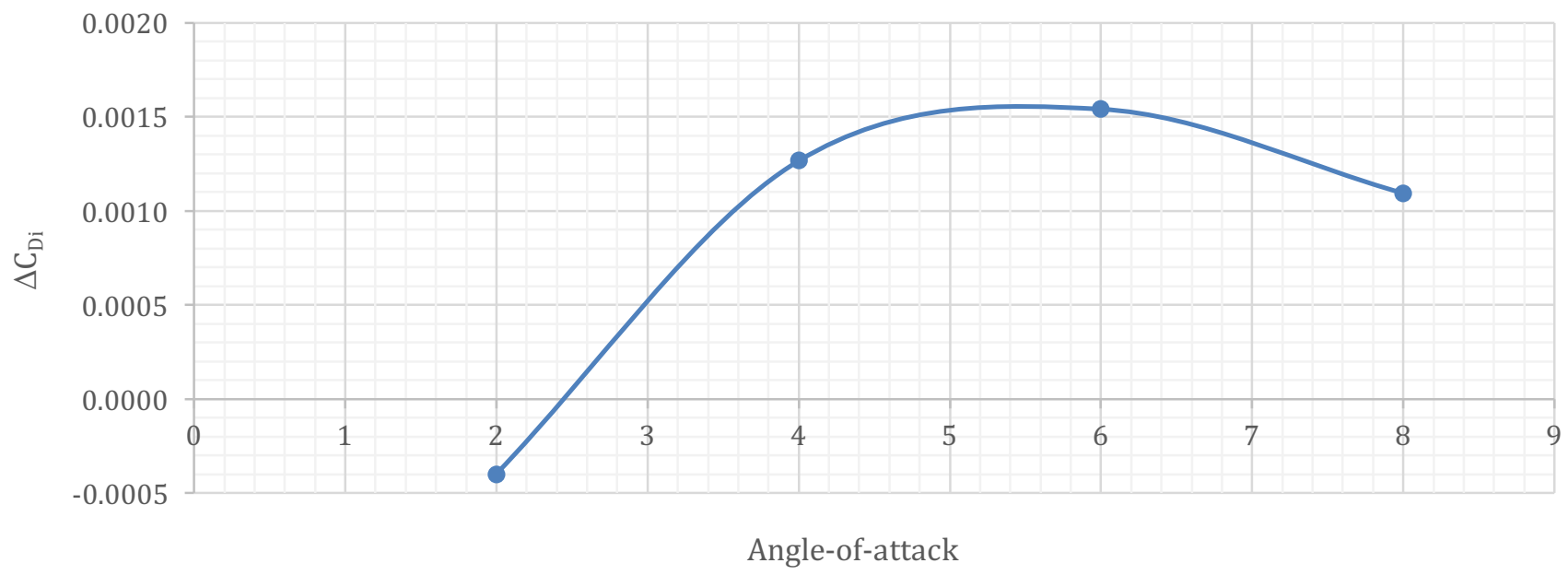

Figure 57. Induced drag difference between two-inboard and wingtip propellers mode

\subsection{Single-Tractor Mode}

The single-tractor mode was analyzed in the VSPAERO vortex lattice code. This software program includes a propeller thrust feature to analyze different propeller-wing combinations. The actuator disk was used for propeller modelling.

Initially, all-propeller-on and wing-alone configurations were analyzed in this program for validation of numerical results with experimental results. The experimentally determined regression models were used to determine the experimental lift coefficient $\left(C_{L}\right)$ changes at $9 \mathrm{~m} / \mathrm{s}$ free-stream velocity, 11500 RPM and 0 - 8 degree angle-of-attack flight conditions. Lift coefficient vs. angle of attack was compared. Experimental and computational results demonstrated close agreement and identical trends. 
Computational models and experimental results comparison are shown in the figures below.

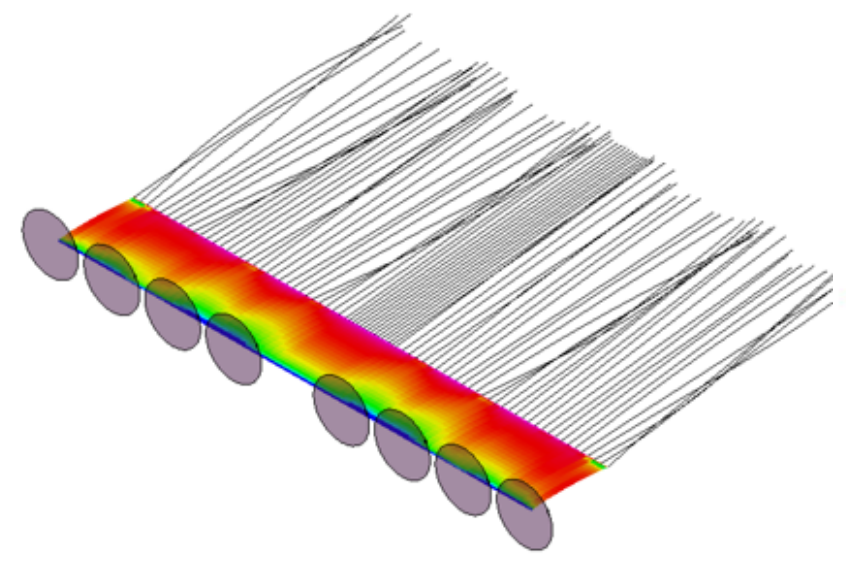

(a)

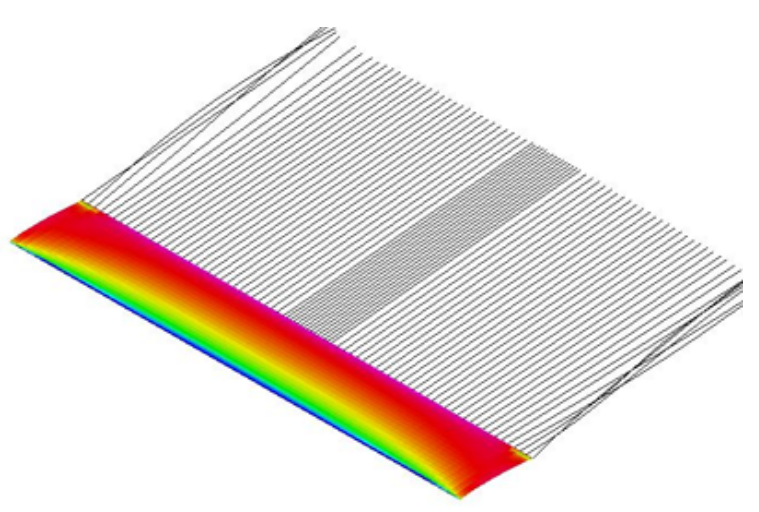

(b)

Figure 58. VSPAERO models (a) distributed propulsion (b) wing-alone

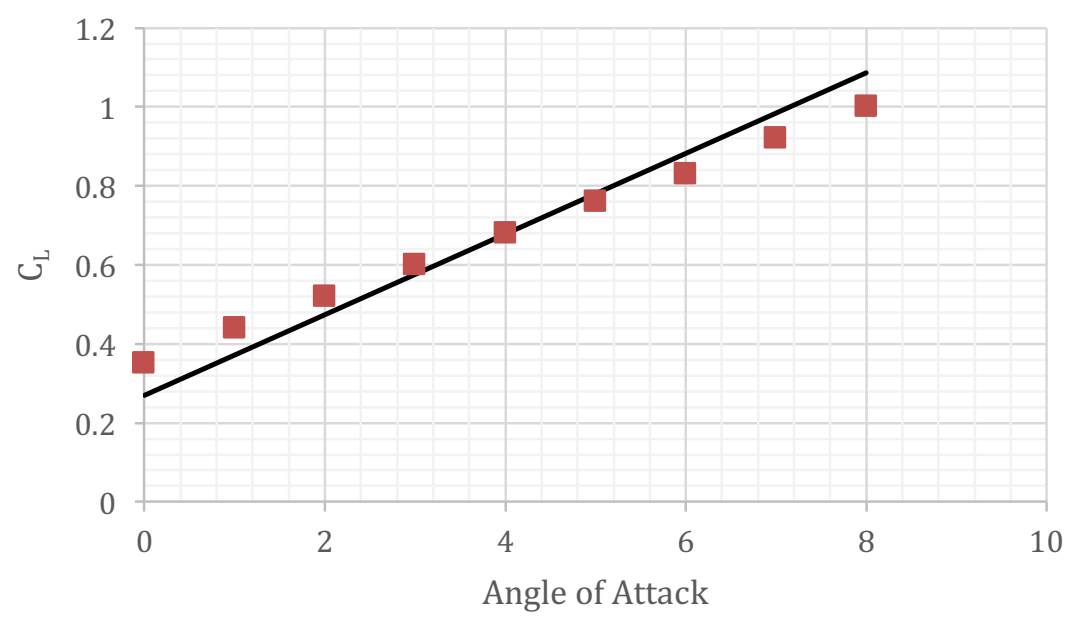

all-propellers-on experimental
regression model

- all-propellers-on VSPAERO

Figure 59. Distributed propulsion VSPAERO and experimental results 


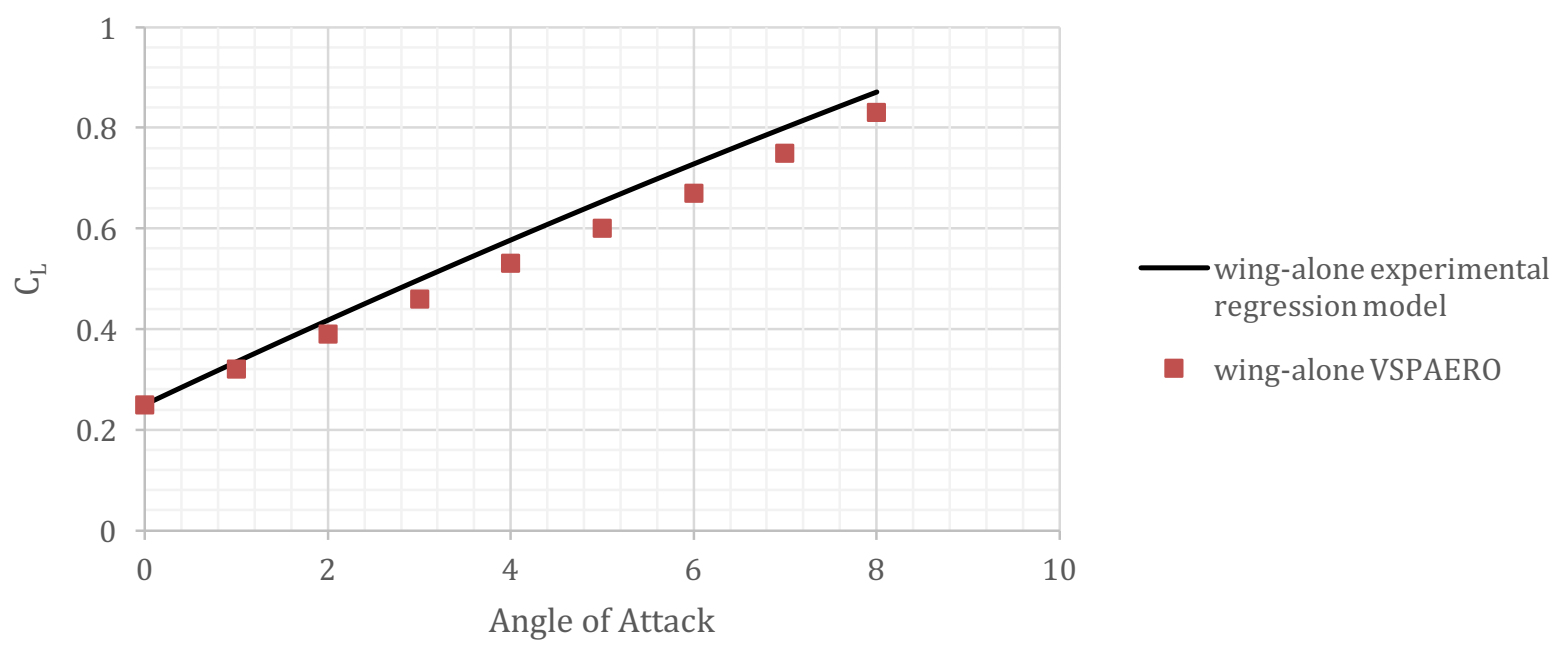

Figure 60. Wing-alone VSPAERO and experimental results

Thrust equality (to the distributed counterpart) was considered for the single-tractor model design at identical flight conditions for each mode of the wind tunnel experiments. Therefore, a GWS $9.0 \times 5.0$ propeller was chosen from the University of Illinois at Urbana Champaign Propeller Data Base (Deters et al., 2014). The propeller was then modelled with a 9inch diameter and 0.04 thrust coefficient at $9 \mathrm{~m} / \mathrm{s}$ free stream velocity in VSPAERO, as shown in Figure 60. Computational results demonstrated close agreement and identical trends with the wing-alone-mode experimental results, as is illustrated in Figure 61. This result supports the use of the wing-alone mode experimental results as a single-tractor mode for making a trade-study between distributed propulsion and single-tractor propulsion concepts. 


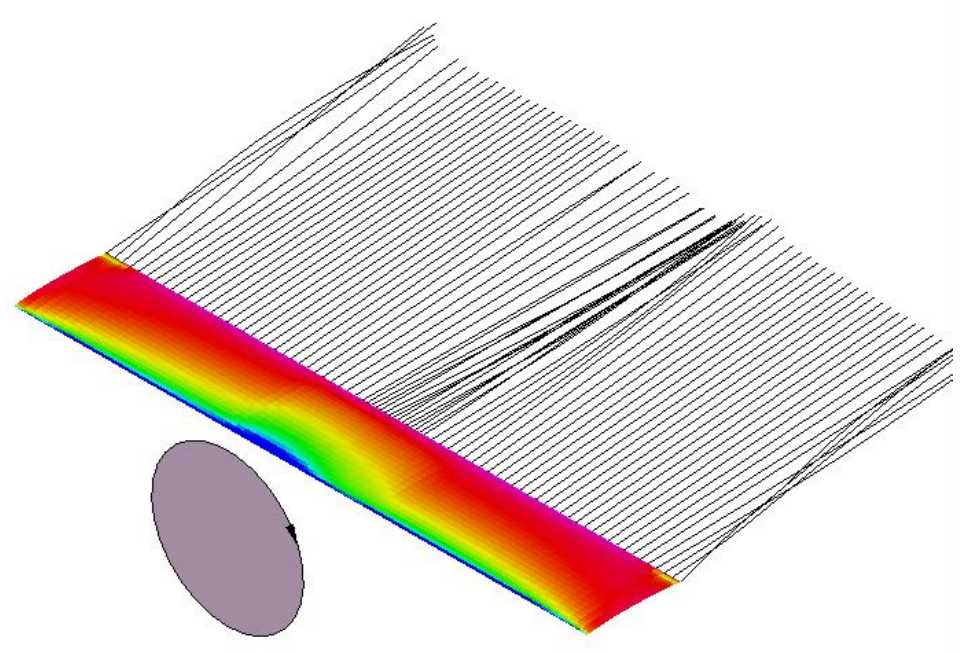

Figure 61. VSPAERO single-tractor

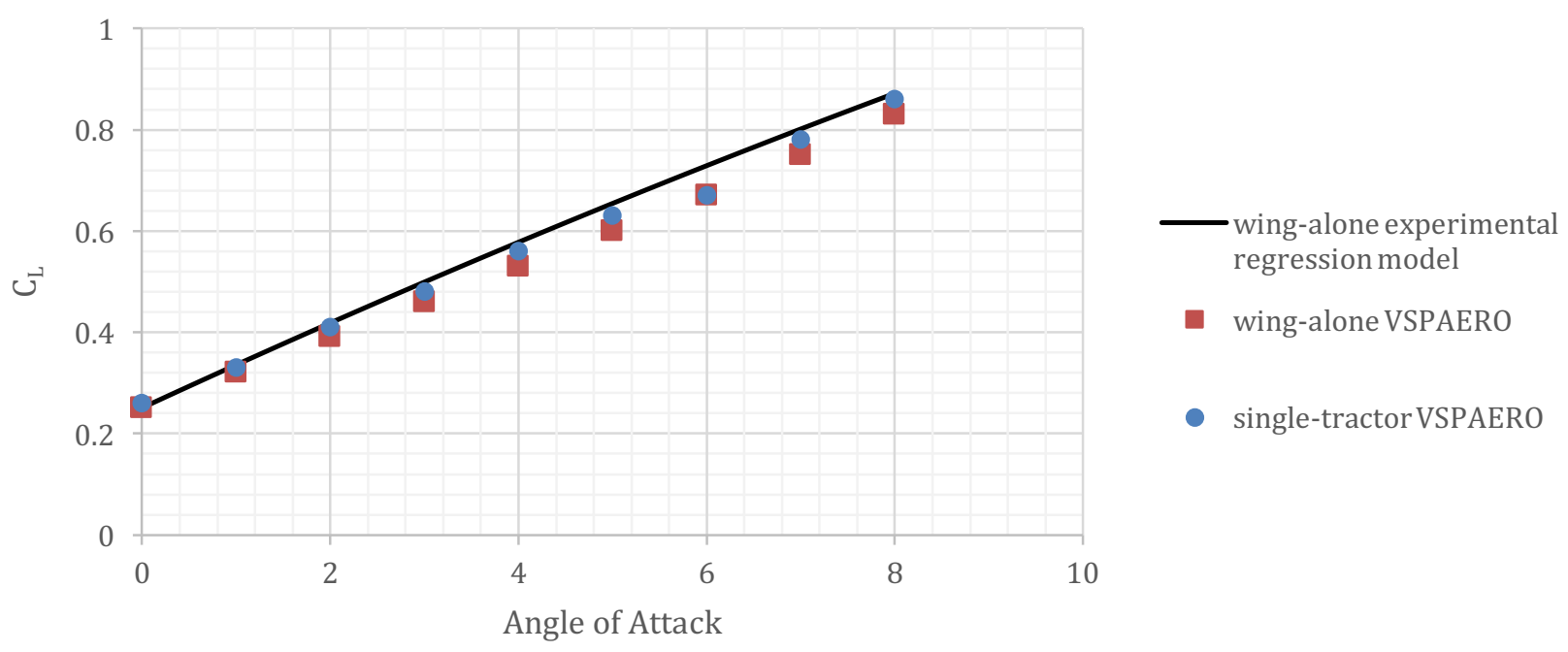

Figure 62. Experimental and VSPAERO results for wing-alone and single-tractor Experimental results were corrected based on Barlow et al. (1999) as illustrated in the Appendix. 


\section{CHAPTER 6}

\section{TRADE STUDY}

An initial trade study between distributed propulsion and single-tractor concepts was based on the relationship between normal force increment $\left(\Delta \mathrm{C}_{\mathrm{N}}\right)$ due to using distributed propulsion (over single tractor) and weight penalty.

The normal force coefficient increment between these concepts is shown in the tables below for take-off (all-propellers-on vs. single-tractor) and cruise (wing-tip-propellers-alone vs. single-tractor) modes at the maximum RPM level.

\begin{tabular}{|c|c|c|}
\hline \multicolumn{3}{|c|}{$\Delta \mathbf{C}_{\mathbf{N}}$ Take-Off } \\
\hline $\boldsymbol{\Delta}_{\mathbf{N}}$ & $\mathbf{A - o - A}$ & Velocity \\
\hline 0.068 & 0 & 8 \\
0.162 & 4 & 8 \\
0.290 & 8 & 8 \\
\hline 0.045 & 0 & 9 \\
0.120 & 4 & 9 \\
0.230 & 8 & 9 \\
\hline 0.022 & 0 & 10 \\
0.079 & 4 & 10 \\
0.170 & 8 & 10 \\
\hline
\end{tabular}

Table 32. $\mathrm{C}_{\mathrm{N}}$ increment for take-off

\begin{tabular}{|c|c|c|}
\hline \multicolumn{3}{|c|}{$\Delta \mathbf{C}_{\boldsymbol{N}}$ Cruise } \\
\hline $\boldsymbol{\Delta} \mathbf{C}_{\mathbf{N}}$ & A-o-A & Velocity \\
\hline 0.026 & 0 & 8 \\
0.046 & 4 & 8 \\
0.073 & 8 & 8 \\
\hline 0.023 & 0 & 9 \\
0.037 & 4 & 9 \\
0.058 & 8 & 9 \\
\hline 0.020 & 0 & 10 \\
0.028 & 4 & 10 \\
0.042 & 8 & 10 \\
\hline
\end{tabular}

Table 33. $\mathrm{C}_{\mathrm{N}}$ increment for cruise 
Although the distributed propulsion system has higher normal force for each flight mode, as seen above, the weight penalty vs. normal force was investigated in this study to draw a fair conclusion about the benefits of a distributed propulsion system. The weight of components for both modes is illustrated in Tables 34 and 35 . While this accounting is for this specific model, it is felt to be representative and, most likely, conservative.

\begin{tabular}{|l|l|}
\hline \multicolumn{2}{|c|}{ Distributed Electric Propulsion } \\
\hline 8 motors (Medusa MR-012-030-4000) & $112 \mathrm{~g}$ \\
\hline 8 propellers (GWS 4.0x2.5) & $12 \mathrm{~g}$ \\
\hline 8 ESC & $64 \mathrm{~g}$ \\
\hline 8 prop-adapters & $12 \mathrm{~g}$ \\
\hline 8 motor mounts & $40 \mathrm{~g}$ \\
\hline Wing core & $340 \mathrm{~g}$ \\
\hline Total Weight & $\mathbf{5 8 0} \mathbf{g}$ \\
\hline
\end{tabular}

Table 34. Distributed propulsion total weight

\begin{tabular}{|l|l|}
\hline \multicolumn{2}{|c|}{ Single-Tractor Propulsion } \\
\hline 1 motor (Astro 020 Planetary System 803P) & $122 \mathrm{~g}$ \\
\hline 1 propeller (GWS 9.0x5.0) & $10 \mathrm{~g}$ \\
\hline 1 ESC & $17 \mathrm{~g}$ \\
\hline 1 prop-adapter & $6.7 \mathrm{~g}$ \\
\hline Wing core & $348 \mathrm{~g}$ \\
\hline Total Weight & $\mathbf{5 0 3 . 7} \mathbf{g}$ \\
\hline
\end{tabular}

Table 35. Single-tractor propulsion total weight

Due to the high number of components, the distributed electric propulsion system is heavier than the single-tractor propulsion system. Also, wiring weight was assumed to be the same for both models. To make a comparison between these concepts, the normal force $(\mathrm{N})$ value was calculated for different wing chord based Reynolds numbers at different angles-ofattack and maximum RPM. Then, the ratio of normal force and total weight was plotted versus angle of attack for take-off/landing and cruise modes, as seen in Figures 62 and 63. 


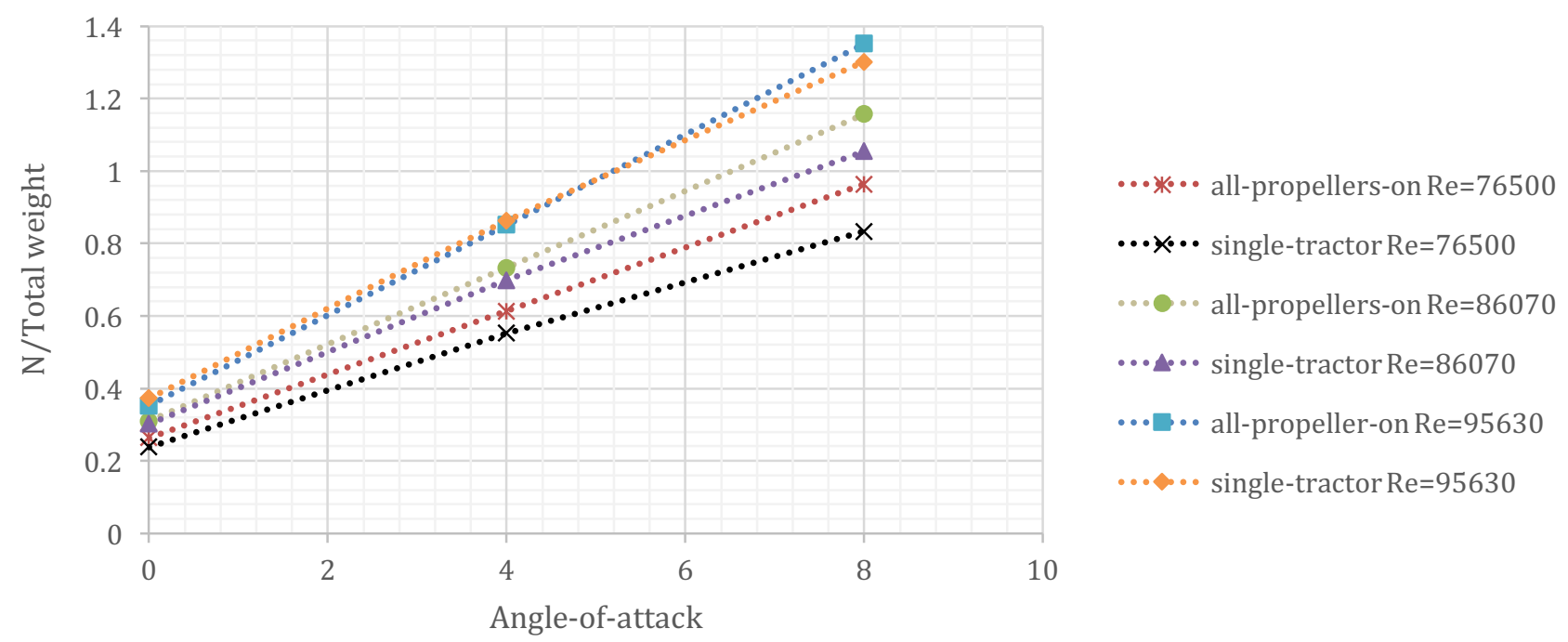

Figure 63. Weight effect on take-off configurations

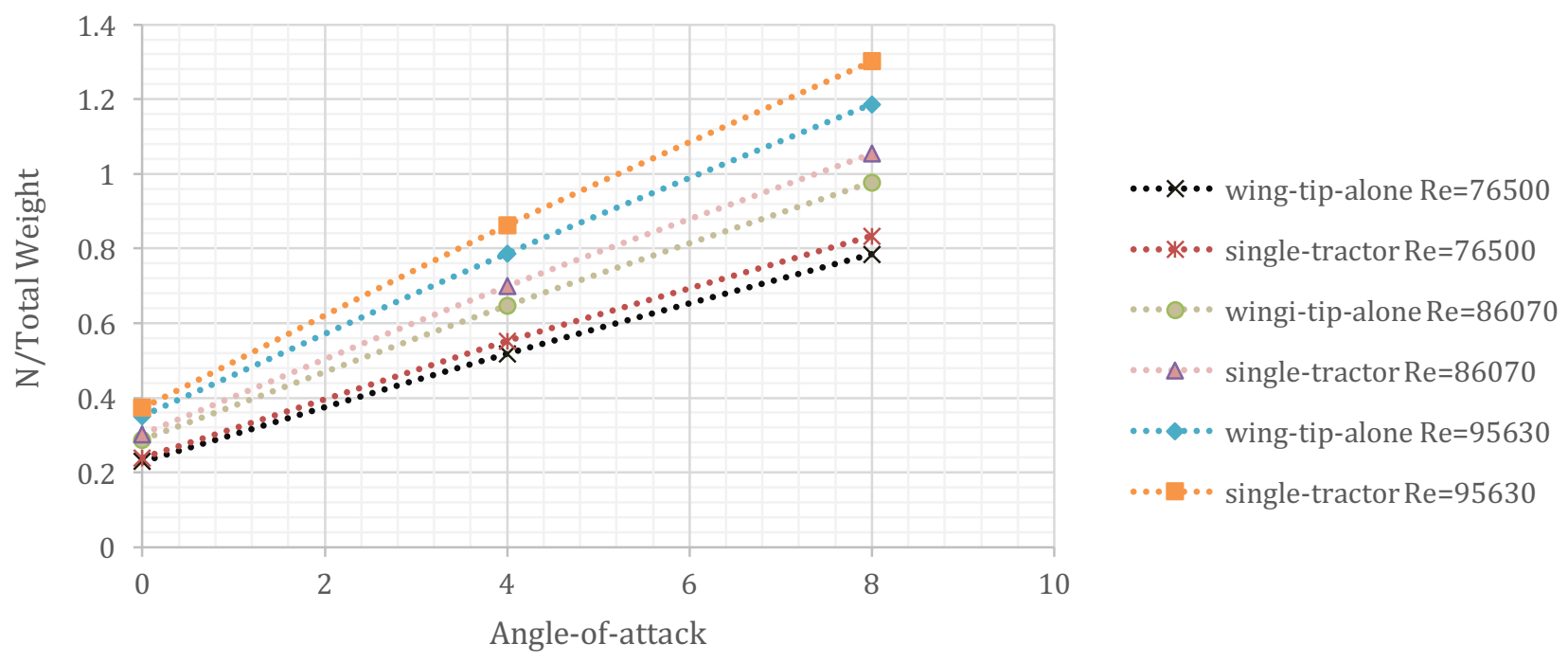

Figure 64. Weight effect on cruise configurations

Results show that distributed propulsion system had a higher normal force to total weight ratio value with increasing angle-of-attack at each Reynolds number for the take-off mode. This ratio difference was reduced with increasing Reynolds numbers. The single-tractor propulsion 
system had a higher normal force to total weight ratio value at each Reynolds number for the cruise mode. This ratio difference increased with increasing Reynolds numbers. These results suggest that larger propellers should be used at the wing-tips (Patterson, 2016) and that the normal force to total weight ratio value increased with increasing Reynolds numbers at each flight mode.

Range and endurance performance were compared based on the Breguet equations developed for electric aircraft (Patterson, German, \& Moore, 2012). Range and endurance equations are shown in equations (53) and (54).

$$
\begin{gathered}
\text { Range }=\eta \frac{L}{D} \frac{W_{\text {bat }}}{W} \frac{u k}{g} \\
\text { Endurance }=\frac{\eta}{V} \frac{L}{D} \frac{W_{\text {bat }}}{W} \frac{u k}{g}
\end{gathered}
$$

where $\mathrm{W}_{\text {bat }}$ is a weight of batteries, $\mathrm{W}$ is a total weight, $\mathrm{u}$ is a battery energy density, $\mathrm{k}$ is a measure of the percent charge of the batteries, $g$ is a center of gravity for constant acceleration, $\eta$ is an overall efficiency of motor-propeller combination and L/D is a lift and drag ratio. Experimental lift and drag force values were used to compute the L/D ratio for both configurations. Wing-alone mode lift values were used for single-tractor mode as explained in section 5.6. Also, drag was assumed same for both modes, whichwas experimental wing-alone drag. The L/D ratios are plotted (all-propellers-on mode vs. single tractor) in Figures 65-67 at different Re numbers. 


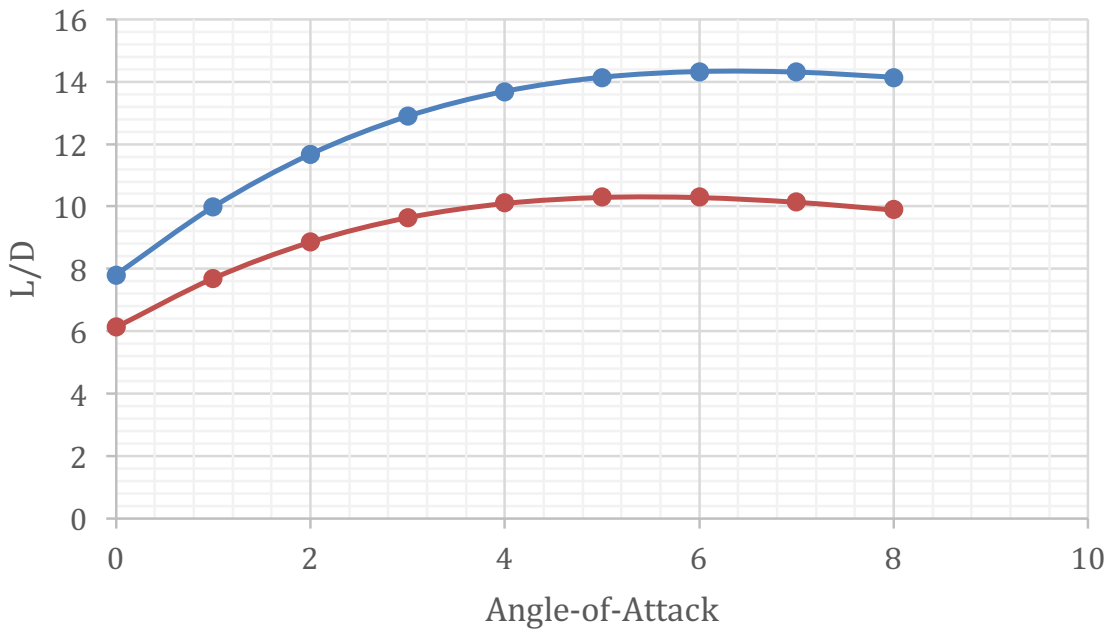

Figure 65. $\mathrm{L} / \mathrm{D} \mathrm{Re}=76500$

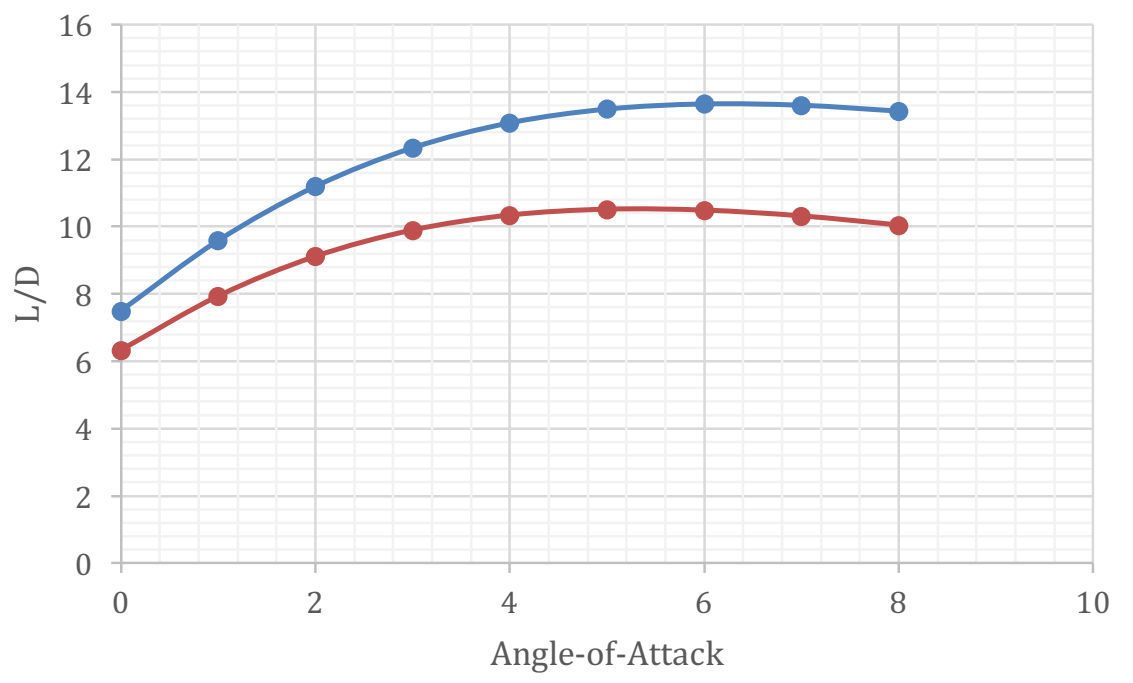

$\longrightarrow$ dist.prop. $\mathrm{Re}=86070$

$\multimap$ single-trcator $\mathrm{Re}=86070$

Figure 66. $\mathrm{L} / \mathrm{D} \mathrm{Re}=86070$ 


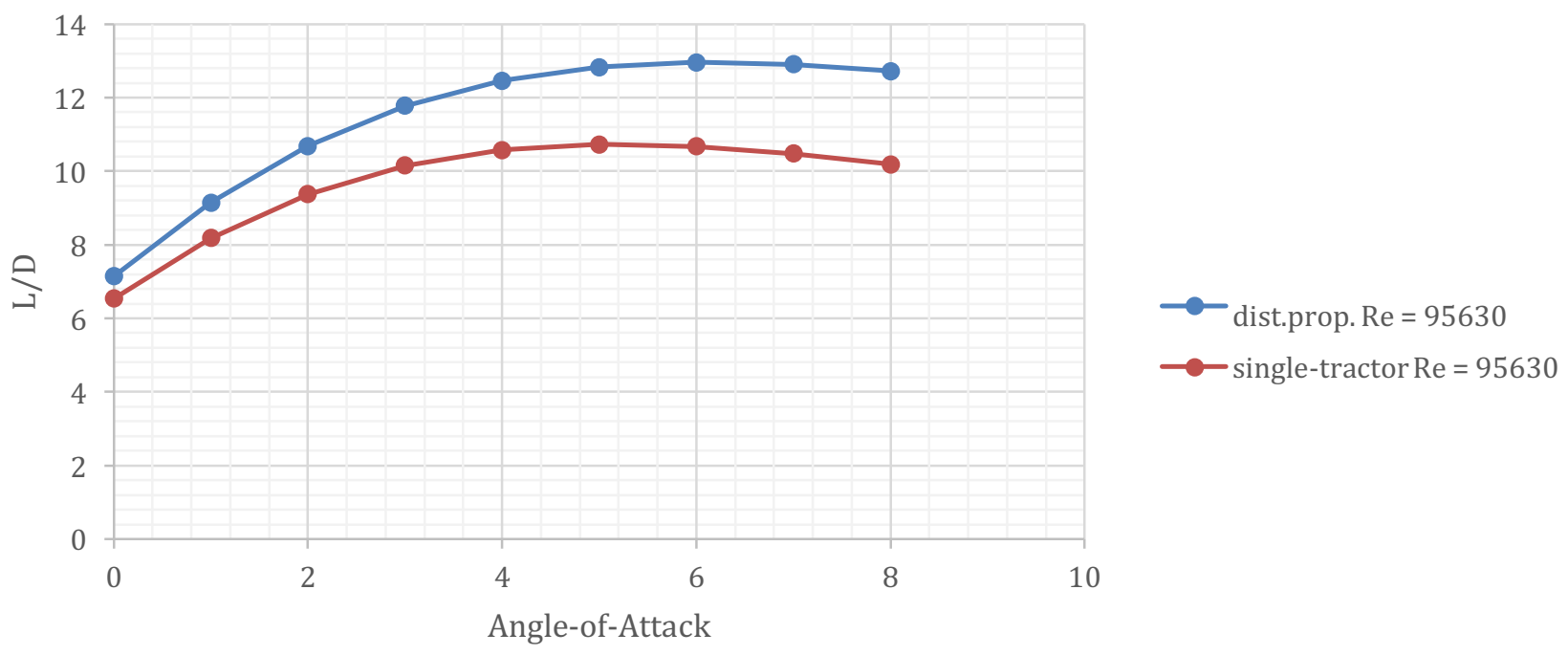

Figure 67. $\mathrm{L} / \mathrm{D} \mathrm{Re}=95630$

Also, $\eta$ was calculated based on motor-propeller efficiency (Deters et al., 2014) at different velocities as shown in Table 36. Propeller efficiency was based on thrust to power ratio and electrical efficiency was based on efficiency of the batteries, motor controller and motor (Patterson et al., 2012). Electrical efficiency was assumed to be the same for both aircraft configurations.

$$
\eta=\eta_{\text {prop }} \eta_{\text {elec }}
$$

\begin{tabular}{|c|c|c|c|c|c|c|}
\hline \multirow{2}{*}{} & \multicolumn{3}{|c|}{ Distributed Propulsion } & \multicolumn{3}{c|}{ Single Tractor } \\
\cline { 2 - 7 } & $\mathbf{V}=\mathbf{8} \mathbf{~ m} / \mathbf{s}$ & $\mathbf{V}=\mathbf{9} \mathbf{~ m} / \mathbf{s}$ & $\mathbf{V}=\mathbf{1 0} \mathbf{~ m} / \mathbf{s}$ & $\mathbf{V}=\mathbf{8} \mathbf{~ m} / \mathbf{s}$ & $\mathbf{V}=\mathbf{9} \mathbf{~ m} / \mathbf{s}$ & $\mathbf{V}=\mathbf{1 0} \mathbf{~ m} / \mathbf{s}$ \\
\hline$\eta$ & 0.56 & 0.6 & 0.58 & 0.51 & 0.56 & 0.6 \\
\hline
\end{tabular}

Table 36. Overall efficiency

The same battery specifications were used for both configurations. 
Finally, range and endurance results were plotted at three different constant velocities and at an angle of attack of three degrees.

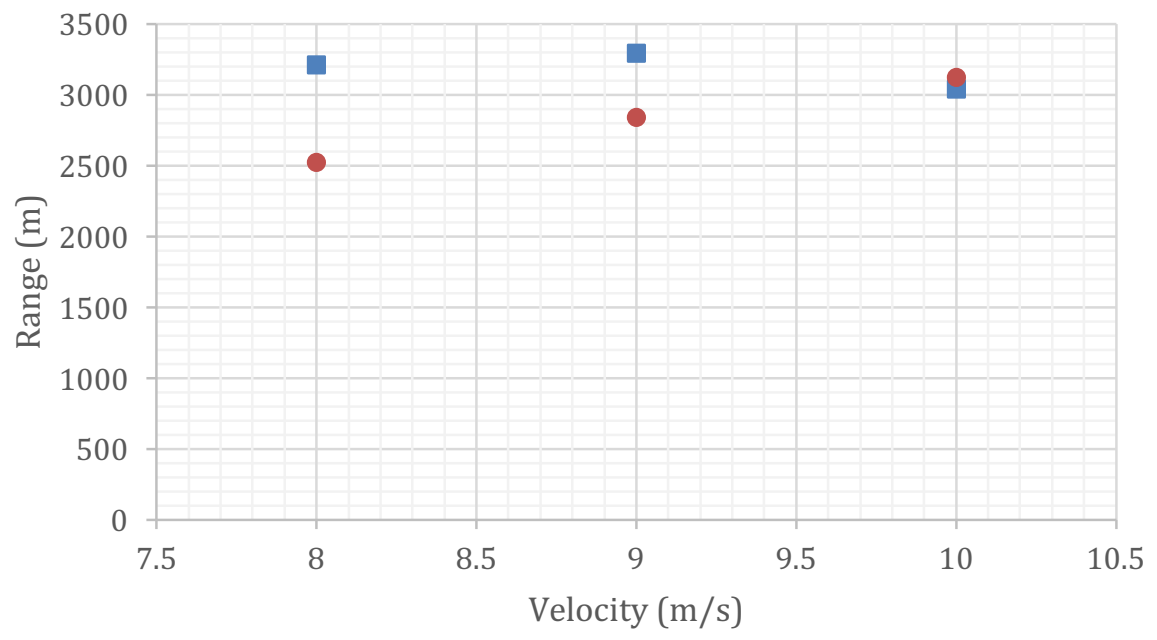

distributed propulsion

- single-tractor

Figure 68. Range

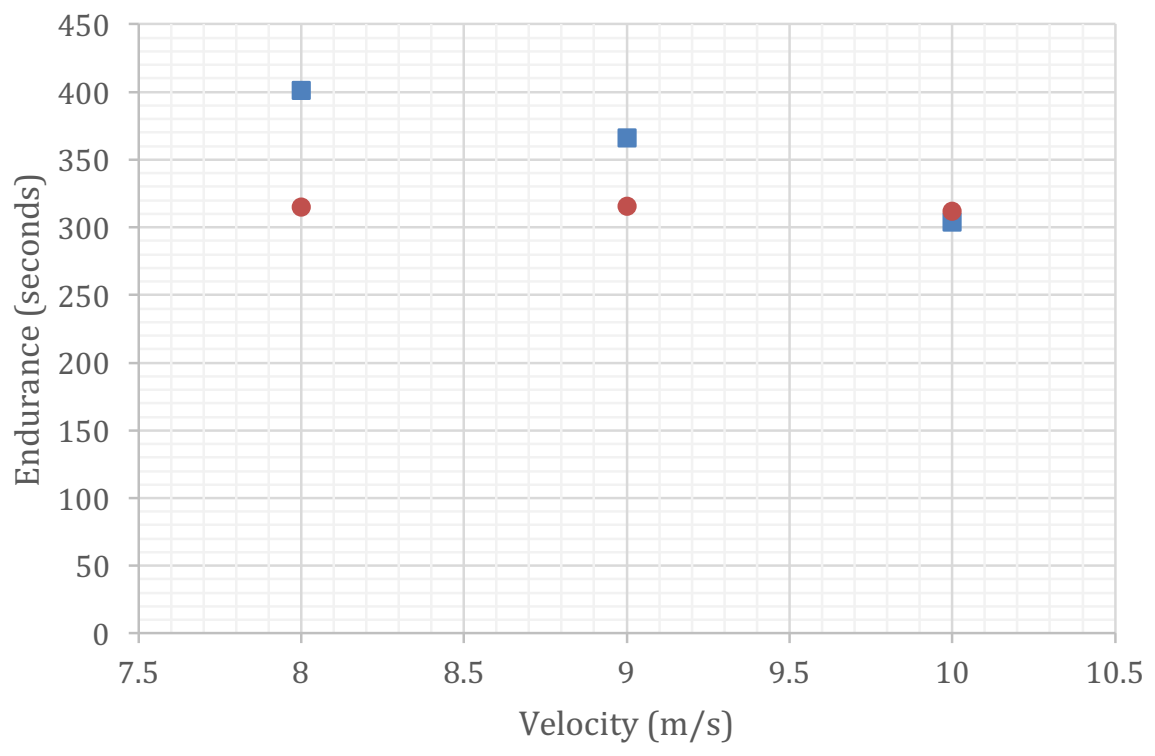

distributed propulsion

- single-tractor

Figure 69. Endurance 


\section{CHAPTER 7}

\section{CONCLUSIONS}

The aerodynamic comparison of a distributed propulsion system and single-tractor propulsion system at low Reynolds numbers was evaluated in this study. Experiments were conducted with DOE methodology for aerodynamic characterization. Additionally, VSPAERO vortex lattice code was used for trade studies. Results demonstrated the potential benefits of the distributed propulsion system at low Reynolds numbers.

The normal force increment and reduction in induced drag was demonstrated as the primary gain afforded due to using a distributed propulsion system. Compared to a single tractor propeller system, assuming that both propulsion systems have equivalent thrust, the distributed propulsion system showed a higher $\mathrm{C}_{\mathrm{N}}$ value, presumably due to the higher local dynamic pressure around the wing in the propeller wake. Low chord Reynolds numbers were raised locally due to the increased velocity, which should have provided a further benefit. Wing-tip propellers were shown to reduce induced drag by opposing the wing tip vortex circumferential velocity direction (Miranda \& Brennan, 1986). The distributed propulsion system had better range and endurance performance due to the higher L/D ratio when based on the same available power.

The weight penalty appeared to be the main disadvantage for the distributed propulsion system used in this research. However, the specific distributed propulsion system was constructed from off-the-shelf hobby-grade components that were not optimized. Therefore, lightweight materials are recommended in future work. Next, the propellers were not specifically designed for high lift (inboard) or cruise (tip). Large propellers can be used at the 
wing tips to provide better aerodynamic performance in the cruise mode (Patterson, 2016). High-lift propellers can be designed for maximum circulation (Patterson, 2016). Additionally, optimal placement of the propellers' position/size and adjacent spacing is a subject for future experiments. The small scale of the model dictated the use of relatively low performance hobby propellers. Also, wing area reduction has been successfully demonstrated in larger scale and could be considered in future small UAV designs to provide important weight and drag reduction (Stoll, Bevirt, Moore, et al., 2014). Despite significant progress in understanding of distributed propulsion aerodynamics, the distributed electric propulsion technology will be more valuable when matched with future battery technology improvements. 


\section{REFERENCES}

Bagai, A. (2016). Vertical takeoff and landing experimental plane (VTOL X-Plane). Retrieved from http://www.darpa.mil/program/vertical-takeoff-and-landing-experimental-plane

Barlow, J. B., Rae, W. H., \& Pope, A. (1999). Low-speed wind tunnel testing (3th ed.). New Jersey, NJ: John Wiley \& Sons Inc.

Barnstorff, K. (2015). Future aircraft. Retrieved from http://www.nasa.gov/langley/ten-engineelectric-plane-completes-successful-flight-test

Borer, N. K., Patterson, M. D., Viken, J. K., Moore, M. D., Clarke, S., Redifer, M. E., ... Osterkamp, P. G. (2016). Design and performance of the NASA SCEPTOR distributed electric propulsion flight demonstrator. In 16th AIAA Aviation Technology, Integration, and Operations Conference.

Box, G. E. P., \& Wilson, K. B. (1951). On the experimental attainment of optimum condition. Journal of the Royal Statistical Society, 13, 1-45

Coleman, H. W., \& Steele, W. G. (2009). Experimentation, validation, and uncertainty analysis for engineers (3rd ed.). New Jersey, NJ: John Wiley \& Sons Inc.

Deters, R. W., Ananda, G. K., \& Selig, M. S. (2014). Reynolds number effects on the performance of small-scale propellers. In 32nd AIAA Applied Aerodynamics Conference, American.

Deters, R. W., \& Selig, M. S. (2008). Static testing of micro propellers. In 26th AIAA Applied Aerodynamics Conference.

Dubois, A., van der Geest, M., Bevirt, J., Clarke, S., Christie, R. J., \& Borer, N. K. (2016). Design of an electric propulsion system for SCEPTOR's outboard nacelle. In 16th AIAA Aviation Technology, Integration, and Operations Conference. 
Fisher, R. A. (1935). The Design of Experiments (1st ed.). New York, NY: Hafner Publishing Company.

Gohardani, A. S. (2013). A synergistic glance at the prospects of distributed propulsion technology and the electric aircraft concept for future unmanned air vehicles and commercial/military aviation. Progress in Aerospace Sciences, 57, 25-70.

Gohardani, A. S., Doulgeris, G., \& Singh, R. (2011). Challenges of future aircraft propulsion: A review of distributed propulsion technology and its potential application for the allelectric commercial aircraft. Progress in Aerospace Sciences, 47(5), 369-391.

Jane's All The World's Aircraft Homepage (2016). All sections search engine. Retrieved from www.janes.com

Ko, Y.-Y. A. (2003). The multidisciplinary design optimization of a distributed propulsion blended-wing-body aircraft. Virginia Polytechnic Institute and State University, Virginia, VA.

Kummer, J. (2010). Propulsive wing aerial utility vehicle development. Retrieved from http://www.propulsivewing.com/index.shtml

Landman, D., Simpson, J., Mariani, R., Ortiz, F., \& Britcher, C. (2007). Hybrid design for aircraft wind-tunnel testing using response surface methodologies. Journal of Aircraft, 44(4), 1214-1221.

Lyon, C. A., Broeren, A. P., Giguere, P., Gopalarathnam, A., \& Selig, M. S. (1997). Summary of low-speed airfoil data (3th ed.). Virginia, VA: SoarTech Publications.

Mark D. Moore, Nicholas K. Borer, Bill Frederics, Daniel Palumbo, Steve Rizzi, Doug Nark, ... Brian German. (2014). Leading Edge Distributed Electric Propulsion Wing Integration for CTOL, STOL and VTOL Missions. Presented at AIAA Aviation Forum. 
Miranda, L. R., \& Brennan, J. E. (1986). Aerodynamic effects of wingtip-mounted propellers and turbines. In 4th AIAA Applied Aerodynamics Conference.

Montgomery, D. C. (2013). Design and analysis of experiments (8th ed.). New Jersey, NJ: John Wiley \& Sons Inc.

Moore, M. D., \& Fredericks, B. (2014). Misconceptions of electric propulsion aircraft and their emergent aviation markets. In 52nd Aerospace Sciences Meeting.

Moore, M. D., Goodrich, K., Viken, J., Smith, J., Fredericks, B., Trani, T.,.. Patterson, M. (2013). High-speed mobility through on-demand aviation. In Aviation Technology, Integration, and Operations Conference.

Murphy, P. C., \& Landman, D. (2015). Experiment design for complex VTOL aircraft with distributed propulsion and tilt wing. In AIAA Atmospheric Flight Mechanics Conference.

Myers, R. H., Montgomery, D. C., \& Anderson-Cook, Christine M. (2009). Response surface methodology (3rd ed.). New Jersey, NJ: John Wiley \& Sons Inc.

National Research Council. (2006). A Review of United States Air Force and Department of Defense Aerospace Propulsion Needs (1st ed.). Air Force Studies Board. Division on Engineering and Physical Sciences. Washington, DC: National Academies Press.

Patterson, M. D. (2016). Conceptual Design of High Lift Propeller Systems for Small Electric Aircraft. Georgia Institute of Technology, Georgia, GA.

Patterson, M. D., German, B. J., \& Moore, M. D. (2012). Performance analysis and design of ondemand electric aircraft concepts. 12th AIAA Aviation Technology, Integration and Operations Conference. 
Perry, A. T., Ansell, P. J., Kerho, M., Ananda, G., \& D’Urso, S. (2016). Design, analysis, and evaluation of a propulsive wing concept. In 34th AIAA Applied Aerodynamics Conference.

Philips, B. D. (2016, June). Design of Experiments Enhanced Statistical Process Control for Wind Tunnel Check Standard Testing. Old Dominion University, Virginia, VA.

Rothhaar, P. M., Murphy, P. C., Bacon Barton, J., Gregory, I. M., Grauer, J. A., Busan, R. C., \& Croom, M. A. (2014). NASA Langley distributed propulsion VTOL tilt-wing aircraft testing, modeling, simulation, control, and flight test development. In 14th AIAA Aviation Technology, Integration, and Operations Conference.

Schetz, J. A., Hosder, S., Dippold, V., \& Walker, J. (2010). Propulsion and aerodynamic performance evaluation of jet-wing distributed propulsion. Aerospace Science and Technology, 14(1), 1-10.

Sehra, A. K., \& Whitlow, W. (2004). Propulsion and power for 21st century aviation. Progress in Aerospace Sciences, 40(4), 199-235.

Sheller, C. (2016a). Aurora successfully flies subscale X-Plane aircraft. Retrieved from http://www.aurora.aero/wp-content/uploads/2016/04/LightningStrike-VTOL-X-PlaneSubscale-Model-First-Flight.pdf

Sheller, C. (2016b). Aurora's revolutionary aircraft design includes the first-ever distributed $\begin{array}{llll}\text { hybrid-electric } & \text { propulsion } & \text { system. } & \text { Retrieved }\end{array}$ http://www.multivu.com/players/English/7617851-aurora-flight-sciences-vtol-xplanedarpa/

Snyder, M. H. (1967). Effects of a Wingtip-Mounted Propeller on Wing Lift, Induced Drag and Shed Vortex Pattern. Oklahoma State University, Oklahoma, OK. 
Stoll, A. M. (2015). Comparison of CFD and experimental results of the LEAPTech distributed electric propulsion blown wing. In 15th AIAA Aviation Technology, Integration, and Operations Conference.

Stoll, A. M., Bevirt, J., Moore, M. D., Fredericks, W. J., \& Borer, N. K. (2014). Drag reduction through distributed electric propulsion. In 14th AIAA Aviation Technology, Integration and Operations Conference.

Stoll, A. M., Bevirt, J., Pei, P. P., \& Stilson, E. V. (2014). Conceptual design of the Joby S2 electric VTOL PAV. In 14th AIAA Aviation Technology, Integration, and Operations Conference.

Stoll, A. M., \& Mikic, G. V. (2016). Design studies of thin-haul commuter aircraft with distributed electric propulsion. In 16th AIAA Aviation Technology, Integration and Operation Conference. 


\section{APPENDICES}

APPENDIX A Model Assembly Technical Drawing

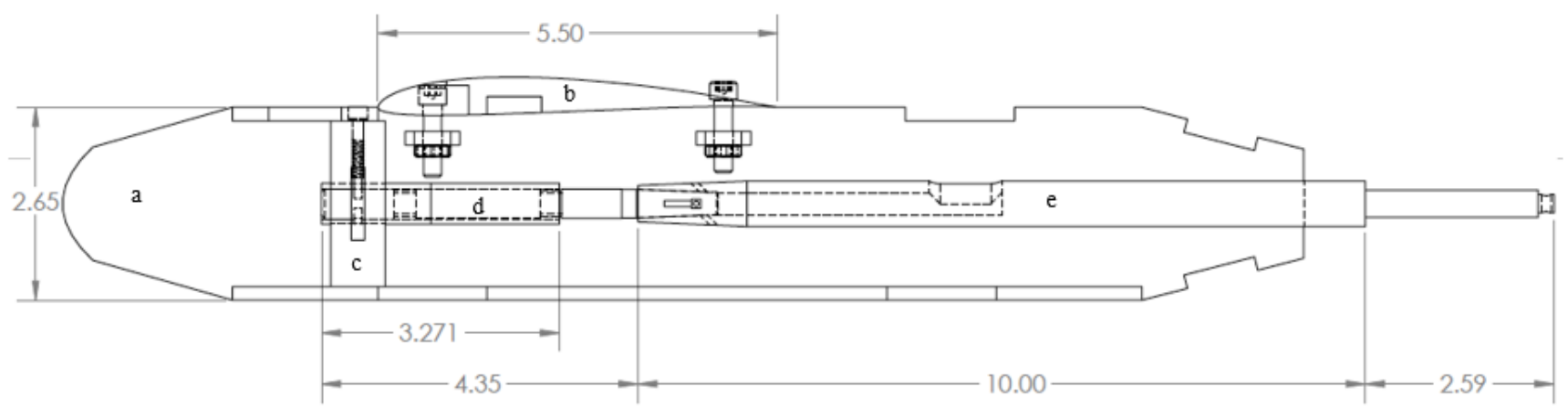

All dimensions are in inches.

a: Fuselage

b: Wing

c: Aluminum bulkhead

d: Balance

e: Balance support 


\section{APPENDIX B 2044A Force Balance Specifications}

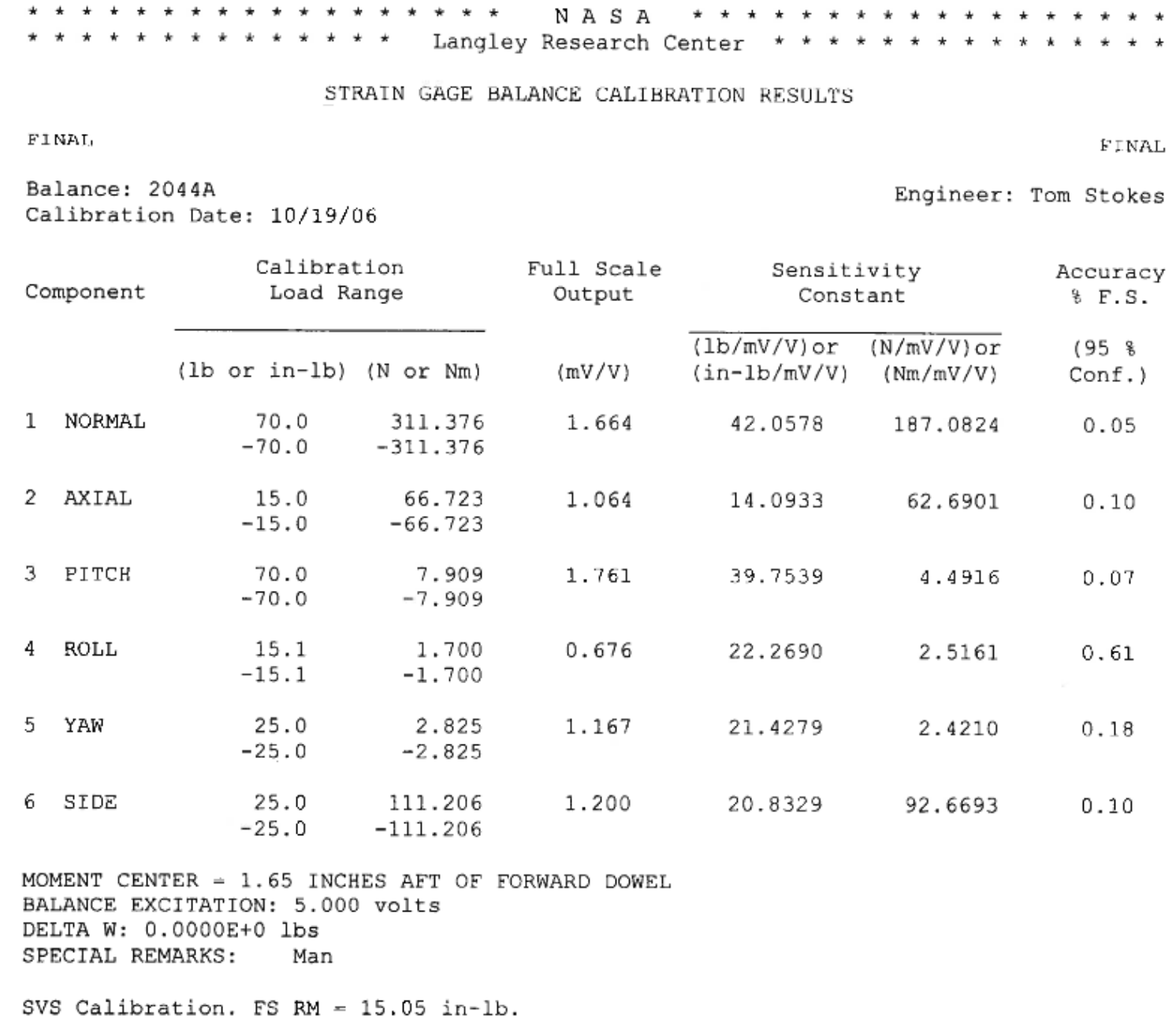

1.200

20.8329

92.6693

0.10

MOMENT CENTER $=1.65$ INCHES AFT OF FORWARD DOWEL BALANCE EXCITATION: 5.000 volts

DELTA W: $0.0000 \mathrm{E}+0$ lbs

SPECIAL REMARKS: Man

SVS Calibration. FS RM $=15.05$ in- $1 \mathrm{~b}$. 
APPENDIX C All-Propellers-On Mode Actual Text Matrix

\begin{tabular}{|c|c|c|c|c|c|c|c|c|}
\hline $\begin{array}{c}\text { Run } \\
\text { Number }\end{array}$ & A-o-A & $\mathbf{V}(\mathbf{m} / \mathbf{s})$ & L1 & $\mathbf{L} 2$ & L3 & L4 & $\mathrm{C}_{\mathrm{N}}$ & $\mathbf{C}_{\mathrm{A}}$ \\
\hline 1 & 8 & 10 & 10000 & 10000 & 10000 & 10000 & 0.911157 & -0.11647 \\
\hline 2 & 0 & 10 & 13000 & 10000 & 10000 & 10000 & 0.238458 & -0.09587 \\
\hline 3 & 4 & 9 & 11500 & 11500 & 11500 & 11500 & 0.654903 & -0.28065 \\
\hline 4 & 4 & 9 & 11500 & 11500 & 11500 & 10000 & 0.645567 & -0.24351 \\
\hline 5 & 4 & 9 & 11500 & 11500 & 11500 & 11500 & 0.66017 & -0.27996 \\
\hline 6 & 4 & 9 & 11500 & 11500 & 11500 & 11500 & 0.657927 & -0.28161 \\
\hline 7 & 0 & 8 & 10000 & 13000 & 10000 & 10000 & 0.265674 & -0.3168 \\
\hline 8 & 8 & 8 & 13000 & 13000 & 13000 & 13000 & 1.16271 & -0.67571 \\
\hline 9 & 8 & 10 & 10000 & 13000 & 13000 & 13000 & 1.0128 & -0.2856 \\
\hline 10 & 0 & 8 & 10000 & 10000 & 10000 & 13000 & 0.265487 & -0.32173 \\
\hline 11 & 4 & 9 & 11500 & 13000 & 11500 & 11500 & 0.662039 & -0.31809 \\
\hline 12 & 8 & 10 & 13000 & 10000 & 13000 & 10000 & 0.979245 & -0.23296 \\
\hline 13 & 4 & 9 & 11500 & 11500 & 10000 & 11500 & 0.635041 & -0.24399 \\
\hline 14 & 0 & 10 & 10000 & 13000 & 10000 & 13000 & 0.229535 & -0.15369 \\
\hline 15 & 8 & 9 & 11500 & 11500 & 11500 & 11500 & 1.04078 & -0.34448 \\
\hline 16 & 4 & 9 & 10000 & 11500 & 11500 & 11500 & 0.638151 & -0.24187 \\
\hline 17 & 4 & 10 & 11500 & 11500 & 11500 & 11500 & 0.61157 & -0.17138 \\
\hline 18 & 4 & 9 & 11500 & 11500 & 13000 & 11500 & 0.667781 & -0.31377 \\
\hline 19 & 4 & 9 & 11500 & 11500 & 11500 & 11500 & 0.655694 & -0.28209 \\
\hline 20 & 4 & 9 & 13000 & 11500 & 11500 & 11500 & 0.669801 & -0.31739 \\
\hline 21 & 0 & 8 & 13000 & 10000 & 13000 & 13000 & 0.305131 & -0.49528 \\
\hline 22 & 8 & 8 & 10000 & 13000 & 10000 & 13000 & 1.09231 & -0.49917 \\
\hline 23 & 4 & 8 & 11500 & 11500 & 11500 & 11500 & 0.705389 & -0.44074 \\
\hline 24 & 8 & 8 & 10000 & 13000 & 13000 & 10000 & 1.08805 & -0.49413 \\
\hline 25 & 0 & 10 & 10000 & 10000 & 13000 & 13000 & 0.239341 & -0.14763 \\
\hline 26 & 0 & 9 & 11500 & 11500 & 11500 & 11500 & 0.265828 & -0.25306 \\
\hline 27 & 0 & 8 & 13000 & 13000 & 13000 & 10000 & 0.307527 & -0.49071 \\
\hline 28 & 8 & 10 & 13000 & 10000 & 10000 & 10000 & 0.941638 & -0.16844 \\
\hline 29 & 8 & 10 & 13000 & 13000 & 10000 & 10000 & 0.965826 & -0.22193 \\
\hline 30 & 0 & 10 & 13000 & 13000 & 13000 & 13000 & 0.270489 & -0.2438 \\
\hline 31 & 4 & 9 & 11500 & 11500 & 11500 & 11500 & 0.636581 & -0.23418 \\
\hline 32 & 4 & 9 & 11500 & 10000 & 11500 & 11500 & 0.654828 & -0.25833 \\
\hline 33 & 0 & 8 & 13000 & 13000 & 10000 & 13000 & 0.308678 & -0.5101 \\
\hline 34 & 4 & 9 & 11500 & 11500 & 11500 & 13000 & 0.678519 & -0.32889 \\
\hline 35 & 8 & 8 & 10000 & 10000 & 13000 & 13000 & 1.10338 & -0.51027 \\
\hline 36 & 0 & 8 & 10000 & 10000 & 13000 & 10000 & 0.271153 & -0.3329 \\
\hline 37 & 4 & 9 & 11500 & 11500 & 11500 & 11500 & 0.65898 & -0.29171 \\
\hline
\end{tabular}

100 


\begin{tabular}{|c|c|c|c|c|c|c|c|c|}
\hline $\begin{array}{c}\text { Run } \\
\text { Number }\end{array}$ & A-o-A & $\mathbf{V}(\mathbf{m} / \mathbf{s})$ & L1 & L2 & L3 & L4 & $\mathbf{C}_{\mathbf{N}}$ & $\mathbf{C}_{\mathrm{A}}$ \\
\hline 38 & 8 & 10 & 13000 & 10000 & 10000 & 13000 & 0.989024 & -0.2456 \\
\hline 39 & 8 & 8 & 13000 & 10000 & 10000 & 10000 & 1.06848 & -0.43199 \\
\hline 40 & 0 & 10 & 10000 & 13000 & 13000 & 10000 & 0.243737 & -0.15218 \\
\hline 41 & 6 & 9.5 & 10750 & 10750 & 10750 & 10750 & 0.805542 & -0.18875 \\
\hline 42 & 2 & 9.5 & 12250 & 10750 & 10750 & 10750 & 0.435889 & -0.18403 \\
\hline 43 & 4 & 9 & 11500 & 11500 & 11500 & 11500 & 0.661623 & -0.29304 \\
\hline 44 & 4 & 9 & 11500 & 11500 & 11500 & 10750 & 0.652365 & -0.2743 \\
\hline 45 & 4 & 9 & 11500 & 11500 & 11500 & 11500 & 0.660209 & -0.29103 \\
\hline 46 & 4 & 9 & 11500 & 11500 & 11500 & 11500 & 0.661952 & -0.2946 \\
\hline 47 & 2 & 8.5 & 10750 & 12250 & 10750 & 10750 & 0.470297 & -0.2991 \\
\hline 48 & 6 & 8.5 & 12250 & 12250 & 12250 & 12250 & 0.903559 & -0.45885 \\
\hline 49 & 6 & 9.5 & 10750 & 12250 & 12250 & 12250 & 0.841833 & -0.28589 \\
\hline 50 & 2 & 8.5 & 10750 & 10750 & 10750 & 12250 & 0.462189 & -0.30049 \\
\hline 51 & 4 & 9 & 11500 & 12250 & 11500 & 11500 & 0.667854 & -0.30696 \\
\hline 52 & 6 & 9.5 & 12250 & 10750 & 12250 & 10750 & 0.834241 & -0.25771 \\
\hline 53 & 4 & 9 & 11500 & 11500 & 10750 & 11500 & 0.642423 & -0.27507 \\
\hline 54 & 2 & 9.5 & 10750 & 12250 & 10750 & 12250 & 0.438511 & -0.21394 \\
\hline 55 & 6 & 9 & 11500 & 11500 & 11500 & 11500 & 0.854618 & -0.31686 \\
\hline 56 & 4 & 9 & 10750 & 11500 & 11500 & 11500 & 0.655342 & -0.2702 \\
\hline 57 & 4 & 9.5 & 11500 & 11500 & 11500 & 11500 & 0.642777 & -0.23131 \\
\hline 58 & 4 & 9 & 11500 & 11500 & 12250 & 11500 & 0.666076 & -0.31046 \\
\hline 59 & 4 & 9 & 11500 & 11500 & 11500 & 11500 & 0.655105 & -0.2891 \\
\hline 60 & 4 & 9 & 12250 & 11500 & 11500 & 11500 & 0.661576 & -0.31015 \\
\hline 61 & 2 & 8.5 & 12250 & 10750 & 12250 & 12250 & 0.487622 & -0.38133 \\
\hline 62 & 6 & 8.5 & 10750 & 12250 & 10750 & 12250 & 0.875673 & -0.38412 \\
\hline 63 & 4 & 8.5 & 11500 & 11500 & 11500 & 11500 & 0.693288 & -0.36079 \\
\hline 64 & 6 & 8.5 & 10750 & 12250 & 12250 & 10750 & 0.885375 & -0.37902 \\
\hline 65 & 2 & 9.5 & 10750 & 10750 & 12250 & 12250 & 0.443626 & -0.20887 \\
\hline 66 & 2 & 9 & 11500 & 11500 & 11500 & 11500 & 0.469742 & -0.27354 \\
\hline 67 & 2 & 8.5 & 12250 & 12250 & 12250 & 10750 & 0.487639 & -0.37149 \\
\hline 68 & 6 & 9.5 & 12250 & 10750 & 10750 & 10750 & 0.817933 & -0.22441 \\
\hline 69 & 6 & 9.5 & 12250 & 12250 & 10750 & 10750 & 0.823863 & -0.25953 \\
\hline 70 & 2 & 9.5 & 12250 & 12250 & 12250 & 12250 & 0.467238 & -0.27502 \\
\hline 71 & 4 & 9 & 11500 & 11500 & 11500 & 11500 & 0.655949 & -0.28695 \\
\hline 72 & 4 & 9 & 11500 & 10750 & 11500 & 11500 & 0.655515 & -0.27196 \\
\hline 73 & 2 & 8.5 & 12250 & 12250 & 10750 & 12250 & 0.48682 & -0.37836 \\
\hline 74 & 4 & 9 & 11500 & 11500 & 11500 & 12250 & 0.676266 & -0.30527 \\
\hline 75 & 6 & 8.5 & 10750 & 10750 & 12250 & 12250 & 0.884032 & -0.37874 \\
\hline 76 & 2 & 8.5 & 10750 & 10750 & 12250 & 10750 & 0.465375 & -0.29669 \\
\hline
\end{tabular}

101 


\begin{tabular}{|c|c|c|c|c|c|c|c|c|}
\hline $\begin{array}{c}\text { Run } \\
\text { Number }\end{array}$ & $\mathbf{A - 0}-\mathbf{A}$ & $\mathbf{V}(\mathbf{m} / \mathbf{s})$ & $\mathbf{L 1}$ & $\mathbf{L 2}$ & $\mathbf{L 3}$ & $\mathbf{L 4}$ & $\mathbf{C}_{\mathbf{N}}$ & $\mathbf{C}_{\mathbf{A}}$ \\
\hline 77 & 4 & 9 & 11500 & 11500 & 11500 & 11500 & 0.661836 & -0.28782 \\
\hline 78 & 6 & 9.5 & 12250 & 10750 & 10750 & 12250 & 0.837175 & -0.25636 \\
\hline 79 & 6 & 8.5 & 12250 & 10750 & 10750 & 10750 & 0.866123 & -0.35248 \\
\hline 80 & 2 & 9.5 & 10750 & 12250 & 12250 & 10750 & 0.444655 & -0.20731 \\
\hline
\end{tabular}


APPENDIX D Wing-Alone Mode Actual Text Matrix

\begin{tabular}{|c|c|c|c|c|}
\hline $\begin{array}{c}\text { Run } \\
\text { Number }\end{array}$ & A-0-A & $V(m / s)$ & $\mathbf{C}_{\mathrm{N}}$ & $\mathbf{C}_{\mathrm{A}}$ \\
\hline 1 & 4 & 10 & 0.580754 & 0.015433 \\
\hline 2 & 0 & 9 & 0.24446 & 0.038629 \\
\hline 3 & 4 & 9 & 0.582542 & 0.017544 \\
\hline 4 & 0 & 8 & 0.25667 & 0.043524 \\
\hline 5 & 4 & 9 & 0.579845 & 0.016238 \\
\hline 6 & 4 & 9 & 0.588075 & 0.019134 \\
\hline 7 & 0 & 10 & 0.254011 & 0.039431 \\
\hline 8 & 4 & 9 & 0.578698 & 0.015075 \\
\hline 9 & 4 & 8 & 0.577522 & 0.017476 \\
\hline 10 & 8 & 10 & 0.873249 & -0.03599 \\
\hline 11 & 8 & 9 & 0.877127 & -0.03271 \\
\hline 12 & 8 & 8 & 0.871012 & -0.03244 \\
\hline 13 & 4 & 9 & 0.577462 & 0.016062 \\
\hline 14 & 4 & 9.5 & 0.579107 & 0.015371 \\
\hline 15 & 2 & 9 & 0.419248 & 0.032096 \\
\hline 16 & 4 & 9 & 0.581159 & 0.017401 \\
\hline 17 & 2 & 8.5 & 0.42118 & 0.031798 \\
\hline 18 & 4 & 9 & 0.579618 & 0.013816 \\
\hline 19 & 4 & 9 & 0.578146 & 0.014333 \\
\hline 20 & 2 & 9.5 & 0.415272 & 0.028723 \\
\hline 21 & 4 & 9 & 0.578349 & 0.013317 \\
\hline 22 & 4 & 8.5 & 0.578935 & 0.013263 \\
\hline 23 & 6 & 9.5 & 0.736362 & -0.00871 \\
\hline 24 & 6 & 9 & 0.734829 & -0.00927 \\
\hline 25 & 6 & 8.5 & 0.734524 & -0.0089 \\
\hline 26 & 4 & 9 & 0.571266 & 0.011979 \\
\hline
\end{tabular}


APPENDIX E Wing-Tip-Propellers-Alone Mode Actual Text Matrix

\begin{tabular}{|c|c|c|c|c|c|}
\hline $\begin{array}{c}\text { Run } \\
\text { Number }\end{array}$ & $\mathbf{A - \mathbf { o } - \mathbf { A }}$ & $\mathbf{V}(\mathbf{m} / \mathbf{s})$ & $\mathbf{L 1} \boldsymbol{\&} \mathbf{R} \mathbf{1}$ & $\mathbf{C}_{\mathbf{N}}$ & $\mathbf{C}_{\mathbf{A}}$ \\
\hline 1 & 4 & 9 & 11500 & 0.623053 & -0.05538 \\
\hline 2 & 8 & 10 & 13000 & 0.934058 & -0.11158 \\
\hline 3 & 8 & 8 & 10000 & 0.93423 & -0.0929 \\
\hline 4 & 0 & 10 & 13000 & 0.279363 & -0.03341 \\
\hline 5 & 0 & 9 & 11500 & 0.274794 & -0.02969 \\
\hline 6 & 4 & 8 & 11500 & 0.631025 & -0.09598 \\
\hline 7 & 4 & 9 & 11500 & 0.612907 & -0.05518 \\
\hline 8 & 8 & 10 & 10000 & 0.891065 & -0.04979 \\
\hline 9 & 8 & 8 & 13000 & 0.94087 & -0.19772 \\
\hline 10 & 4 & 9 & 11500 & 0.605739 & -0.05527 \\
\hline 11 & 4 & 9 & 11500 & 0.599797 & -0.0563 \\
\hline 12 & 0 & 8 & 13000 & 0.277246 & -0.11639 \\
\hline 13 & 0 & 10 & 10000 & 0.248668 & 0.026765 \\
\hline 14 & 4 & 9 & 11500 & 0.611355 & -0.05421 \\
\hline 15 & 4 & 10 & 11500 & 0.596003 & -0.02915 \\
\hline 16 & 4 & 9 & 11500 & 0.604289 & -0.057 \\
\hline 17 & 8 & 9 & 11500 & 0.911977 & -0.11208 \\
\hline 18 & 0 & 8 & 10000 & 0.248404 & -0.02259 \\
\hline 19 & 4 & 9 & 13000 & 0.610632 & -0.09735 \\
\hline 20 & 4 & 9 & 10000 & 0.5787 & -0.01639 \\
\hline 21 & 4 & 9 & 11500 & 0.599238 & -0.05653 \\
\hline 22 & 6 & 9.5 & 12250 & 0.764972 & -0.08548 \\
\hline 23 & 6 & 8.5 & 10750 & 0.759139 & -0.07708 \\
\hline 24 & 2 & 9.5 & 12250 & 0.426751 & -0.04294 \\
\hline 25 & 2 & 9 & 11500 & 0.429846 & -0.03889 \\
\hline 26 & 4 & 8.5 & 11500 & 0.610207 & -0.07023 \\
\hline 27 & 4 & 9 & 11500 & 0.600563 & -0.05489 \\
\hline 28 & 6 & 9.5 & 10750 & 0.748062 & -0.04769 \\
\hline 29 & 6 & 8.5 & 12250 & 0.780009 & -0.11525 \\
\hline 30 & 4 & 9 & 11500 & 0.598284 & -0.05444 \\
\hline 31 & 4 & 9 & 11500 & 0.605593 & -0.05439 \\
\hline 32 & 2 & 8.5 & 12250 & 0.443644 & -0.07195 \\
\hline 33 & 2 & 9.5 & 10750 & 0.416765 & -0.006 \\
\hline 34 & 4 & 9 & 11500 & 0.594774 & -0.05659 \\
\hline 35 & 4 & 9.5 & 11500 & 0.591937 & -0.04044 \\
\hline 36 & 4 & 9 & 11500 & 0.591076 & -0.05598 \\
\hline & 6 & 9 & 11500 & 0.754342 & -0.08327 \\
\hline
\end{tabular}

104 


\begin{tabular}{|c|c|c|c|c|c|}
\hline $\begin{array}{c}\text { Run } \\
\text { Number }\end{array}$ & $\mathbf{A - o - A}$ & $\mathbf{V ( m / s )}$ & $\mathbf{L 1} \& \mathbf{R 1}$ & $\mathbf{C}_{\mathbf{N}}$ & $\mathbf{C}_{\mathbf{A}}$ \\
\hline 38 & 2 & 8.5 & 10750 & 0.418349 & -0.03351 \\
\hline 39 & 4 & 9 & 12250 & 0.600602 & -0.07509 \\
\hline 40 & 4 & 9 & 10750 & 0.591662 & -0.03359 \\
\hline
\end{tabular}


APPENDIX F Wing-Tip-Propellers-Alone and Two-Inboard-Propellers-Alone Mode Actual Text Matrix

\begin{tabular}{|c|c|c|c|c|c|}
\hline $\begin{array}{c}\text { Run } \\
\text { Number }\end{array}$ & A-o-A & $\begin{array}{c}\mathrm{C}_{\mathrm{N}} \\
(\mathrm{L} 1 \& \mathrm{R} 1)\end{array}$ & $\begin{array}{c}\mathrm{C}_{\mathrm{A}} \\
\text { (L1\&R1) }\end{array}$ & $\begin{array}{c}\mathrm{C}_{\mathrm{N}} \\
(\mathrm{L3} \& \mathrm{R} 3)\end{array}$ & $\begin{array}{c}\mathrm{C}_{\mathrm{A}} \\
\text { (L3\&R3) }\end{array}$ \\
\hline 1 & 2 & 0.44243 & -0.04439 & 0.422858 & -0.04356 \\
\hline 2 & 4 & 0.608836 & -0.06375 & 0.604334 & -0.05725 \\
\hline 3 & 6 & 0.768302 & -0.08863 & 0.762772 & -0.08127 \\
\hline 4 & 8 & 0.9307 & -0.11494 & 0.899144 & -0.10819 \\
\hline 5 & 2 & 0.446292 & -0.04398 & 0.423123 & -0.04235 \\
\hline 6 & 4 & 0.613023 & -0.06167 & 0.601034 & -0.05553 \\
\hline 7 & 6 & 0.777917 & -0.08736 & 0.759695 & -0.08045 \\
\hline 8 & 8 & 0.928933 & -0.1141 & 0.901081 & -0.10987 \\
\hline 9 & 2 & 0.445822 & -0.04354 & 0.41496 & -0.04369 \\
\hline 10 & 4 & 0.609765 & -0.06344 & 0.596909 & -0.05613 \\
\hline 11 & 6 & 0.776107 & -0.08962 & 0.749228 & -0.08236 \\
\hline 12 & 8 & 0.924996 & -0.11898 & 0.897639 & -0.11134 \\
\hline
\end{tabular}

\begin{tabular}{|c|c|c|c|c|c|}
\hline $\begin{array}{c}\begin{array}{c}\text { Run } \\
\text { Number }\end{array} \\
\end{array}$ & A-o-A & $\begin{array}{c}C_{L} \\
\text { (L1\&R1) } \\
\end{array}$ & $\begin{array}{c}C_{D} \\
\text { (L1\&R1) } \\
\end{array}$ & $\begin{array}{c}C_{L} \\
(L 3 \& R 3) \\
\end{array}$ & $\begin{array}{c}C_{D} \\
(L 3 \& R 3) \\
\end{array}$ \\
\hline 1 & 2 & 0.44213603 & -0.0289224 & 0.42257748 & -0.0287759 \\
\hline 2 & 4 & 0.60715804 & -0.0211245 & 0.60268871 & -0.0149543 \\
\hline 3 & 6 & 0.76331637 & -0.007835 & 0.75788877 & -0.0010934 \\
\hline 4 & 8 & 0.91945265 & 0.01570699 & 0.88840853 & 0.01799956 \\
\hline 5 & 2 & 0.4459957 & -0.0283778 & 0.42284296 & -0.0275574 \\
\hline 6 & 4 & 0.61134009 & -0.0187575 & 0.59940301 & -0.0134687 \\
\hline 7 & 6 & 0.77288071 & -0.005567 & 0.75483882 & -0.0005995 \\
\hline 8 & 8 & 0.91772383 & 0.0162929 & 0.89028992 & 0.01660548 \\
\hline 9 & 2 & 0.44552626 & -0.0279545 & 0.41468465 & -0.0291815 \\
\hline 10 & 4 & 0.60808545 & -0.0207504 & 0.59528736 & -0.014355 \\
\hline 11 & 6 & 0.77106158 & -0.0080038 & 0.74442183 & -0.0035932 \\
\hline 12 & 8 & 0.91373683 & 0.01091247 & 0.88686079 & 0.01467076 \\
\hline
\end{tabular}


APPENDIX G Wind Tunnel Data Boundary Corrections

Wing and body properties;

$\mathrm{S}_{\mathrm{ref}}=1.298 \mathrm{ft}^{2}=0.120 \mathrm{~m}^{2}$

Wing volume $=0.036 \mathrm{ft}^{3}=0.00101 \mathrm{~m}^{3}$

Body volume $=0.0668 \mathrm{ft}^{3}=0.00189 \mathrm{~m}^{3}$

$\mathrm{C}=12 \mathrm{ft}^{2}=1.114 \mathrm{~m}^{2}$

Solid blockage correction;

$$
\begin{aligned}
& \varepsilon_{s b, w}=\frac{K_{1} \tau_{1}(\text { wing volume })}{C^{3 / 2}} \\
& \varepsilon_{s b, b}=\frac{K_{3} \tau_{1}(\text { body volume })}{C^{3 / 2}}
\end{aligned}
$$

where $K_{1}$ is $0.98, K_{3}$ is 0.93 and $\tau_{1}$ is 0.84 .

Wake blockage correction;

$$
\begin{aligned}
& \varepsilon_{w b}=\frac{S_{r e f}}{4 C} C_{D u} \\
& \varepsilon_{T}=\varepsilon_{s b}+\varepsilon_{w b} \\
& q_{c}=q_{A}\left(1+\varepsilon_{T}\right)^{2} \\
& V_{c}=V_{A}\left(1+\varepsilon_{T}\right)
\end{aligned}
$$

\begin{tabular}{|c|c|c|c|c|c|c|c|}
\hline \multicolumn{7}{|c|}{ All-Propellers-On } \\
\hline$\alpha$ & $\varepsilon_{\mathrm{sb}}$ & $\varepsilon_{\mathrm{wb}}$ & $1+\varepsilon_{\mathrm{T}}$ & $\mathrm{q}_{\mathrm{A}}(\mathrm{Pa})$ & $\mathrm{q}_{\mathrm{c}}(\mathrm{Pa})$ & $\mathrm{V}_{\mathrm{A}}(\mathrm{m} / \mathrm{s})$ & $\mathrm{V}_{\mathrm{c}}(\mathrm{m} / \mathrm{s})$ \\
\hline 0 & 0.001968 & -0.006842 & 0.995126 & 48.6 & 48.1274 & 8.9835 & 8.9398 \\
4 & 0.001968 & -0.006325 & 0.995643 & 48.5 & 48.0783 & 8.9743 & 8.9352 \\
8 & 0.001968 & -0.005305 & 0.996663 & 48.8 & 48.4749 & 9.0020 & 8.9720 \\
\hline
\end{tabular}




\begin{tabular}{|c|c|c|c|c|c|c|c|}
\hline \multicolumn{8}{|c|}{ Wing-Alone } \\
\hline$\alpha$ & $\varepsilon_{\mathrm{sb}}$ & $\varepsilon_{\mathrm{wb}}$ & $1+\varepsilon_{\mathrm{T}}$ & $\mathrm{q}_{\mathrm{A}}(\mathrm{Pa})$ & $\mathrm{q}_{\mathrm{c}}(\mathrm{Pa})$ & $\mathrm{V}_{\mathrm{A}}(\mathrm{m} / \mathrm{s})$ & $\mathrm{V}_{\mathrm{c}}(\mathrm{m} / \mathrm{s})$ \\
\hline 0 & 0.001968 & 0.001027 & 1.002995 & 48.7 & 48.9921 & 8.9928 & 9.0197 \\
4 & 0.001968 & 0.001568 & 1.003536 & 48.7 & 49.0450 & 8.9928 & 9.0246 \\
8 & 0.001968 & 0.002406 & 1.004374 & 48.6 & 49.0261 & 8.9835 & 9.0228 \\
\hline
\end{tabular}

$$
\begin{aligned}
& \Delta C_{D w}=\frac{K_{1} \tau_{1}(\text { wing volume })}{C^{3 / 2}} C_{D u} \\
& \Delta C_{D b}=\frac{K_{3} \tau_{1}(\text { body volume })}{C^{3 / 2}} C_{D u}
\end{aligned}
$$

Downwash and streamline curvature corrections;

$$
\Delta \alpha_{s c}=\tau_{2} \delta\left(\frac{S_{r e f}}{C}\right) C_{L w}
$$

where $\tau_{2}$ is 0.13 and $\delta$ is 0.125 .

\begin{tabular}{|c|c|c|c|c|c|c|}
\hline \multicolumn{7}{|c|}{ All-Propellers-On } \\
\hline$\alpha$ & $\Delta \alpha$ & $\alpha_{c}$ & $\mathrm{C}_{\mathrm{Du}}$ & $\Delta \mathrm{C}_{\mathrm{DT}}$ & $\mathrm{C}_{\mathrm{Dc}}$ & $\mathrm{C}_{\mathrm{Lw}}$ \\
\hline 0 & 0.000467 & 0.000467 & -0.2530 & -0.00050 & -0.2535 & 0.266 \\
4 & 0.001184 & 4.001184 & -0.2339 & -0.00046 & -0.2344 & 0.674 \\
8 & 0.001894 & 8.001894 & -0.1962 & -0.00039 & -0.1966 & 1.079 \\
\hline
\end{tabular}

\begin{tabular}{|c|c|c|c|c|c|c|}
\hline \multicolumn{7}{|c|}{ Wing-Alone } \\
\hline$\alpha$ & $\Delta \alpha$ & $\alpha_{\mathrm{c}}$ & $\mathrm{C}_{\mathrm{Du}}$ & $\Delta \mathrm{C}_{\mathrm{DT}}$ & $\mathrm{C}_{\mathrm{Dc}}$ & $\mathrm{C}_{\mathrm{Lw}}$ \\
\hline 0 & 0.000428 & 0.000428 & 0.038 & 0.0000747 & 0.0381 & 0.244 \\
4 & 0.001001 & 4.001001 & 0.058 & 0.0001142 & 0.0581 & 0.570 \\
8 & 0.001529 & 8.001529 & 0.089 & 0.0001752 & 0.08918 & 0.870 \\
\hline
\end{tabular}




\title{
VITA
}

\author{
Engin Baris \\ Mechanical and Aerospace Engineering Department \\ Norfolk, VA 23529
}

Engin Baris received his Bachelor's Degree in Mechanical Engineering from Sakarya University in 2012. His research interests include experimental aerodynamics and UAV design. 